\title{
Myosin II Isoforms in Breast Cancer: Role of Contractility in Matrix Organization, Cell Migration, and Endothelial Barrier Function
}

Bridget Ruth Hindman

Follow this and additional works at: https://researchrepository.wvu.edu/etd

\section{Recommended Citation}

Hindman, Bridget Ruth, "Myosin II Isoforms in Breast Cancer: Role of Contractility in Matrix Organization, Cell Migration, and Endothelial Barrier Function" (2015). Graduate Theses, Dissertations, and Problem Reports. 5808.

https://researchrepository.wvu.edu/etd/5808

This Dissertation is protected by copyright and/or related rights. It has been brought to you by the The Research Repository @ WVU with permission from the rights-holder(s). You are free to use this Dissertation in any way that is permitted by the copyright and related rights legislation that applies to your use. For other uses you must obtain permission from the rights-holder(s) directly, unless additional rights are indicated by a Creative Commons license in the record and/ or on the work itself. This Dissertation has been accepted for inclusion in WVU Graduate Theses, Dissertations, and Problem Reports collection by an authorized administrator of The Research Repository @ WVU.

For more information, please contact researchrepository@mail.wvu.edu. 


\title{
Myosin II Isoforms in Breast Cancer: Role of Contractility in Matrix Organization, Cell Migration, and Endothelial Barrier Function
}

\author{
Bridget Ruth Hindman
}

Dissertation Submitted to the School of Medicine at West Virginia

University in Partial Fulfillment of the Requirements for the Degree of

Doctor of Philosophy in Cancer Cell Biology

J. Michael Ruppert, M.D., Ph.D., Chair

Michael Schaller, Ph.D.

Laura Gibson, Ph.D.

Erik Bey, Ph.D.

Fred Minnear, Ph.D.

Robert Wysolmerski, Ph.D., Mentor

Cancer Cell Biology Program

Morgantown, West Virginia

2015

Keywords: Breast Cancer, Myosin II, Mechanosensing, Cell Migration, Barrier Function

Copyright 2015 Bridget R. Hindman 


\begin{abstract}
Myosin II Isoforms in Breast Cancer: Role of Contractility in Matrix Organization, Cell Migration, and Endothelial Barrier Function
\end{abstract}

Bridget R. Hindman

Breast cancer is a devastating and complicated disease. A large proportion of breast cancer related deaths are due to metastasis. Metastasis is when cancer cells leave the primary tumor, travel through the bloodstream, and proliferate in distant sites. Cell contractility is involved in a number of cellular processes associated with metastasis including matrix organization, tumor cell migration, and endothelial cell barrier function. The main regulator of contractility in nonmuscle cells is nonmuscle myosin II. There are three isoforms of this protein: myosin IIA, IIB, and IIC. The specific roles of the individual isoforms in cancer progression and metastasis have yet to elucidated. This works aims to determine if myosin II isoforms play separate roles in three functions associated with cancer progression: tumor cell organization of a collagen matrix, tumor cell migration, and endothelial cell barrier function. In Study 1 , the ability of breast cancer cells lacking myosin II isoforms to organize a collagen matrix was assessed. In addition, the migration potential of these cells in 3D matrices was measured. Myosin II isoforms were found to play distinct roles in cancer cell matrix organization and cell migration. In Study 2, the barrier function of endothelial cells lacking myosin II isoforms was tested. This cell function is involved in metastasis when cancer cells cross the blood vessel wall to enter and exit the bloodstream. Both myosin II isoforms were found to be involved in endothelial cell contractility, and the IIA isoform was found to be necessary for barrier function. Collectively, these studies indicate that myosin II isoforms play distinct and non-redundant roles in cell processes associated with cancer metastasis. 


\section{Acknowledgements}

As anyone who has been through graduate school can tell you, it is not an easy path. Science can be a cruel master. An experiment that works one day will fail the next week. Cells will inexplicably die. Collagen will refuse to polymerize. Friends, family, and the occasional vent session are necessary to any graduate student's sanity. Thankfully, I have a loving and supportive family and amazing friends.

First, to my family. Both of my parents overcame obstacles to provide their children with an amazing childhood and wonderful opportunities. Watching my mother juggle college classes and two teenage children in order to achieve the goals she discovered later in life gave me the determination to follow my dreams now. And the confidence to know I have the capability to be whatever I want, as long as I am willing to put in the work.

To my best friend, Courtney. Thank you for reminding me that no matter how many random facts I know, there are still things I don't know. Also, your son is adorable, hilarious, and reminds me that science is all about improving the future for our children.

Thank you to my committee, especially Dr. Schaller. The last 7 months of my graduate career took a hard left turn. Your support, advice, and feedback helped to minimize the bumps in the road.

Finally, thank you to all former and current graduate students. It always helps to have friends in the trenches. To commiserate with, to bounce ideas off of, to celebrate with when something goes gloriously right. To help you up when you fall down. And we all know I fall down a lot, literally.

I could end here with a terrible cliché. Instead, I'll just take a leaf from the Sopranos book and end in the middle of a sen 


\section{Table of Contents}

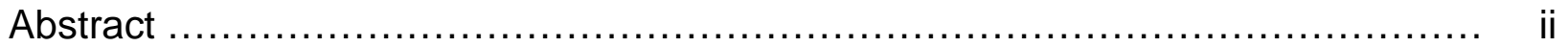

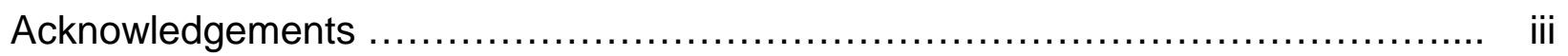

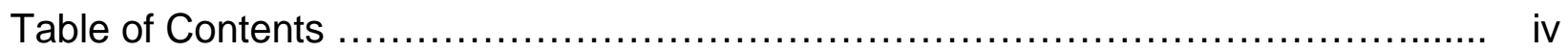

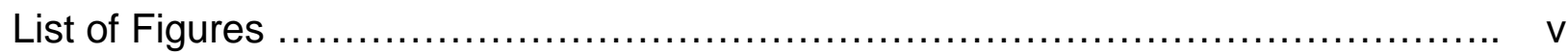

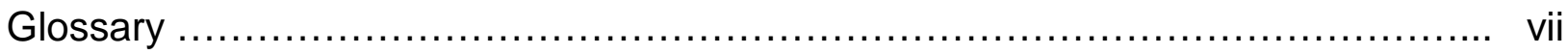

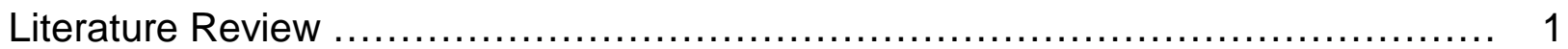
Breast Cancer
Nonmuscle Myosin II
Mechanotransduction in Development and Disease
Cancer Cell Migration and Metastasis
Endothelial Cells and Barrier Function

Study 1: Non-muscle Myosin II Isoforms Have Different Functions in Matrix

Rearrangement and Migration of MDA-MB-231 Cells

Study 2: Myosin II Isoforms are Necessary for Endothelial Cell Permeability Function

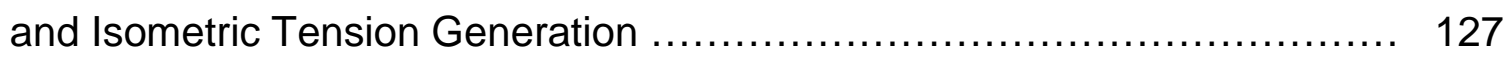

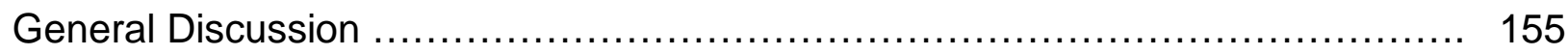

Appendix

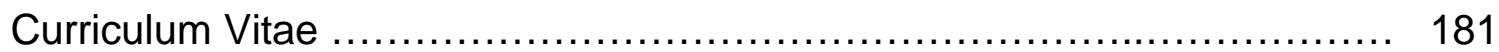




\section{List of Figures and Tables}

\section{Literature Review}

1. General Steps of Cancer Metastasis.

2. Domain Structure and Regulation of Myosin II Activity and Filament Assembly.

\section{Study 1}

Tables

1. Elastic modulus of collagen constructs seeded with MDA-MB-231 cells.

2. Elastic recovery of collagen constructs seeded with MDA-MB-231 cells.

3. Calculated elastic modulus of MDA-MB-231 cells within collagen constructs.

4. Migration speed of MDA-MB-231 cells in 3D models.

5. Migration track displacement of MDA-MB-231 cells

6. Migration track length of MDA-MB-231 cells

Figures

1. Knockdown of myosin II isoforms.

2. Knockdown of myosin II isoforms induces cytoskeletal changes in MDA-MB-231 cells in 2D.

3. Loss of myosin II isoforms induces morphological changes in 3D.

4. Morphological characteristics of cells lacking myosin II isoforms.

5. Loss of myosin II isoforms inhibits the ability of MDA-MB-231 cells to compress a collagen gel.

6. Isometric tension development of MDA-MB-231 cells.

7. Matrix rigidity of MDA-MB-231 cells.

8. Loss of myosin II isoforms affects cell viscoelasticity as measured by cell poking. 
9. Loss of a myosin II isoform has a distinct effect on the ability of the cell to migrate in 3D

10. Migration track patterns of cells migrating in the plug model.

Supplemental Figures

1. Quantification of myosin II expression

\section{Study 2}

1. Knockdown of myosin II isoforms.

2. Knockdown of myosin II isoforms induces cytoskeletal changes in SVEC cells in 2D.

3. Myosin II isoforms are needed for efficient barrier permeability.

4. Myosin II isoforms are needed for isometric force generation. 


\section{Glossary}

\begin{tabular}{|c|c|}
\hline$\mu \mathrm{m}$ & micrometer (micron) \\
\hline ADP & adenosine diphosphate \\
\hline $\mathrm{AJ}$ & adherens junction \\
\hline ATP & adenosine triphosphate \\
\hline CAF & cancer associated fibroblast \\
\hline CXCL12 & C-X-C motif chemokine 12 \\
\hline CXCR4 & C-X-C motif receptor 4 \\
\hline DDR1 & discoidin domain receptor 1 \\
\hline ECIS & Electric Cell-substrate Impedance Sensing \\
\hline ECM & extracellular matrix \\
\hline FAK & focal adhesion kinase \\
\hline HER2 & human epidermal growth factor receptor 2 \\
\hline KLF-2 & Krüppel like factor 2 \\
\hline LOX & lysyl oxidase \\
\hline $\mathrm{MHC}$ & myosin heavy chain \\
\hline MLCK & myosin light chain kinase \\
\hline MMTV-PyMT & mouse mammary tumor virus-polyoma middle $\mathrm{T}$ antigen \\
\hline $\mathrm{Pa}$ & Pascal \\
\hline $\mathrm{PI} 3 \mathrm{~K}$ & phosphoinositide 3-kinase \\
\hline PKC & protein kinase $\mathrm{C}$ \\
\hline RLC & regulatory light chain \\
\hline ROCK & Rho associated protein kinase \\
\hline SHG & second harmonics generation \\
\hline ShRNA & short hairpin ribonucleic acid \\
\hline SVEC & small vein endothelial cells \\
\hline TGF- $\beta 1$ & Transforming growth factor beta 1 \\
\hline $\mathrm{TJ}$ & tight junction \\
\hline VEGF & vascular endothelial growth factor \\
\hline
\end{tabular}




\section{Literature Review}

\section{Breast Cancer}

Breast cancer is a potentially devastating disease that affects women worldwide. In 2015, there were an estimated 234,190 new cases and 40,730 expected deaths in the United States alone, making breast cancer the second leading cause of cancer related death in women [1]. The specific characteristics of each patient's disease must be determined to decide on the best treatment regimen. Often, this process starts with determining the type of tumor; for breast cancer, the most common type is ductal carcinoma, followed by lobular carcinoma [2]. Once the type of cancer is determined, the tumor is further classified into a disease subtype. Patient prognosis depends on disease subtype, which is a major determinant of treatment options. Patients are initially classified into general disease subtypes based on the expression of certain proteins as detected by histology staining of biopsy samples. Biopsy samples are investigated for the presence of the estrogen and progesterone receptors as well as the HER2 epidermal growth factor receptor [3]. For tumors expressing high levels of hormone receptors or HER2, there are therapies that directly target the overexpressed receptors. However, there are no such targeted therapies for cancers that do not express high levels of these proteins, known as triple negative cancers, giving these patients a poor short-term prognosis [4]. The final tumor characteristic important for determining patient prognosis and treatment regimen is tumor staging. Staging for solid tumors, including breast cancer, is based on factors such as the tumor size, if the tumor has invaded local nymph nodes, and if any distant metastases have been detected [5]. Patients whose cancers are caught and treated early (stage I/II) have a better prognosis than patients whose disease is diagnosed at a later 
stage (stave IV) in disease progression [5]. However, even patients who are diagnosed with stage I disease, a primary tumor $\leq 20 \mathrm{~mm}$ on the longest dimension and no lymph node involvement or a lymph node metastasis $\leq 1 \mathrm{~mm}[5]$, are at risk of developing distant metastases in the future $[6,7]$. These distant metastases often occur in vital organs such as the liver, lungs, and brain, and it is these secondary tumors that are often fatal for cancer patients [6, 8-11]. Tumor staging and disease subtype greatly influence treatment options for the patient. Tumor size, lymph node involvement, and presence of metastases determine the suitability of surgery and radiation, while disease subtype determines the tumor's response to chemotherapeutic agents $[3,5]$.

Patients with stage IV, or metastatic, disease at initial diagnosis have a poor prognosis. Metastasis is a multi-step process in which cancer cells from a primary tumor invade local tissue, travel through the bloodstream, and proliferate to form a secondary tumor in a distant organ (Figure 1) [7, 10]. Tumors that metastasize to vital organs are life-threatening and can be difficult to treat $[7,9,12]$. Due to the staging conventions in breast cancer, many patients assume that metastasis happens later in the disease process. However, patients with successfully treated early stage cancer may present years later with metastatic disease and no recurrent primary tumor, implying that the metastatic cells had already entered the bloodstream at the time of the initial diagnosis [12]. A risk factor for these early metastatic events is infiltration of the primary tumor by the vasculature in a process known as angiogenesis [6]. When tumors successfully initiate angiogenesis, often the vasculature is abnormal with a low barrier function, and hence high permeability. This leaky vasculature makes it easier for individual tumor cells to enter the bloodstream and circulate to target organs [13]. These tumor cells can enter 
a dormant state after arriving in a metastatic niche. Dormancy makes these cells refractory to many chemotherapeutic agents that are designed to target highly proliferative cells. The dormant cells that survive treatment remain in the metastatic organs, eventually proliferating into a secondary tumor [12].

Given the effect of metastasis on the outcome for cancer patients, it is an important area to focus research efforts. There are two primary theories as to how an individual metastatic cell, or group of cells, arrives at a specific distant organ. The first is the 'seed and soil' hypothesis, in which cells home to a specific organ through characteristics specific to the cell and its metastatic niche $[7,8]$. Many cancers have specific metastatic patterns, which lends credence to the seed and soil hypothesis. For example, in breast cancer metastasis to bone, the metastatic microenvironment produces the chemokine CXCL12, which acts as a chemoattractant to cancer cells expressing its receptor CXCR4 [14]. This hypothesis is further supported by the establishment of breast cancer cell lines that selectively metastasize to specific organs after intracardiac injection [15]. The second theory is that cells follow circulatory patterns and become lodged in the first capillary bed with vessel diameters small enough to trap cells. These two models of metastasis are not mutually exclusive $[7,8,10,11,16]$. For instance, breast cancer tends to metastasize to the bone, liver, brain and lungs [7]. While some of these sites are explained by circulatory patterns, others are better explained by the seed and soil hypothesis. There are several possibilities as to how these two models collectively explain metastasis. Different cell populations within a single primary tumor may separately follow either model. Some metastatic cells follow the seed and soil hypothesis, while other cells from the same primary tumor are simply trapped by a small capillary bed and proliferate. 
It is also possible that circulating tumor cells follow both models simultaneously. In this case, individual cells do become physically trapped in capillary beds based on cell size/deformability and circulatory patterns, but selectively grow in organs where the molecular interactions with the microenvironment are favorable. Cells trapped in unfavorable environments die. In this scenario, the two theories are both partially correct.

Throughout tumor progression and the metastatic process, cells must interact with their surroundings. During the initial stages of tumorigenesis, cells sense and respond to change in the extracellular matrix (ECM). The ECM is altered in breast cancer and influences cell proliferation, invasion, and metastasis [17-19]. Cancer cells alter the ECM directly; both physical alterations such as collagen bundling and alignment and biochemical alterations such as cross-linking. These alterations promote tumor progression $[20,21]$. During metastasis, cells migrate through the ECM to local blood or lymph vessels. While migrating, cells form and break adhesions to the matrix. This cycle of adhesion formation and disassembly is necessary for migration. New adhesions are formed as the cell extends forward, while old adhesions at the cell rear must be disassembled in order for the entire cell body to move and the rear of the cell to retract. The matrix also directs how the cells migrate by providing contact guidance, a physical scaffold for cell movement, as well as a physical barrier the cells must degrade or maneuver through as they migrate [22-24]. During the latter steps of metastasis, cancer cells attach to and transmigrate across the blood or lymph vessel wall to enter and exit the bloodstream. This requires complex interactions with the cells composing the vessel wall $[7,10,11,25]$. Researchers have investigated the molecular events involved in these processes, and in many cases it has been found to be dependent on actomyosin 
contractility [26-36]. Contractility is necessary for adhesion maturation, making it a critical component of cell-matrix interactions $[37,38]$. During cell migration through the matrix, contractile forces propel the cell body forward [27]. While the role of contractility in tumor cell transmigration across the vessel wall has not been thoroughly investigated, contractility is necessary in leukocyte diapedesis, a process highly similar to tumor cell extravasation from the blood vessel [39]. Since nonmuscle myosin II is the main regulator of actin contractility in nonmuscle cells [40], defining its role in these cellular processes could be of great benefit to understanding and treating this disease.

\section{Nonmuscle Myosin II}

Nonmuscle myosin II proteins are members of the class II myosin family of actin motor proteins. As such, they are capable of turning the chemical energy of ATP hydrolysis into mechanical work. Like all myosins, the functional form of nonmuscle myosin II is a hexamer, consisting of a homodimer of heavy chains and two pairs of light chains, essential and regulatory [30, 41]. The heavy chain homodimer forms when the C-terminal region of the heavy chains form a helical coiled coil, leaving the $\mathrm{N}$-terminal motor domains free to interact with ATP and actin. Between the head domain and the coiled coil tail domain lies the neck domain. This is where both sets of light chains interact with the heavy chain dimer [42]. The tail domains of myosin hexamers further interact with other hexamers to form bipolar thick filaments. There are three nonmuscle myosin II heavy chain (MHC) isoforms: $A, B$, and $C$. These isoforms are encoded by three separate genes in humans, MYH 9, MYH 10, and MYH 14, respectively [43]. All three isoforms share significant sequence similarity, but have variations in the C-terminal tail, allowing for specific interactions with regulatory molecules. This variation has been exploited in the 
development of antibodies and shRNAs targeting specific isoforms for research purposes $[42,44,45]$. Myosin II isoforms are differentially expressed in different tissues and have non-redundant roles in development $[44,46,47]$. Myosin IIA ablation in mice is lethal at embryonic day 6.5. Embryos present severe defects in cell-cell adhesion and fail to develop a visceral endoderm [47]. Myosin IIB ablated mice die between E14.5 and birth. These animals have brain and heart abnormalities, notably, hydrocephalus and abnormal neuronal migration $[46,47]$. Replacing the IIB isoform with IIA in knock-in experiments results in a fraction of mice surviving into adulthood. However, these mice still have abnormalities in neuron migration and develop cardiomyopathy, defects in the heart muscle which typically lead to heart failure [46]. Ablation of myosin IIC in mice results in no obvious defects and there is still relatively little known about its role in various tissues [47]. The absence of embryonic defects in myosin IIC knockout mice is likely because IIC, while highly expressed in a number of adult tissues, has substantially lower expression levels in fetal tissue [48].

The separate functions of the myosin II isoforms in development could be explained by multiple factors, including differential expression in different cell types, different subcellular localization, differential regulation, and inherent differences in the biochemical properties of the isoforms [42, 43, 48-50]. Myosins have a cyclical interaction pattern with actin, ATP, and ADP. Binding of ATP causes the myosin to release actin. When the ATP molecule is hydrolyzed, myosin again binds to actin and the release of phosphate induces the "power stroke", a conformational change in the neck region of the heavy chain that moves the myosin along the actin filament. Myosin-ADP-actin is a relatively stable structure, and the myosin molecule is reset when ADP is exchanged for 
ATP and myosin releases actin [40]. Changes in ATPase activity and the release rate of ADP will affect the relative time a myosin molecule spends bound to actin, i.e. the duty ratio [43]. Kovács et al [49] have shown that the two main isoforms of nonmuscle myosin II, A and B, have different kinetics of ATP hydrolysis and substrate release. Both isoforms have relatively high ADP affinities and slow kinetics compared to other myosins, such as those found in muscle tissue. However, the IIB isoform exhibits slower kinetics of ATP hydrolysis than IIA. In addition, the IIB isoform releases ADP at a slower rate than IIA, meaning that it spends more of its ATPase cycle bound to actin $[49,50]$. This relatively high duty ratio, as well as the fact that the IIB ATPase significantly slows ADP release when a resisting load is applied, indicates that the IIB isoform is likely responsible for cellular tension maintenance [51]. Myosin II isoforms also have different filament assembly characteristics that likely play a role in their different functions in cell processes. This is especially true of the IIC isoform, which forms filaments with larger "bare zones", areas of the filament lacking myosin heads and composed solely of the rod domains, indicating that the filaments are made up of fewer molecules and likely have a lower actin processivity than the other two isoforms [43]. There are several small molecule inhibitors that block myosin II activity. The most commonly used is blebbistatin. Blebbistatin binds the myosin-ADP-Pi complex, blocking $\mathrm{Pi}_{\mathrm{i}}$ release. This locks myosin into a conformation with low affinity for actin. Blebbistatin shows myosin II specificity, however, it is believed to act on all three isoforms equally, making it inadequate for studying the different isoforms in cell processes [52].

Nonmuscle myosin II is involved in wide variety of cellular functions, and is regulated by a number of signaling molecules. Myosin II function is mainly regulated 
through phosphorylation of the regulatory light chain (RLC) Phosphorylation of the regulatory light chain on Ser19, or on both Thr18 and Ser19, enhances motor complex ATPase activity. Phosphorylation of these residues allows the myosin complex to extend from an inhibitory folded state, allowing for filament formation which is vital for effective myosin function $[30,40,42,43,45,49,53-57]$ (See Figure 2). Myosin light chain kinase (MLCK) activates myosin II by phosphorylating RLC downstream of $\mathrm{Ca}^{+2}$-calmodulin signaling. Rho-associated-coiled-coil-containing-kinase (ROCK) phosphorylates RLC as part of the Rho signaling pathway. Not only does ROCK directly phosphorylate RLC, it also inhibits protein phosphatase 1, a protein which dephosphorylates and deactivates RLC [40, 41, 43, 49]. In addition to MLCK and ROCK, citron kinase, leucine zipper interacting kinase, myotonic dystrophy kinase-related CDC42-binding kinase, and nearly a dozen others can phosphorylate RLC and activate myosin II [42, 53]. These activating kinases are regulated in different ways through calcium, growth factor, and mechanical signaling. They are also differentially located within the cell, for example MLCK is peripheral as compared to the more centrally located ROCK. The differential regulation and location of these kinases provides temporal and spatial control on myosin II activity in response to distinct stimuli [58]. Finally, protein kinase C phosphorylates RLC on Ser1, Ser2, and Thr9, which decreases myosin II activity [59]. Phosphorylation of the heavy chain in the C-terminal tail domain also regulates myosin II activation. This mechanism of regulation is less well defined than phosphorylation of the light chain, however it is thought to primarily function to negatively regulate filament assembly and binding to other proteins such as S100A4 [41, 42]. 
Nonmuscle myosin II is vital for a number of cellular processes including cell division, cell migration, and cell adhesion [41, 42, 44, 60]. In cell division, myosin II is needed for contraction of the cleavage furrow during cytokinesis [60]. Given that mice lacking a single isoform are able to survive partially through gestation, the nonmuscle myosin II isoforms can likely play redundant roles in this cellular function. In cell migration, myosin IIA and IIB are required for migration during development and other normal physiological functions such as wound healing $[30,42,43,53]$. This is especially true of the IIB isoform in neuron migration and the formation and stabilization of actin structures that are needed for synaptic plasticity and memory formation [61-63]. Myosin II is also involved in other types of cell migration, including leukocyte motility during inflammation $[30,41]$. In cell-cell adhesions, which are important for barrier function in tissues, myosin is involved in the proper localization of adhesion complex members and adhesion maturation [30]. For example, myosin II contractility is necessary during cadherinmediated adhesion maturation [64]. Cadherins are transmembrane proteins that form complexes with cadherins on adjacent cells and are associated with catenins and the actin cytoskeleton on the intracellular domain. After forming initial cell-cell contacts, the actin cytoskeleton undergoes significant reorganization to expand the area of cell contacts and cluster cadherin molecules, a process known as compaction. Myosin II activity is necessary during this process $[64,65]$. In integrin mediated adhesions to the matrix, myosin II is needed for adhesion maturation [41]. Integrins are transmembrane proteins that form heterodimers in the cell membrane, composed of one $\alpha$ subunit and one $\beta$ subunit. Different combinations of the $\alpha$ and $\beta$ subunits can have different ligands in the ECM as well as different downstream effectors [22]. Nascent focal adhesions form 
when the transmembrane integrins bind their ligands in the ECM, such as fibronectin. This induces the recruitment of other members of the focal adhesion complex, which includes scaffolding proteins, cytoskeletal-binding proteins, kinases, and other enzymes. It has been shown that myosin II activity in cellular tension generation is involved in the phosphorylation of paxillin by focal adhesion kinase, which recruits vinculin to the nascent adhesions [37]. In addition, integrin signaling enhances myosin II activity through RhoA signaling [41].

Given the involvement of myosin II in these cell processes, it is no surprise that defects in myosin II activity and regulation are involved in a myriad of human diseases $[41,42]$. Mutations in the MYH9 gene, which encodes the nonmuscle myosin IIA isoform, are associated with several diseases which cause deafness, cataracts, nephritis, and thrombocytopenia [42]. A MYH9 chimeric transcript is associated with anaplastic large cell lymphoma $[41,42]$. A de novo mutation, a mutation not inherited from a parent but spontaneously formed in a germ cell or the fertilized egg, in MYH10 is found in patients with brain malformations such as microcephaly and hydrocephalus. Altered expression levels of myosin IIB are also indirectly linked to myocardial infarction and scar tissue formation. Mutations in myosin II interacting proteins are also implicated in a number of diseases which result in asthma, seizures, dementia, and psychomotor disturbances [42]. Alterations in myosin II activity and regulation are also implicated in the progression of a variety of cancers. In esophageal cancer, overexpression of myosin IIA is associated with poor prognosis in patients [66]. In a retrospective study in lung cancer patients, an overabundance of myosin IIA was implicated as a prognostic factor for reduced overall survival [67]. A microRNA, Let-7f, was found to inhibit tumor invasion and metastasis in 
human gastric cancer cell lines and tissues. Let- $7 \mathrm{f}$ was found to directly bind to, and inhibit translation of, myosin IIA mRNA. Tissue samples from patients with metastatic disease had lower levels of Let-7f, which would effectively result in an increase of myosin IIA [68]. An in depth study in the expression levels of both the myosin IIA and IIB isoforms in a carcinogen induced murine hind leg tumor model found that tumor tissue had 25 fold more myosin IIA and 19 fold more IIB than adjacent normal tissue [69]. Finally, a network-based analysis of microRNAs found that miR-940 inhibits phosphorylation of myosin II. This inhibition resulted in reduced cell invasion. In human breast cancer tissues, miR-940 was consistently downregulated [70]. These studies suggest that myosin II has a role in caner

progression and metastasis. However, it is critical that myosin's role is more rigorously tested and that the involvement of the separate isoforms is made clear before we can truly understand how these proteins impact disease progression in solid tumors.

\section{Mechanotransduction in Development and Disease}

The ECM plays a significant role in tissue development and disease [29, 71-74]. This is dependent on the ability of cells to sense and respond to changes in the mechanical properties of the ECM, a process known as mechanosensing. Adhesions to the matrix and surrounding cells are important components in this cell process. Since myosin II is needed for integrin mediated adhesion maturation and cell force generation, it is hardly surprising that it has been proposed to play a vital role in mechanosensing of the matrix by cells [53]. Cells sense the stiffness of the ECM, which plays a role in controlling cellular stiffness, which in turn can influence ECM stiffness in a phenomenon known as mechanoreciprocity or tensional homeostasis $[17,19,75]$. Both mechanical and biochemical cues from the matrix regulate cell proliferation, determine cell fate, control 
cell shape, and influence cell migration [29]. In development, the stiffness and elasticity of the ECM contribute to stem cell differentiation. This effect is dependent on myosin II activity in the stem cells [76]. Blocking stem cell mechanosensing by inhibiting myosin II activity increases stem cell viability and prevents ECM induced differentiation [77]. During mammary gland development, changes in $\beta 1$ integrin expression levels controlled by hormone signaling alter how cells are anchored to the ECM [71]. Integrin signaling is a key player in stiffness sensing by cells, and therefore changes in the expression levels of these proteins can alter the tensional homeostasis by tissues [78]. Changes in the ECM and mechanosensing machinery of cells is associated with various diseases, including cancer. The stiffness of the ECM can be altered by increased deposition of matrix proteins such as collagen or fibronectin, alterations in cross-linking by enzymes like lysyl oxidase (LOX), or changes in the microarchitecture (how ECM proteins are physically organized and bundled) [79-81]. A stiffer ECM leads to integrin clustering, increased signaling through focal adhesions, and increased cell survival and proliferation; therefore, the biophysical properties of the ECM must be tightly controlled, and disruptions in ECM properties and tensional homeostasis are associated with a number of diseases, including many solid cancers [73].

Extracellular matrix changes, especially in stiffness, have a well-established role in breast cancer progression. The first sign of disease in many patients is the presence of a palpable lump in the breast [33]. This is due to increased cell density in the tumor, increased interstitial pressure, and increased ECM stiffness in the immediate tumor microenvironment [33]. In human patients, an extremely dense parenchymal pattern on a mammographic scan is a risk factor for developing breast cancer and is associated with 
connective tissue hyperplasia [82]. This hyperplasia is likely due to not only an increased number of cells but increased collagen deposition [83]. An increase of collagen in the tumor microenvironment has been shown to promote tumor progression in mice. Provenzano, et al, used the MMTV-PyMT mouse model of breast cancer to study how changes in the local collagen matrix affect tumor formation and metastasis. The MMTVPyMT is a transgenic mouse model which spontaneously develop metastatic mammary tumors. Researchers inserted a second gene into these mice, making them bi-transgenic, to increase stromal collagen deposition in the mammary gland. These bi-transgenic animals had increased tumor formation and an increased incidence of lung metastasis compared to PyMT controls [84]. Several studies have shown that the matrix surrounding tumors exhibits consistent changes, called "tumor associated collagen signatures", which contribute to disease progression [21, 84]. Using second harmonics generation (SHG) and scanning electron microscopy, these signatures have been studied and characterized. SHG is a form of multiphoton laser scanning microscopy (MPLSM) that allows direct imaging of certain cell/tissue elements, including collagen, that have a particular kind of symmetry without the need for fluorescent dyes or markers [85]. Provenzano, et al, used SHG to define three tumor associated collagen signatures based on imaging of intact normal mammary glands, mammary tumors, and tumor explants in 3D collagen from mice [21]. These three collagen signatures are: 1 ) increased collagen surrounding the tumor; 2) taut collagen fibers stretched across the tumor; 3) and greater alignment of collagen fibers, especially oriented perpendicular to the tumor edge [21]. Presence of these signatures were strongly associated with poor patient prognosis and were a prognostic marker independent of tumor size, hormone receptor expression, and 
HER2 expression [20]. This indicates that the spatial organization of collagen itself, in addition to the increased deposition of ECM proteins, promotes tumor progression.

While it is known that many breast tumors have increases in collagen and other ECM protein deposition, the exact origin of these proteins has not been definitively explained. The cancer cells themselves could be depositing collagen, the cancer cells could activate local stromal cells such as fibroblasts to increase collagen production, or it could be a combination of both [86]. This increased deposition of matrix proteins is referred to as desmoplasia, a fibrotic response to the neoplasia that results in an increased in type I and III collagens around the tumor [80]. Changes in the physical orientation of collagen fibers can also influence ECM stiffness. Bundled collagen and collagen fibers that have been organized in a linear fashion increase ECM stiffness [80]. A more rigid ECM increases the contractility of cells embedded in it, which stimulates cell proliferation and migration [19]. Cells measure matrix stiffness by exerting force on the matrix, much as a person determines the hardness of a surface by pressing on it. Since myosin II is a major component of the cell's force machinery, it is probably required for this process. Changes in the ECM surrounding tumors influence cell behavior through cell-matrix adhesions containing integrins. Integrin signaling affects cell survival, proliferation, and migration, and dysregulation of this process can promote cancer progression [22, 87]. When integrins bind their ligand, they relieve the autoinhibition of focal adhesion kinase (FAK), leading to its activation. FAK then activates a variety of other proteins involved in focal adhesions, which are extremely complex structures composed of a large number of proteins [87]. After activation of FAK, myosin II contractility is needed to recruit and engage other proteins in the focal adhesion complex such as vinculin and 
paxillin [37]. Myosin II contractility is also necessary for the axial localization of focal adhesion component proteins. This axial localization is important in focal adhesion stability and signaling and is dependent on matrix stiffness. Therefore, myosin II has a vital role in cell sensing of increased matrix protein deposition through integrin signaling [38]. Cell-matrix adhesions are important for cell survival. Cells lacking these adhesions undergo a specialized form of apoptosis known as anoikis. Surviving detachment, or being "anoikis resistant" is a hallmark of cancer cells [88]. Myosin Il's role in cell-matrix adhesions make it a possible regulator of anoikis. In fact, Ma et al. found that treating cells with the any of the myosin II inhibitors, blebbistatin, ML-7, or 2,3 butanedione monoxime, decreased anoikis [89]. It has been established in the literature that metastatic tumor cells are softer than their non-malignant counterparts. These softer cells are likely less contractile, unable to form mature adhesions, and therefore do not sense their detachment [90, 91].

Beyond its role in cell proliferation and migration, the matrix associated with a tumor can also influence signaling and the efficacy of chemotherapeutic agents. Transforming growth factor $\beta 1$ (TGF- $\beta 1$ ) is a cytokine that controls proliferation and is known to play a role in cancer, especially in its effect on stromal cells. TGF- $\beta 1$ is secreted by cells and is sequestered in the ECM, where it remains in its latent form. The latent TGF- $\beta 1$ is bound to the ECM component LTBP-1 through its latency-associated propeptide (LAP). Cell contractility through integrins causes a conformational change in LAP that releases TGF- $\beta 1$ from the ECM. It has been shown that even the relatively low contractile forces generated by epithelial cells (as compared to the more highly contractile fibroblasts) are enough to activate latent TGF- $\beta 1$ [92]. Recently, it has been discovered 
that the latent TGF- $\beta 1$ in the ECM can be "primed" for cell contractility mediated activation by ECM remodeling [93]. Klingberg, et al. pre-strained a cell-free ECM using a mechanical straining device and then seeded human dermal myofibroblasts onto these matrices. Seeding cells onto pre-strained matrices significantly increased the efficiency of TGF- $\beta 1$ release from the ECM [93]. Since TGF- $\beta 1$ is known to be involved in cancer progression, this implies that the ECM remodeling that occurs during tumor development may encourage this signaling process. Collagen, a major component of the ECM in breast tissue, can affect the efficacy of the chemotherapeutic agent, doxorubicin. Doxorubicin is a DNA intercalating agent used to treat a variety of cancers. At doses sub-lethal to cells, it has an anti-migratory effect on cancer cells in vitro. However, when the cancer cells are embedded in a 3D collagen matrix, the same doses of doxorubicin have no effect on cell migration [94]. Matrix changes can also affect the efficacy of radiation therapy. In breast cancer cells embedded in collagen, radiation treatment induced expression of myosin IIA. This increase in myosin expression led to collagen reorganization that decreased the apoptosis of the cells exposed to lethal doses of radiation [95]. Finally, it has been shown that a stiffer matrix can protect cells from the effects of the microtubule stabilizing agent paclitaxel. [96]. It is unclear if the protective effects of the matrix are due to a direct effect on the cell or matrix sequestering of the drugs, much as the matrix sequesters TGF- $\beta$. If the effects of matrix organization on cancer cell resistance to doxorubicin, radiation, and paclitaxel effects hold true in human disease, then not only do changes in ECM promote cancer progression, they also protect the tumor cells from treatment.

The ECM can also act as a niche for cancer stem cells as well as metastatic cancer cells. The ECM has been shown to be involved in stem cell fate and differentiation. It is 
also involved in maintenance of stemness in adult stem cells; that is, it enables cells to retain their ability to self-renew. It is thought that the ECM serves as a physical anchor for the stem cells that allows them to undergo asymmetric cell division, a trait that is important in self-renewal and differentiation. The ECM also provides biochemical and biomechanical cues in stem cell maintenance and differentiation [97]. It stands to reason that cancer stem cells, which share a variety of characteristics with adult stem cells and are capable of establishing a tumor, may also depend on the ECM for regulation of their proliferation and potential differentiation. Cancer stem cells are a debated topic. It is unknown if they are truly involved in every solid tumor, and if so, if they derive from dedifferentiation of the tumor cell of origin, or if the tumor itself results from abnormal stem cell expansion [97]. In either scenario, de-differentiation or population expansion, the ECM is likely to play a significant role. There is growing evidence that the ECM is also involved in the metastatic niche for cancer cells, as well as at the primary tumors. For instance, circulating breast cancer cells that express high levels of CD44, a receptor for hyaluronan, form metastatic tumors at a higher rate than cells expressing lower levels. Hyaluronan may promote survival of these metastatic cells [98]. Additionally, lysyl oxidase (LOX), an enzyme responsible for cross-linking fibrillar matrix proteins, is upregulated in metastatic sites. It is being produced either by the metastatic cancer cells themselves or activated fibroblasts and increases the stiffness of the ECM in the metastatic niche. The increased stiffness likely promotes cell proliferation and growth of the metastatic tumor [99]. There is evidence that cancer cells in the primary tumor or in circulation remotely signal for modification of the metastatic niche, probably by activating stromal cells local to the metastatic site [97]. 
The ECM changes associated with cancer also contribute to tumor angiogenesis. Part of the angiogenic process can be activated through hypoxia signaling. Hypoxia induces tumor cells to express vascular endothelial growth factor (VEGF), which promotes recruitment of endothelial cells to the tumor [100]. Hypoxia can also regulate expression levels of LOX. The LOX induced increase in ECM cross-linking and stiffness promotes sprouting angiogenesis [101]. These biomechanical properties likely play a role in endothelial cell survival after recruitment to the tumor space by signaling through the cell mechanical machinery for increased cell proliferation [97]. In addition, other changes to the ECM are made throughout the process of angiogenesis. Typically, the basement membrane of existing blood vessels is broken down by matrix metalloproteinases before vascular branching can occur, and a new basement membrane laid after the process is complete $[72,97]$. The ECM also plays a role in branching patterns during angiogenesis as well as in proper vessel formation [97].

The specific mechanisms by which altered ECM protein composition and mechanics affect cell function are still largely unknown, though they are beginning to be elucidated. For instance, it has been shown that a stiffer matrix can increase PI3K activation and signaling, which is involved in cell survival and migration. This occurs through increased vinculin association with talin and actin which causes changes in membrane topology. This leads to clustering of PIP3 at focal adhesions, the site of vinculin engagement, which enhances Akt activation. The association of vinculin with talin is dependent on the axial localization of these proteins, a process which needs myosin II activity [38]. As previously discussed, changes in matrix properties are likely sensed by cells through integrins [102]. In prostate cells, it has been shown that increased cellular 
stiffness in response to a stiff 3D matrix is dependent on $\beta 1$ integrins [19]. More recently, it has been postulated that different integrin heterodimers have different functions in mechanosensing, and that the $\alpha 5 \beta 1$ integrins anchor stress fibers that orient ROCKmyosin II based traction forces [78]. It has also been suggested that the physical stress put on a cell by a stiffer ECM is physically transmitted to the nucleus through stress fibers. This process would depend on stress wave propagation through myosin II activity on the stress fibers from the periphery of the cell to the nuclear laminins [103]. Changes in ECM stiffness also influence filopodia dynamics in lung cancer cells, which are associated with cell migration. A stiffer matrix caused shorter filopodia with a faster retraction rate, and the alterations were myosin II activity dependent, as treatment with the general myosin II inhibitor blebbistatin blocked the matrix stiffness induced changes in dynamics [104].

The rigidity of the ECM has also been shown to affect invadopodia dynamics. Invadopodia are actin structures that include matrix degrading enzymes and are associated with cancer cell migration and metastasis. Increased cell rigidity increased the activity and number of invadopodia in cells in a MLCK and myosin II dependent manner [105]. It is known that increased matrix stiffness induces cell proliferation through RhoGTPase signaling and cell contractility [35]. A soft matrix inhibits cell proliferation. Blocking cell actomyosin contractility blocks this effect, indicating that mechanosensing by cells is dependent on myosin II activity [106]. However, Yu et al, showed that cancer cell contraction of a collagen gel is independent of myosin light chain kinase (MLCK). Protein expression of MLCK was lower in cancer cells than normal cells, and inhibiting MLCK or ROCK had no effect on how these cells performed in a gel contraction assay. However, blebbistatin had a partial effect on these cells, indicating that myosin II is 
needed for gel contraction, perhaps through activation by a kinase other than MLCK [107]. A basic theme running throughout the majority of papers discussing mechanotransduction

is the activity of nonmuscle myosin II. However, few studies have investigated how individual myosin isoforms are involved in this process, instead focusing on general myosin II activity. It is thought that matrix stiffness regulates myosin kinetics as force transmitted through the cell stalls the myosin cycle, causing a longer interaction with actin [53]. Since it has been shown that the different myosin isoforms react differently to mechanical loads, it is likely that these isoforms have distinct roles in mechanotransduction [51]. Understanding how the different isoforms are involved in this process could give valuable insight into mechanotransduction and how this link between matrix stiffness and cancer progression could be targeted for treatment.

\section{Cancer Cell Migration and Metastasis}

An important step of the metastatic process occurs when cells leave the primary tumor and migrate through the surrounding ECM space until reaching a blood or lymphatic vessel. Cell migration is a multi-step process, and the general mechanisms have been well defined in two dimensional systems. Cell motility in 2D is a cycle of cytoskeletal dynamics and contractility in which cells extend a protrusion from the leading edge of the cell, create new adhesions to the substrate in front of the cell, undergo contractility which moves the bulk of the cell body forwards into the new cell footprint, and finally the adhesions between the cell rear and the substrate are broken down [108]. Myosin II is involved in this process, especially during the contractility that drives movement of the cell body forward. However, as with mechanotransduction, it is usually general myosin II activity, rather than the individual isoform function, that is tested $[30,53]$. The two main 
isoforms, $A$ and $B$, seem to play different roles in cell spreading and migration [28, 36]. In MDA-MB-231 cells on 2D fibronectin substrates, both the IIA and IIB isoforms are recruited to areas of lamellar spreading. When the IIA isoform is selectively targeted using shRNA mediated knockdown, the cells actually spread more to cover a larger area, and their migration is impeded. When the IIB isoform is knocked down, however, cells spread at a slower rate than normal counterparts, and the cell migration is impeded [28]. Furthermore, it has been shown that in 1D fibrillar migration assays, which is thought to model how cells in 3D matrices migrate along bundled collagen fibers, IIA is the main isoform involved, [36]. While two dimensional models have been quite useful in determining some of the general steps and molecular mechanisms involved in cell motility, the situation in human disease is more complicated. Within a human body, cells move in three dimensions and encounter an ECM composed of various proteins and with a complicated microarchitecture and topology. These factors have a large impact on how cells move and migrate in three dimensions, and therefore studying cells in 3D matrices is a better way to model cancer cell migration and metastasis.

While modeling cell migration in 3D is important for understanding human disease, it is also more complicated than 2D migration assays. The choice of matrix type, the matrix concentration, and a host of other factors impact how cells migrate in 3D [109]. In 3D, individual cancer cells move in one of two ways: proteolytic dependent migration or amoeboid cell migration. Cancer cells are also capable of collective cell migration [23]. In proteolytic dependent migration, cells degrade the matrix using matrix metalloproteinases and then migrate through the tracks they have generated. After the ECM is broken down and a track has been at least partially generated, the cell contracts 
to push the cell body forward and the cell rear loses focal adhesions and retracts. This resets the cell for another cycle and further forward motion. The molecular mechanisms in this mode of invasion are similar to that in 2D migration. The cells first send out actin based protrusive structures and then establish integrin mediated focal adhesions to the matrix. When cells undergo this mode of migration, they appear highly elongated within the matrix [24]. The other form of single cell migration in 3D matrices is known as amoeboid cell movement. This type of cell movement is independent of proteolytic matrix degradation, and more dependent on cell actomyosin contractility. Cells undergoing amoeboid cell movement have a more rounded cell appearance and squeeze through the existing pores in the matrix, rather than creating new tracks through matrix degradation. Cells move more quickly and persistently using this form of migration [110]. The final form of cancer cell migration seen in $3 \mathrm{D}$ matrices is collective migration. Cells using this method of migration move in either a sheet or a string of cells. The leading cell, or cells, forge a path through the matrix that the cells behind follow. This particular form of migration is seen more often in particular types of cancer, such as head and neck cancer $[23,111]$. Which type of migration a cell undergoes is dependent on cell and matrix characteristics $[23,112,113]$.

There has been significant debate in the literature about which type of 3D matrix is the best model for in vitro cancer cell migration $[109,114]$. This is especially important since the matrix influences the mode of cell migration, and these modes use different cellular machinery. Sabeh et al [114] found that the degree of matrix cross-linking was a major determinant of the mode of cell migration. Cells in the derived basement membrane Matrigel or in pepsin extracted collagen showed the rounded, protease-independent, form 
of cell migration [114]. The commonality between these two matrices is that neither is extensively cross-linked. During the extraction process, pepsin removes the telopeptides from the termini of the collagen protein. These non-helical telopeptides contain lysine residues that are the substrate for the cross-linking enzyme, lysyl oxidase. Lysyl oxidase modifies side chains on these lysine residues to generate aldehyde moieties. These moieties will spontaneously react with nearby modified lysine residues to form a Schiff base, creating the cross-linked collagen network [115-117]. This lack of cross-linking impacts how cells invade the collagen matrix. Specifically, cells migrate farther, in a shorter amount of time, in a matrix without cross-linking, and this migration is unaffected by treatment with matrix metalloprotease inhibitors [114]. When collagen is extracted in acid the lysine containing telopeptides necessary for lysyl oxidase mediated collagen cross-linking remain intact. The acidic conditions reverse Schiff base reactions, preventing cross-linking until the collagen solution is brought to a more physiological $\mathrm{pH}$ [114]. Cells embedded in acid extracted, and therefore cross-linked, collagen exhibit matrix metalloprotease dependent migration. The influence of matrix architecture, specifically pore size, on cell migration is further supported by studies showing that cells in a physically constrained environment spontaneously migrate, with high persistence and in some cases high speeds [118].

Beyond pore size and cross-linking, other matrix characteristics, such as stiffness, influence cell migration [109]. In a process known as durotaxis, cells will migrate from a pliant matrix to a stiffer matrix [119]. This effect is likely due to a number of influences of the matrix on the cells. For example, the matrix supplies a scaffold for the cells to use while they migrate $[21,34,84]$. The force the matrix exerts on the cells also promotes 
invasive behavior through the focal adhesion protein vinculin. The involvement of vinculin in cell invasion and migration is supported by previous studies showing that fibroblasts lacking vinculin move much slower in 3D matrices than wildtype fibroblasts [32]. Mature focal adhesions are needed for cells to generate traction forces as they pull against the matrix. These traction forces are needed for cells to propel or pull themselves forward as they migrate through the matrix $[120,121]$. The influence of matrix characteristics on cell motility is also dependent on the cells used. Cell lines that have been transformed or are highly motile are more likely to respond to matrix changes, and in a more pronounced manner, than non-malignant or non-metastatic cells lines [113, 122]. Given the influence of the matrix on how cells migrate and the cellular machinery the cells use, it is important to consider this when choosing a migration model to investigate the molecular mechanisms of cell migration.

Understanding cancer cell migration and metastasis is made complicated by the fact that different cancer types use different mechanisms. These mechanisms can even differ between cell lines of the same cancer type. The different subtypes of breast cancer have different modes and mechanisms of interaction with the microenvironment, invasion, and migration [96]. These differences can be partially explained by the fact that myosin II isoforms are differentially expressed in breast cancer cell lines of different subtypes. Luminal type cell lines express the A and C isoforms of nonmuscle myosin II, but very little of the IIB isoform. However, basal subtypes, specifically cell lines of the basal B subtype, express IIA and IIB but very little of the IIC isoform. It is thought that this switch in isoform expression patterns is a downstream effect of TGF- $\beta 1$ induced epithelialmesenchymal transition. Further, for the basal type cell lines expressing the IIB isoform, 
loss of myosin IIB inhibited cell invasion and transmigration in a transwell assay [123]. These differences illustrate the importance of continued investigation into the mechanisms of cancer cell migration.

Due to its complexity and multi-step nature, studying the metastatic process in vitro can only be done by investigating each step of the process individually. Initial stages of tumor cell dissemination can be approximated in 3D migration and invasion models [34, 111]. Tumor cells crossing the blood vessel wall can be partially studied using transmigration assays where tumor cells cross an endothelial cell monolayer [124-126]. Travel through the bloodstream is more difficult to study, though some labs have had success using microfluidic devices that apply shear stress to the tumor cells using a constant flow rate of media through the device [127]. In order to study the full metastatic process, however, in vivo models are necessary. In animal models of breast cancer, there are two main metastasis xenograft models: orthotopic injection of cells into the mammary fat pad and tail vein injection. These two approaches have distinct advantages and disadvantages. The orthotopic injection model puts the cancer cells into an environment that resembles their physiological one. It also allows for the fuller study of tumorigenesis and metastasis, since cancer cells must go through all the steps of initiating a primary tumor and metastasis before detection at secondary sites. However, if cells fail to initiate a primary tumor, or the primary tumor grows slowly, metastases may never form and it can be difficult to elucidate where in the metastatic process the cells fail to progress. Finally, this model can take several months before metastasis occurs $[128,129]$. The tail vein injection model is generally much quicker than the mammary fat pad injection model; typically taking just a few weeks before lung metastases are detected and/or animals 
must be euthanized. However, since the cells are injected directly into the bloodstream, this model only measures the ability of the cells to survive in the bloodstream and a secondary organ. The site of metastatic growth depends on where in the bloodstream the cells are injected. The tail vein is common, however it is possible to inject the cells into the heart, spleen, or other organs. The cells will become trapped in the next organ in the circulation pathway with a small capillary bed. For injections into the tail vein, this organ is the lungs [128]. Intracardiac injection results in bone metastases, while intrasplenic injection results in liver metastases. These models are used to study how changes to cells affect metastasis to these specific organs [130]. Because of the limitations of both the mammary fat pad and tail vein injection models, many investigators use the two methods in conjunction in an attempt to generate a more detailed and well-rounded picture of how metastasis is affected by their protein or signaling pathway of choice. Peter Friedl and others have pioneered the use of an in vivo imaging system that allows for the tracking of metastatic cells as they leave the primary tumor. Using two-photon microscopy and second harmonics generation imaging, cancer cells are tracked in real time as they metastasize and their interactions with the microenvironment can be investigated [23, 131]. This method allows a more detailed study of the mechanisms of cell metastasis, though the method limits the injection site for the primary tumor due to imaging depth limits of two-photon microscopy.

While many animal studies have been performed investigating the role of various proteins that affect nonmuscle myosin II activity, no animal studies to date have been performed directly investigating how the myosin II status of the cells affects tumor formation and metastasis in animal models of breast cancer. In vitro studies indicate that 
myosin II is likely to be involved at a number of steps in the metastatic process, including initial tumorigenesis, matrix organization by the tumor cells, invasion, and migration. In these in vitro studies, general myosin II activity is investigated while the potentially separate roles of the isoforms are ignored. Investigating how this protein contributes to the cellular processes involved in this disease may give insight into the potential of myosin II or its regulators as therapeutic targets.

\section{Endothelial Cells and Barrier Function}

Endothelial cells line blood and lymphatic vessel walls, and play an important role in a number of physiological functions. They form the barrier between the bloodstream and tissues, and tightly control the passage of molecules and cells into and out of the bloodstream. This property of endothelial cells, the barrier function, is vital and is highly regulated. Changes in the barrier function of endothelial cells is involved in several disease states and can lead to physical problems such as edema, improper nutrient flow, and inflammation $[132,133]$. A lower barrier function may also play a role in tumor metastasis $[13,25,125,126,134]$. The blood vessels that form as a result of angiogenesis within a tumor often have a decreased barrier function, which may make it easier for tumor cells to cross this physical barrier to entering the bloodstream [11, 100, 135]. In fact, newly developed drugs, especially those using nanoparticles, are designed to exploit this leaky vasculature. Solid tumors have an enhanced permeability and retention effect; nanoparticle based drugs easily enter the tumor through the abnormal vasculature and the high interstitial pressure prevents the drugs from leaving. This causes

the drugs to accumulate in the tumor, without specific targeting to the tumor [134]. Even in normal blood vessels with an intact endothelial layer, signaling between the tumor cell 
and the endothelial cells may induce a temporary increase in permeability, allowing the tumor cells to more easily cross the blood vessel wall [125, 135]. Investigating how tumor cells exploit the weakness of the blood vessels, or use signaling machinery to ease their passage, may provide future treatment options to block this stage of metastasis.

Barrier function and monolayer permeability is dependent on interendothelial cell junctions. These junctions include adherens junctions and tight junctions [133]. Tight junctions (TJ) are composed of transmembrane occludins and claudins, as well as various intracellular proteins. TJs provide apical-basolateral polarity in endothelial cells by preventing the movement of transmembrane proteins. TJs also tightly control passage of ions, solutes, and other molecules between the endothelial cells [136]. Adherens junctions (AJ) contain cadherins, transmembrane proteins that form dimers with cadherins molecules on adjacent cells. AJs are linked to the actin cytoskeleton through catenins, which interact with the cytoplasmic domain of cadherin proteins. VE-cadherin is especially important in the barrier function of endothelial cells [132]. VE-cadherin interacts with contractile actin stress fibers through catenin proteins. When these stress fibers contract and pull the cadherin molecule away from its binding partner on an adjacent cell, the VE-cadherin is internalized. The stress fiber contractility is MLCK dependent [133]. This process is speculated to be responsible for TGF- $\beta 1$ induced vascular permeability, since blocking MLCK activity during TGF- $\beta 1$ treatments prevents the loss of barrier function. It is thought that TGF- $\beta 1$ activates MLCK to stimulate contraction, which leads to adherens junction disassembly [137]. This same mechanism is involved in thrombin induced decreases in barrier function: thrombin activates MLCK, inducing myosin contractility, disruptions to adherens junctions, and gaps in the endothelial monolayer 
[138, 139]. Additionally, Krüppel-Like Factor-2 (KLF-2) regulates endothelial barrier function by inhibiting phosphorylation of MLC, preventing cell contraction. The exact mechanism of KLF-2 control of MLC phosphorylation is not known, though it may regulate expression of MLC-phosphatase [140]. Finally, during leukocyte diapedesis, leukocyte interaction with the endothelium stimulates an increase in free intracellular calcium in the endothelial cells. Calcium activates MLCK, which phosphorylates MLC and activates myosin II. This myosin II contractility weakens the endothelial barrier function, allowing the leukocytes to exit the bloodstream into the surrounding infected or damaged tissue [141]. These mechanisms all converge on MLC activation and myosin II dependent cell contractility. Cancer cells may use a similar mechanism during metastasis, and understanding how cancer cells influence endothelial contractility could provide valuable insight into potential treatment options.

The endothelial cells have been assumed to play a passive role in transmigration. However, more recent studies have shown that the endothelial cells may contribute to tumor cell transmigration [126]. Previous studies show that tumor cells can cause a breakdown in barrier function through several mechanisms, including decreasing the barrier function of the endothelial monolayer, inducing apoptosis of endothelial cells, and decreasing the endothelial cell stiffness [124-126]. There are two possible routes for a cell to take across an endothelial monolayer: between the endothelial cells (paracellular) or through the endothelial cells themselves (transcellular). Breast cancer cells have been shown to utilize both mechanisms. During transcellular transmigration, there is a high level of MLC phosphorylation near the point of entry for the tumor cell, referred to as the invasion array. This specialized cell architecture may provide the structural support the 
endothelial cells need to dissipate the radial compressive force exerted by the invading tumor cell [142]. There are several possible mechanisms for myosin II involvement in paracellular tumor cell transmigration. Tumor cells may decrease myosin II activation in endothelial cells. The resulting decreased contractility of the cells makes the monolayer more compliant, and an easier barrier for the tumor cells to cross. Tumor cells may increase myosin II activation in endothelial cells, which would have a similar effect to thrombin treatment in that it would lead to a disruption of barrier function through the breakdown of adherens junctions. Finally, tumor cells may signal for myosin II activation in the formation of the transcellular invasion array. Live cell microscopy of the transmigration process can distinguish between the latter two mechanisms. The transcellular invasion array is a contractile actin ring surrounding the invasion pore as the tumor cell invades the endothelial cell and is a significant disruption in endothelial cell morphology. Different cancer types may use different mechanisms of endothelial transmigration. In fact, different subpopulations of the same tumor may use different mechanisms. Given these possibilities, the exact role of cell contractility and myosin II activity in tumor cells as well as the endothelial cells has yet to be determined.

\section{Myosin II in Cancer Cell Processes}

Myosin II isoforms likely play a role in a number of cancer cell processes, from cell growth and proliferation to cell-matrix interactions to metastasis. However, the roles of the specific isoforms in these process is often undetermined, with studies concentrating on global myosin II behavior using general inhibitors such as blebbistatin. The individual myosin II isoforms have redundant and non-redundant roles in cell processes and development. Investigating how the isoforms are differentially involved in cancer may 
provide a starting point for understanding the complex signaling pathways involved in cell contractility regulation. In addition, these proteins have differential localization, regulation, and protein interactions that could be exploited. Understanding how the individual isoforms are involved may provide valuable insight in the development of new therapeutic agents targeted to myosin itself or its regulatory molecules. 


\section{References}

1. Society AC. Cancer Facts \& Figures 2015. Atlanta: American Cancer Society, 2015.

2. Bombonati A, Sgroi DC. The molecular pathology of breast cancer progression. J Pathol. 2011;223(2):307-17. Epub 2010/12/03. doi: 10.1002/path.2808. PubMed PMID: 21125683; PubMed Central PMCID: PMCPMC3069504.

3. Barnard ME, Boeke CE, Tamimi RM. Established breast cancer risk factors and risk of intrinsic tumor subtypes. Biochim Biophys Acta. 2015;1856(1):73-85. Epub 2015/06/15. doi: 10.1016/j.bbcan.2015.06.002. PubMed PMID: 26071880.

4. Schnitt SJ. Classification and prognosis of invasive breast cancer: from morphology to molecular taxonomy. Mod Pathol. 23 Suppl 2. United States2010. p. S60-4.

5. Edge SB, Cancer AJCo. AJCC cancer staging manual 7ed. New York, USA: Springer; 2010. 648 p.

6. Gullino PM. Natural history of breast cancer. Progression from hyperplasia to neoplasia as predicted by angiogenesis. Cancer. 1977;39(6 Suppl):2697-703. Epub 1977/06/01. PubMed PMID: 326375.

7. Chambers AF, Groom AC, MacDonald IC. Dissemination and growth of cancer cells in metastatic sites. Nat Rev Cancer. 2. England2002. p. 563-72.

8. Fidler IJ. The pathogenesis of cancer metastasis: the 'seed and soil' hypothesis revisited. Nat Rev Cancer. 3. England2003. p. 453-8.

9. Talmadge JE, Fidler IJ. AACR centennial series: the biology of cancer metastasis: historical perspective. Cancer Res. 2010;70(14):5649-69. PubMed PMID: 20610625.

10. Sahai E. Illuminating the metastatic process. Nat Rev Cancer. 2007;7(10):737-49. PubMed PMID: 17891189.

11. Woodhouse EC, Chuaqui RF, Liotta LA. General mechanisms of metastasis. Cancer. 80. United States1997. p. 1529-37.

12. Banys M, Hartkopf AD, Krawczyk N, Kaiser T, Meier-Stiegen F, Fehm T, et al. Dormancy in breast cancer. Breast Cancer (Dove Med Press). 4. New Zealand2012. p. 183-91. 
13. Hida K, Ohga N, Akiyama K, Maishi N, Hida Y. Heterogeneity of tumor endothelial cells. Cancer Sci. 2013;104(11):1391-5. Epub 2013/08/13. doi: 10.1111/cas.12251. PubMed PMID: 23930621.

14. Langley RR, Fidler IJ. The seed and soil hypothesis revisited--the role of tumor-stroma interactions in metastasis to different organs. Int J Cancer. 2011;128(11):2527-35. Epub 2011/03/03. doi: 10.1002/ijc.26031. PubMed PMID: 21365651; PubMed Central PMCID: PMCPmc3075088.

15. Yoneda T, Williams PJ, Hiraga T, Niewolna M, Nishimura R. A bone-seeking clone exhibits different biological properties from the MDA-MB-231 parental human breast cancer cells and a brain-seeking clone in vivo and in vitro. J Bone Miner Res. 2001;16(8):1486-95. Epub 2001/08/14. doi: 10.1359/jbmr.2001.16.8.1486. PubMed PMID: 11499871.

16. Minn AJ, Gupta GP, Siegel PM, Bos PD, Shu W, Giri DD, et al. Genes that mediate breast cancer metastasis to lung. Nature. 2005;436(7050):518-24. PubMed PMID: 16049480.

17. Butcher DT, Alliston T, Weaver VM. A tense situation: forcing tumour progression. Nat Rev Cancer. 2009;9(2):108-22. PubMed PMID: 19165226.

18. DuFort CC, Paszek MJ, Weaver VM. Balancing forces: architectural control of mechanotransduction. Nat Rev Mol Cell Biol. 2013;12(5):308-19. PubMed PMID: 21508987.

19. Baker EL, Bonnecaze RT, Zaman MH. Extracellular matrix stiffness and architecture govern intracellular rheology in cancer. Biophys J. 97. United States2009. p. 1013-21.

20. Conklin MW, Eickhoff JC, Riching KM, Pehlke CA, Eliceiri KW, Provenzano PP, et al. Aligned collagen is a prognostic signature for survival in human breast carcinoma. Am J Pathol. 178. United States: 2011 American Society for Investigative Pathology. Published by Elsevier Inc; 2011. p. 1221-32.

21. Provenzano PP, Eliceiri KW, Campbell JM, Inman DR, White JG, Keely PJ. Collagen reorganization at the tumor-stromal interface facilitates local invasion. BMC Med. 2006;4(1):38. PubMed PMID: 17190588.

22. Berrier AL, Yamada KM. Cell-matrix adhesion. J Cell Physiol. 2007;213(3):565-73. Epub 2007/08/08. doi: 10.1002/jcp.21237. PubMed PMID: 17680633. 
23. Friedl $\mathrm{P}$, Wolf $\mathrm{K}$. Plasticity of cell migration: a multiscale tuning model. $\mathrm{J}$ Cell Biol. 2009;188(1):11-9. PubMed PMID: 19951899.

24. Friedl $\mathrm{P}$, Wolf $\mathrm{K}$. Proteolytic interstitial cell migration: a five-step process. Cancer Metastasis Rev. 2009;28(1-2):129-35. Epub 2009/01/21. doi: 10.1007/s10555-008-91743. PubMed PMID: 19153672.

25. Reymond N, d'Agua BB, Ridley AJ. Crossing the endothelial barrier during metastasis. Nat Rev Cancer. 13. England2013. p. 858-70.

26. Samuel MS, Lopez JI, McGhee EJ, Croft DR, Strachan D, Timpson P, et al. ActomyosinMediated Cellular Tension Drives Increased Tissue Stiffness and b-Catenin Activation to Induce Epidermal Hyperplasia and Tumor Growth. Cancer Cell. 2011;19:776-91. Epub June 14, 2011. doi: 10.1016/j.ccr.2011.05.008.

27. Poincloux R, Collin O, Lizarraga F, Romao M, Debray M, Piel M, et al. Contractility of the cell rear drives invasion of breast tumor cells in 3D Matrigel. Proc Natl Acad Sci U S A. 2011;108(5):1943-8. PubMed PMID: 21245302.

28. Betapudi V, Licate LS, Egelhoff TT. Distinct roles of nonmuscle myosin II isoforms in the regulation of MDA-MB-231 breast cancer cell spreading and migration. Cancer Res. 2006;66(9):4725-33. PubMed PMID: 16651425.

29. Wozniak MA, Chen CS. Mechanotransduction in development: a growing role for contractility. Nat Rev Mol Cell Biol. 10. England2009. p. 34-43.

30. Conti MA, Adelstein RS. Nonmuscle myosin II moves in new directions. J Cell Sci. 121. England2008. p. 11-8.

31. Delorme-Walker VD, Peterson JR, Chernoff J, Waterman CM, Danuser G, DerMardirossian C, et al. Pak1 regulates focal adhesion strength, myosin IIA distribution, and actin dynamics to optimize cell migration. J Cell Biol. 2011;193(7):1289-303. PubMed PMID: 21708980.

32. Mierke CT, Kollmannsberger P, Zitterbart DP, Diez G, Koch TM, Marg S, et al. Vinculin facilitates cell invasion into three-dimensional collagen matrices. J Biol Chem. 2010;285(17):13121-30. PubMed PMID: 20181946.

33. Huang S, Ingber DE. Cell tension, matrix mechanics, and cancer development. Cancer Cell. 8. United States2005. p. 175-6. 
34. Provenzano PP, Inman DR, Eliceiri KW, Trier SM, Keely PJ. Contact guidance mediated three-dimensional cell migration is regulated by Rho/ROCK-dependent matrix reorganization. Biophys J. 2008;95(11):5374-84. PubMed PMID: 18775961.

35. Provenzano PP, Keely PJ. Mechanical signaling through the cytoskeleton regulates cell proliferation by coordinated focal adhesion and Rho GTPase signaling. J Cell Sci. 124. England2011. p. 1195-205.

36. Doyle AD, Kutys ML, Conti MA, Matsumoto K, Adelstein RS, Yamada KM. Microenvironmental control of cell migration--myosin IIA is required for efficient migration in fibrillar environments through control of cell adhesion dynamics. J Cell Sci. 2011;125(Pt 9):2244-56. PubMed PMID: 22328520.

37. Pasapera AM, Schneider IC, Rericha E, Schlaepfer DD, Waterman CM. Myosin II activity regulates vinculin recruitment to focal adhesions through FAK-mediated paxillin phosphorylation. J Cell Biol. 188. United States2010. p. 877-90.

38. Rubashkin MG, Cassereau L, Bainer R, DuFort CC, Yui Y, Ou G, et al. Force engages vinculin and promotes tumor progression by enhancing PI3K activation of phosphatidylinositol (3,4,5)-triphosphate. Cancer Res. 74. United States: 2014 American Association for Cancer Research.; 2014. p. 4597-611.

39. Stroka KM, Hayenga HN, Aranda-Espinoza H. Human neutrophil cytoskeletal dynamics and contractility actively contribute to trans-endothelial migration. PLoS One. 2013;8(4):e61377. Epub 2013/04/30. doi: 10.1371/journal.pone.0061377. PubMed PMID: 23626676 ; PubMed Central PMCID: PMCPmc3634075.

40. Sellers JR. Myosins: a diverse superfamily. Biochim Biophys Acta. 2000;1496(1):3-22. PubMed PMID: 10722873.

41. Vicente-Manzanares M, Ma X, Adelstein RS, Horwitz AR. Non-muscle myosin II takes centre stage in cell adhesion and migration. Nat Rev Mol Cell Biol. 2009;10(11):778-90. PubMed PMID: 19851336.

42. Betapudi V. Life without double-headed non-muscle myosin II motor proteins. Front Chem. 2014;2:45. Epub 2014/07/30. doi: 10.3389/fchem.2014.00045. PubMed PMID: 25072053; PubMed Central PMCID: PMCPMC4083560. 
43. Billington N, Wang A, Mao J, Adelstein RS, Sellers JR. Characterization of three full-length human nonmuscle myosin II paralogs. J Biol Chem. 2013;288(46):33398-410. PubMed PMID: 24072716.

44. Beach JR, Hammer JA, 3rd. Myosin II isoform co-assembly and differential regulation in mammalian systems. Exp Cell Res. 2015. Epub 2015/02/07. doi: 10.1016/j.yexcr.2015.01.012. PubMed PMID: 25655283.

45. Clayton JE, Pollard LW, Murray GG, Lord M. Myosin motor isoforms direct specification of actomyosin function by tropomyosins. Cytoskeleton (Hoboken). 2015. Epub 2015/02/26. doi: 10.1002/cm.21213. PubMed PMID: 25712463.

46. Bao J, Ma X, Liu C, Adelstein RS. Replacement of nonmuscle myosin II-B with II-A rescues brain but not cardiac defects in mice. J Biol Chem. 282. United States2007. p. 22102-11.

47. Wang A, Ma X, Conti MA, Adelstein RS. Distinct and redundant roles of the non-muscle myosin II isoforms and functional domains. Biochem Soc Trans. 39. England2011. p. 1131-5.

48. Golomb E, Ma X, Jana SS, Preston YA, Kawamoto S, Shoham NG, et al. Identification and characterization of nonmuscle myosin II-C, a new member of the myosin II family. J Biol Chem. 279. United States2004. p. 2800-8.

49. Kovacs M, Wang F, Hu A, Zhang Y, Sellers JR. Functional divergence of human cytoplasmic myosin II: kinetic characterization of the non-muscle IIA isoform. J Biol Chem. 2003;278(40):38132-40. PubMed PMID: 12847096.

50. Wang F, Kovacs M, Hu A, Limouze J, Harvey EV, Sellers JR. Kinetic mechanism of nonmuscle myosin IIB: functional adaptations for tension generation and maintenance. J Biol Chem. 2003;278(30):27439-48. PubMed PMID: 12704189.

51. Kovacs M, Thirumurugan K, Knight PJ, Sellers JR. Load-dependent mechanism of nonmuscle myosin 2. Proc Natl Acad Sci U S A. 2007;104(24):9994-9. PubMed PMID: 17548820.

52. Kovacs M, Toth J, Hetenyi C, Malnasi-Csizmadia A, Sellers JR. Mechanism of blebbistatin inhibition of myosin II. J Biol Chem. 2004;279(34):35557-63. PubMed PMID: 15205456. 
53. Aguilar-Cuenca R, Juanes-Garcia A, Vicente-Manzanares M. Myosin II in mechanotransduction: master and commander of cell migration, morphogenesis, and cancer. Cell Mol Life Sci. 2014;71(3):479-92. PubMed PMID: 23934154.

54. Dulyaninova NG, Malashkevich VN, Almo SC, Bresnick AR. Regulation of myosin-IIA assembly and Mts1 binding by heavy chain phosphorylation. Biochemistry. 2005;44(18):6867-76. PubMed PMID: 15865432.

55. Kolega J. Cytoplasmic dynamics of myosin IIA and IIB: spatial 'sorting' of isoforms in locomoting cells. J Cell Sci. 1998;111 ( Pt 15):2085-95. PubMed PMID: 9664030.

56. Maciver SK. Myosin II function in non-muscle cells. Bioessays. 1996;18(3):179-82. PubMed PMID: 8867731.

57. Shutova M, Yang C, Vasiliev JM, Svitkina T. Functions of nonmuscle myosin II in assembly of the cellular contractile system. PLoS One. 7. United States2012. p. e40814.

58. Totsukawa G, Yamakita Y, Yamashiro S, Hartshorne DJ, Sasaki Y, Matsumura F. Distinct roles of ROCK (Rho-kinase) and MLCK in spatial regulation of MLC phosphorylation for assembly of stress fibers and focal adhesions in 3T3 fibroblasts. J Cell Biol. 2000;150(4):797-806. Epub 2000/08/23. PubMed PMID: 10953004; PubMed Central PMCID: PMCPmc2175273.

59. Beach JR, Licate LS, Crish JF, Egelhoff TT. Analysis of the role of Ser1/Ser2/Thr9 phosphorylation on myosin II assembly and function in live cells. BMC Cell Biol. 2011;12:52. Epub 2011/12/06. doi: 10.1186/1471-2121-12-52. PubMed PMID: 22136066; PubMed Central PMCID: PMCPmc3257205.

60. Straight AF, Cheung A, Limouze J, Chen I, Westwood NJ, Sellers JR, et al. Dissecting temporal and spatial control of cytokinesis with a myosin II Inhibitor. Science. 299. United States2003. p. 1743-7.

61. Rex CS, Gavin CF, Rubio MD, Kramar EA, Chen LY, Jia Y, et al. Myosin IIb regulates actin dynamics during synaptic plasticity and memory formation. Neuron. 2010;67(4):60317. PubMed PMID: 20797537.

62. Brown JA, Wysolmerski RB, Bridgman PC. Dorsal root ganglion neurons react to semaphorin $3 \mathrm{~A}$ application through a biphasic response that requires multiple myosin II isoforms. Mol Biol Cell. 2009;20(4):1167-79. PubMed PMID: 19109430. 
63. Geraldo S, Gordon-Weeks PR. Cytoskeletal dynamics in growth-cone steering. J Cell Sci. 2009;122(Pt 20):3595-604. PubMed PMID: 19812305.

64. Adams CL, Chen YT, Smith SJ, Nelson WJ. Mechanisms of epithelial cell-cell adhesion and cell compaction revealed by high-resolution tracking of E-cadherin-green fluorescent protein. J Cell Biol. 1998;142(4):1105-19. Epub 1998/08/29. PubMed PMID: 9722621; PubMed Central PMCID: PMCPmc2132880.

65. Cavey M, Lecuit T. Molecular bases of cell-cell junctions stability and dynamics. Cold Spring Harb Perspect Biol. 2009;1(5):a002998. Epub 2010/01/13. doi: 10.1101/cshperspect.a002998. PubMed PMID: 20066121; PubMed Central PMCID: PMCPmc2773640.

66. Xia ZK, Yuan YC, Yin N, Yin BL, Tan ZP, Hu YR. Nonmuscle myosin IIA is associated with poor prognosis of esophageal squamous cancer. Dis Esophagus. 2011;25(5):42736. PubMed PMID: 21951916.

67. Maeda J, Hirano T, Ogiwara A, Akimoto S, Kawakami T, Fukui Y, et al. Proteomic analysis of stage I primary lung adenocarcinoma aimed at individualisation of postoperative therapy. Br J Cancer. 2008;98(3):596-603. PubMed PMID: 18212748.

68. Liang S, He L, Zhao X, Miao Y, Gu Y, Guo C, et al. MicroRNA let-7f inhibits tumor invasion and metastasis by targeting MYH9 in human gastric cancer. PLoS One. 2011;6(4):e18409. PubMed PMID: 21533124.

69. Saha S, Dey SK, Das P, Jana SS. Increased expression of nonmuscle myosin Ils is associated with 3MC-induced mouse tumor. Febs J. 2011;278(21):4025-34. PubMed PMID: 21848673.

70. Bhajun R, Guyon L, Pitaval A, Sulpice E, Combe S, Obeid P, et al. A statistically inferred microRNA network identifies breast cancer target miR-940 as an actin cytoskeleton regulator. Sci Rep. 5. England2015. p. 8336.

71. Kass L, Erler JT, Dembo M, Weaver VM. Mammary epithelial cell: influence of extracellular matrix composition and organization during development and tumorigenesis. Int $\mathrm{J}$ Biochem Cell Biol. 2007;39(11):1987-94. PubMed PMID: 17719831.

72. Lu P, Takai K, Weaver VM, Werb Z. Extracellular matrix degradation and remodeling in development and disease. Cold Spring Harb Perspect Biol. 2011;3(12). Epub 2011/09/16. 
doi: 10.1101/cshperspect.a005058. PubMed PMID: 21917992; PubMed Central PMCID: PMCPMC3225943.

73. Jaalouk DE, Lammerding J. Mechanotransduction gone awry. Nat Rev Mol Cell Biol. 10. England2009. p. 63-73.

74. Lopez JI, Kang I, You WK, McDonald DM, Weaver VM. In situ force mapping of mammary gland transformation. Integr Biol (Camb). 2011;3(9):910-21. PubMed PMID: 21842067.

75. DuFort CC, Paszek MJ, Weaver VM. Balancing forces: architectural control of mechanotransduction. Nat Rev Mol Cell Biol. 12. England2011. p. 308-19.

76. Engler AJ, Sen S, Sweeney HL, Discher DE. Matrix elasticity directs stem cell lineage specification. Cell. 126. United States2006. p. 677-89.

77. Walker A, Su H, Conti MA, Harb N, Adelstein RS, Sato N. Non-muscle myosin II regulates survival threshold of pluripotent stem cells. Nat Commun. 1. England2010. p. 71.

78. Balcioglu HE, van Hoorn H, Donato DM, Schmidt T, Danen EH. Integrin expression profile modulates orientation and dynamics of force transmission at cell matrix adhesions. J Cell Sci. 2015. Epub 2015/02/11. doi: 10.1242/jcs.156950. PubMed PMID: 25663698.

79. Frantz C, Stewart KM, Weaver VM. The extracellular matrix at a glance. J Cell Sci. 123. England2010. p. 4195-200.

80. Egeblad M, Rasch MG, Weaver VM. Dynamic interplay between the collagen scaffold and tumor evolution. Curr Opin Cell Biol. 22. England: 2010 Elsevier Ltd; 2010. p. 697-706.

81. Geiger B, Spatz JP, Bershadsky AD. Environmental sensing through focal adhesions. Nat Rev Mol Cell Biol. 10. England2009. p. 21-33.

82. Wolfe JN. Risk for breast cancer development determined by mammographic parenchymal pattern. Cancer. 1976;37(5):2486-92. Epub 1976/05/01. PubMed PMID: 1260729.

83. Martin LJ, Boyd NF. Mammographic density. Potential mechanisms of breast cancer risk associated with mammographic density: hypotheses based on epidemiological evidence. Breast Cancer Res. 10. England2008. p. 201. 
84. Provenzano PP, Inman DR, Eliceiri KW, Knittel JG, Yan L, Rueden CT, et al. Collagen density promotes mammary tumor initiation and progression. BMC Med. 6. England2008. p. 11.

85. Campagnola PJ, Clark HA, Mohler WA, Lewis A, Loew LM. Second-harmonic imaging microscopy of living cells. J Biomed Opt. 2001;6(3):277-86. Epub 2001/08/23. doi: 10.1117/1.1383294. PubMed PMID: 11516317.

86. Allen M, Louise Jones J. Jekyll and Hyde: the role of the microenvironment on the progression of cancer. J Pathol. 2011;223(2):162-76. Epub 2010/12/03. doi: 10.1002/path.2803. PubMed PMID: 21125673.

87. Seguin L, Desgrosellier JS, Weis SM, Cheresh DA. Integrins and cancer: regulators of cancer stemness, metastasis, and drug resistance. Trends Cell Biol. 2015;25(4):234-40. Epub 2015/01/13. doi: 10.1016/j.tcb.2014.12.006. PubMed PMID: 25572304; PubMed Central PMCID: PMCPMC4380531.

88. Frisch SM, Screaton RA. Anoikis mechanisms. Curr Opin Cell Biol. 13. United States2001. p. 555-62.

89. Ma Z, Myers DP, Wu RF, Nwariaku FE, Terada LS. p66Shc mediates anoikis through RhoA. J Cell Biol. 179. United States2007. p. 23-31.

90. Suresh S. Biomechanics and biophysics of cancer cells. Acta Biomater. 3. England2007. p. $413-38$.

91. Li QS, Lee GY, Ong CN, Lim CT. AFM indentation study of breast cancer cells. Biochem Biophys Res Commun. 2008;374(4):609-13. PubMed PMID: 18656442.

92. Giacomini MM, Travis MA, Kudo M, Sheppard D. Epithelial cells utilize cortical actin/myosin to activate latent TGF-beta through integrin alpha(v)beta(6)-dependent physical force. Exp Cell Res. 318. United States: A 2012 Elsevier Inc; 2012. p. 716-22.

93. Klingberg F, Chow ML, Koehler A, Boo S, Buscemi L, Quinn TM, et al. Prestress in the extracellular matrix sensitizes latent TGF-beta1 for activation. J Cell Biol. 207. United States: 2014 Klingberg et al.; 2014. p. 283-97.

94. Millerot-Serrurot E, Guilbert M, Fourre N, Witkowski W, Said G, Van Gulick L, et al. 3D collagen type I matrix inhibits the antimigratory effect of doxorubicin. Cancer Cell Int. 2010;10:26. PubMed PMID: 20707917. 
95. Blockhuys S, Van Rompaye B, De Rycke R, Lambein K, Claes K, Bracke M, et al. Radiation-induced myosin IIA expression stimulates collagen type I matrix reorganization. Radiother Oncol. 2013;108(1):162-7. Epub 2013/06/08. doi: 10.1016/j.radonc.2013.04.001. PubMed PMID: 23742963.

96. Zustiak S, Nossal R, Sackett DL. Multiwell stiffness assay for the study of cell responsiveness to cytotoxic drugs. Biotechnol Bioeng. 2014;111(2):396-403. Epub 2013/09/11. doi: 10.1002/bit.25097. PubMed PMID: 24018833; PubMed Central PMCID: PMCPMC3933463.

97. Lu P, Weaver VM, Werb Z. The extracellular matrix: a dynamic niche in cancer progression. J Cell Biol. 196. United States2012. p. 395-406.

98. Yu Q, Toole BP, Stamenkovic I. Induction of apoptosis of metastatic mammary carcinoma cells in vivo by disruption of tumor cell surface CD44 function. J Exp Med. 1997;186(12):1985-96. Epub 1998/02/12. PubMed PMID: 9396767; PubMed Central PMCID: PMCPMC2199167.

99. Erler JT, Bennewith KL, Cox TR, Lang G, Bird D, Koong A, et al. Hypoxia-induced lysyl oxidase is a critical mediator of bone marrow cell recruitment to form the premetastatic niche. Cancer Cell. 15. United States2009. p. 35-44.

100. Shweiki D, Itin A, Soffer D, Keshet E. Vascular endothelial growth factor induced by hypoxia may mediate hypoxia-initiated angiogenesis. Nature. 1992;359(6398):843-5. Epub 1992/10/29. doi: 10.1038/359843a0. PubMed PMID: 1279431.

101. Erler JT, Bennewith KL, Nicolau M, Dornhofer N, Kong C, Le QT, et al. Lysyl oxidase is essential for hypoxia-induced metastasis. Nature. 440. England2006. p. 1222-6.

102. Levental KR, Yu H, Kass L, Lakins JN, Egeblad M, Erler JT, et al. Matrix crosslinking forces tumor progression by enhancing integrin signaling. Cell. 2009;139(5):891-906. PubMed PMID: 19931152.

103. Wang N, Tytell JD, Ingber DE. Mechanotransduction at a distance: mechanically coupling the extracellular matrix with the nucleus. Nat Rev Mol Cell Biol. 10. England2009. p. 7582.

104. Liou YR, Torng W, Kao YC, Sung KB, Lee CH, Kuo PL. Substrate stiffness regulates filopodial activities in lung cancer cells. PLoS One. 9. United States2014. p. e89767. 
105. Alexander NR, Branch KM, Parekh A, Clark ES, Iwueke IC, Guelcher SA, et al. Extracellular matrix rigidity promotes invadopodia activity. Curr Biol. 18. England2008. p. 1295-9.

106. Mih JD, Marinkovic A, Liu F, Sharif AS, Tschumperlin DJ. Matrix stiffness reverses the effect of actomyosin tension on cell proliferation. J Cell Sci. 125. England2012. p. 597483.

107. Yu HJ, Serebryannyy LA, Fry M, Greene M, Chernaya O, Hu WY, et al. Tumor stiffness is unrelated to myosin light chain phosphorylation in cancer cells. PLoS One. 2013;8(11):e79776. PubMed PMID: 24224004.

108. Ridley AJ, Schwartz MA, Burridge K, Firtel RA, Ginsberg MH, Borisy G, et al. Cell migration: integrating signals from front to back. Science. 302. United States2003. p. 1704-9.

109. Brabek J, Mierke CT, Rosel D, Vesely P, Fabry B. The role of the tissue microenvironment in the regulation of cancer cell motility and invasion. Cell Commun Signal. 8. England2010. p. 22.

110. Ruprecht V, Wieser S, Callan-Jones A, Smutny M, Morita H, Sako K, et al. Cortical contractility triggers a stochastic switch to fast amoeboid cell motility. Cell. 2015;160(4):673-85. Epub 2015/02/14. doi: 10.1016/j.cell.2015.01.008. PubMed PMID: 25679761; PubMed Central PMCID: PMCPMC4328143.

111. Provenzano PP, Eliceiri KW, Keely PJ. Shining new light on 3D cell motility and the metastatic process. Trends Cell Biol. 2009;19(11):638-48. PubMed PMID: 19819146.

112. Sanz-Moreno V, Marshall CJ. The plasticity of cytoskeletal dynamics underlying neoplastic cell migration. Curr Opin Cell Biol. 2010;22(5):690-6. PubMed PMID: 20829016.

113. Dang TT, Prechtl AM, Pearson GW. Breast cancer subtype-specific interactions with the microenvironment dictate mechanisms of invasion. Cancer Res. 71. United States: 2011 Aacr.; 2011. p. 6857-66.

114. Sabeh F, Shimizu-Hirota R, Weiss SJ. Protease-dependent versus -independent cancer cell invasion programs: three-dimensional amoeboid movement revisited. J Cell Biol. 2009;185(1):11-9. PubMed PMID: 19332889. 
115. Wolf K, Muller R, Borgmann S, Brocker EB, Friedl P. Amoeboid shape change and contact guidance: T-lymphocyte crawling through fibrillar collagen is independent of matrix remodeling by MMPs and other proteases. Blood. 102. United States2003. p. 3262-9.

116. Wolf K, Mazo I, Leung H, Engelke K, von Andrian UH, Deryugina El, et al. Compensation mechanism in tumor cell migration: mesenchymal-amoeboid transition after blocking of pericellular proteolysis. J Cell Biol. 160. United States2003. p. 267-77.

117. Wolf K, Wu YI, Liu Y, Geiger J, Tam E, Overall C, et al. Multi-step pericellular proteolysis controls the transition from individual to collective cancer cell invasion. Nat Cell Biol. 9. England2007. p. 893-904.

118. Irimia D, Toner M. Spontaneous migration of cancer cells under conditions of mechanical confinement. Integr Biol (Camb). 2009;1(8-9):506-12. PubMed PMID: 20023765.

119. Raab M, Swift J, Dingal PC, Shah P, Shin JW, Discher DE. Crawling from soft to stiff matrix polarizes the cytoskeleton and phosphoregulates myosin-II heavy chain. J Cell Biol. 2012;199(4):669-83. Epub 2012/11/07. doi: 10.1083/jcb.201205056. PubMed PMID: 23128239; PubMed Central PMCID: PMCPmc3494847.

120. Kraning-Rush CM, Carey SP, Califano JP, Smith BN, Reinhart-King CA. The role of the cytoskeleton in cellular force generation in 2D and 3D environments. Phys Biol. 2011;8(1):015009. PubMed PMID: 21301071.

121. Mierke CT, Frey B, Fellner M, Herrmann M, Fabry B. Integrin alpha5beta1 facilitates cancer cell invasion through enhanced contractile forces. J Cell Sci. 2011;124(Pt 3):36983. PubMed PMID: 21224397.

122. Baker EL, Srivastava J, Yu D, Bonnecaze RT, Zaman MH. Cancer cell migration: integrated roles of matrix mechanics and transforming potential. PLoS One. 2011;6(5):e20355. PubMed PMID: 21647371.

124. Mierke CT. Cancer cells regulate biomechanical properties of human microvascular endothelial cells. J Biol Chem. 2011;286(46):40025-37. PubMed PMID: 21940631.

125. Mierke CT, Zitterbart DP, Kollmannsberger P, Raupach C, Schlotzer-Schrehardt U, Goecke TW, et al. Breakdown of the endothelial barrier function in tumor cell transmigration. Biophys J. 2008;94(7):2832-46. PubMed PMID: 18096634. 
126. Mierke СT. Role of the endothelium during tumor cell metastasis: is the endothelium a barrier or a promoter for cell invasion and metastasis? J Biophys. 2008;2008:183516. PubMed PMID: 20107573.

127. Yang $\mathrm{Y}$, Kulangara K, Sia J, Wang L, Leong KW. Engineering of a microfluidic cell culture platform embedded with nanoscale features. Lab Chip. 2011;11(9):1638-46. Epub 2011/03/29. doi: 10.1039/c0lc00736f. PubMed PMID: 21442110.

128. Iorns E, Drews-Elger K, Ward TM, Dean S, Clarke J, Berry D, et al. A new mouse model for the study of human breast cancer metastasis. PLoS One. 2012;7(10):e47995. PubMed PMID: 23118918.

129. Aslakson CJ, Miller FR. Selective events in the metastatic process defined by analysis of the sequential dissemination of subpopulations of a mouse mammary tumor. Cancer Res. 1992;52(6):1399-405. Epub 1992/03/15. PubMed PMID: 1540948.

130. Warren S, Gates O. The Fate of Intravenously Injected Tumor Cells. The American Journal of Cancer. 1936;27(3):485-92. doi: 10.1158/ajc.1936.485.

131. Alexander S, Weigelin B, Winkler F, Friedl P. Preclinical intravital microscopy of the tumour-stroma interface: invasion, metastasis, and therapy response. Curr Opin Cell Biol. 2013;25(5):659-71. Epub 2013/07/31. doi: 10.1016/j.ceb.2013.07.001. PubMed PMID: 23896198.

132. Sumpio BE, Riley JT, Dardik A. Cells in focus: endothelial cell. Int J Biochem Cell Biol. 34. England2002. p. 1508-12.

133. Vandenbroucke E, Mehta D, Minshall R, Malik AB. Regulation of endothelial junctional permeability. Ann N Y Acad Sci. 1123. United States2008. p. 134-45.

134. Ho KS, Poon PC, Owen SC, Shoichet MS. Blood vessel hyperpermeability and pathophysiology in human tumour xenograft models of breast cancer: a comparison of ectopic and orthotopic tumours. BMC Cancer. 12. England2012. p. 579.

135. Chung AS, Lee J, Ferrara N. Targeting the tumour vasculature: insights from physiological angiogenesis. Nat Rev Cancer. 10. England2010. p. 505-14.

136. Hartsock A, Nelson WJ. Adherens and tight junctions: structure, function and connections to the actin cytoskeleton. Biochim Biophys Acta. 2008;1778(3):660-9. Epub 2007/09/15. 
doi: 10.1016/j.bbamem.2007.07.012. PubMed PMID: 17854762; PubMed Central PMCID: PMCPmc2682436.

137. Hurst VI, Goldberg PL, Minnear FL, Heimark RL, Vincent PA. Rearrangement of adherens junctions by transforming growth factor-beta1: role of contraction. Am J Physiol. 1999;276(4 Pt 1):L582-95. Epub 1999/04/13. PubMed PMID: 10198356.

138. Garcia JG, Verin AD, Schaphorst KL. Regulation of thrombin-mediated endothelial cell contraction and permeability. Semin Thromb Hemost. 1996;22(4):309-15. Epub 1996/01/01. doi: 10.1055/s-2007-999025. PubMed PMID: 8944415.

139. van Nieuw Amerongen GP, Musters RJ, Eringa EC, Sipkema P, van Hinsbergh VW. Thrombin-induced endothelial barrier disruption in intact microvessels: role of RhoA/Rho kinase-myosin phosphatase axis. Am J Physiol Cell Physiol. 294. United States2008. p. C1234-41.

140. Lin Z, Natesan V, Shi H, Dong F, Kawanami D, Mahabeleshwar GH, et al. Kruppel-like factor 2 regulates endothelial barrier function. Arterioscler Thromb Vasc Biol. 30. United States2010. p. 1952-9.

141. Muller WA. Leukocyte-endothelial-cell interactions in leukocyte transmigration and the inflammatory response. Trends Immunol. 2003;24(6):327-34. PubMed PMID: 12810109.

142. Arvanitis C, Khuon S, Spann R, Ridge KM, Chew TL. Structure and biomechanics of the endothelial transcellular circumferential invasion array in tumor invasion. PLoS One. 9. United States2014. p. e89758. 


\section{Figure Legends}

Figure 1. General Steps of Cancer Metastasis. Cancer cells in a primary tumor invade the local stromal environment and migrate through the surrounding matrix towards blood or lymphatic vessels. The cells must then cross the vessel wall and enter the bloodstream. Once the tumor cells have reached a secondary site, they exit the bloodstream. Cancer cells can undergo apoptosis, enter a dormant state, or proliferate to form a secondary tumor at the site of metastasis.

Reymond N, d'Agua BB, Ridley AJ. Crossing the endothelial barrier during metastasis. Nat Rev Cancer. 13. England2013. p. 858-70 (modified).

Figure 2. Domain Structure and Regulation of Myosin II Activity and Filament Assembly. Nonmuscle myosin II is a hexamer formed of a pair of heavy chains that interact through coiled coil domains, and two pairs of light chains. Each heavy chain contains a globular head domain that interacts with actin and contains ATPase activity. Unphosphorylated myosin II head and tail domains interact to form a compact structure that cannot interact with other myosin molecules. When the regulatory light chain is phosphorylated, the molecule unfolds and associates with other myosin molecules to form bipolar thick filaments that interact with actin to generate cell contractility. Phosphorylation of the heavy chain prevents filament assembly.

Vicente-Manzanares M, Ma X, Adelstein RS, Horwitz AR. Non-muscle myosin II takes centre stage in cell adhesion and migration. Nat Rev Mol Cell Biol. 2009;10(11):778-90 (modified). 


\section{Figure 1}

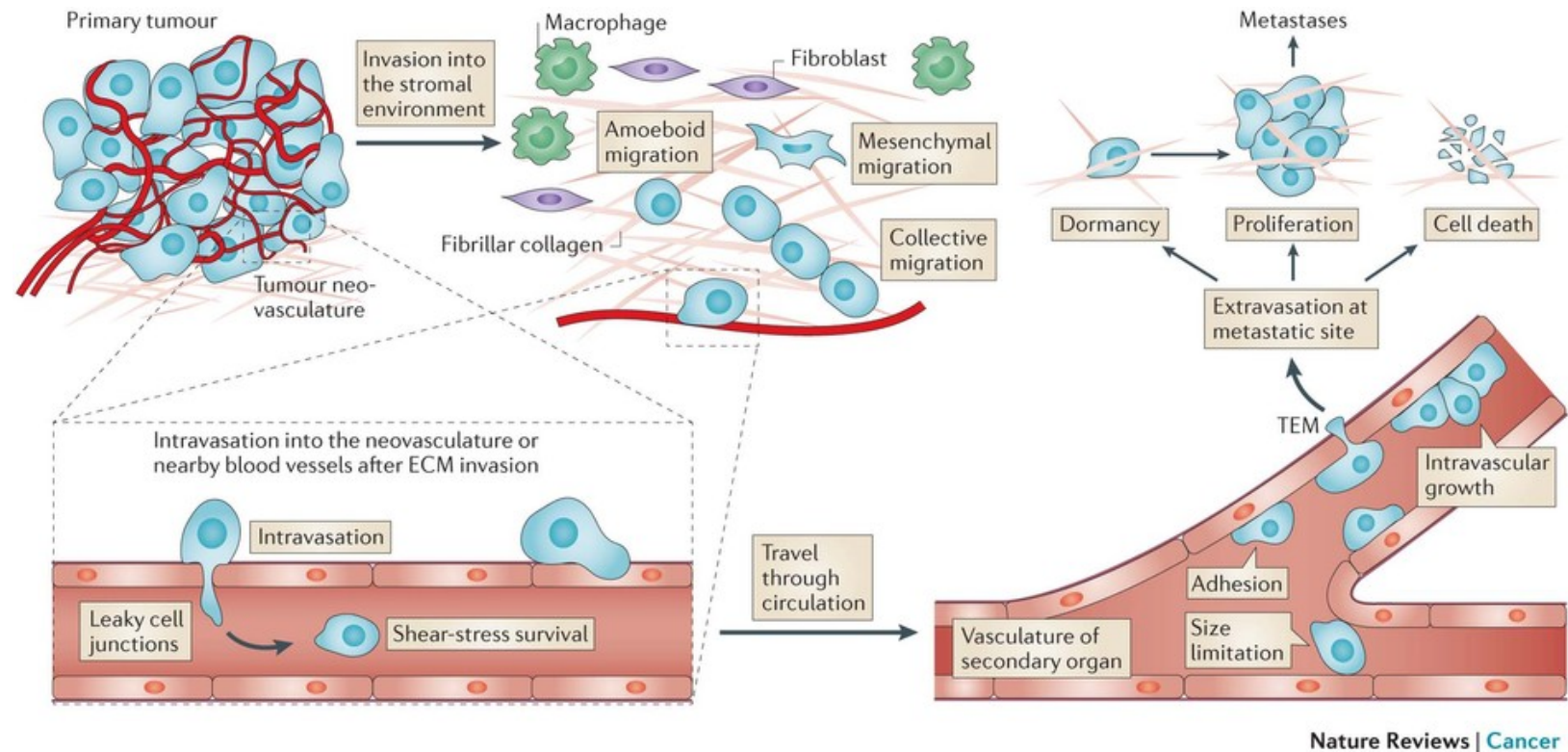




\section{Figure 2}

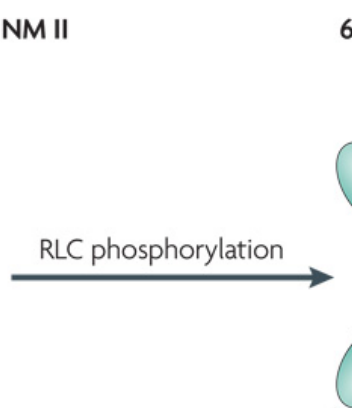

S assembly-competent NM II

Globular head domain

(actin binding and

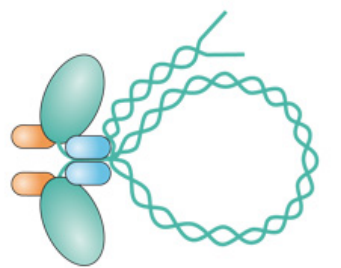

b Bipolar NM II filaments

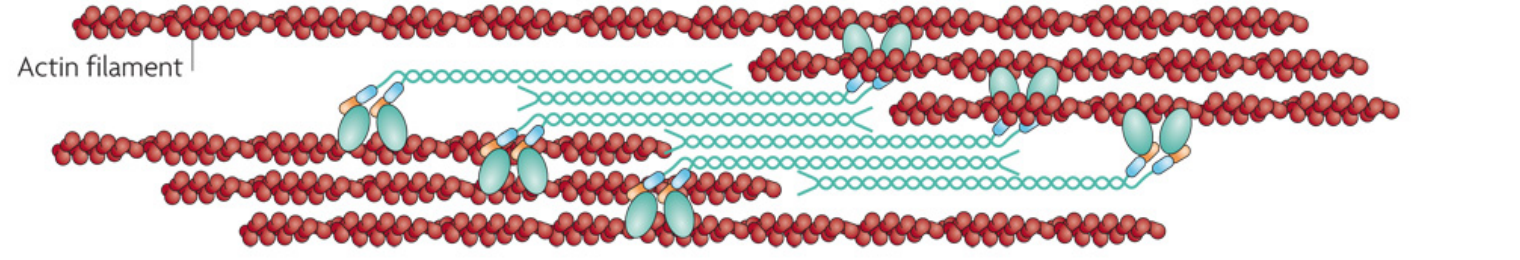


Non-muscle Myosin II Isoforms Have Different Functions in Matrix Rearrangement and Migration of MDA-MB-231 Cells

\section{Bridget Hindman ${ }^{1}$}

Zoe Goeckeler ${ }^{2}$

\section{Kostas Sierros ${ }^{3}$}

Robert Wysolmerski ${ }^{1,2^{\star}}$

1 Mary Babb Randolph Cancer Center, West Virginia University, Robert C. Byrd Health Sciences Center, Morgantown, West Virginia, United States of America

2 Center for Cardiovascular and Respiratory Diseases, West Virginia University, Robert C. Byrd Health Sciences Center, Morgantown, West Virginia, United States of America 3 Mechanical and Aerospace Engineering, Statler College of Engineering and Mineral Resources, West Virginia University, Morgantown, West Virginia, United States of America

* Corresponding Author

Email: rwysolmerski@hsc.wvu.edu (RW) 


\section{Abstract}

The role of a stiffening extra-cellular matrix (ECM) in cancer progression is documented but poorly understood. Here we use a novel conditioning protocol to test the role of nonmuscle myosin II isoforms in cell mediated ECM arrangement using collagen constructs seeded with breast cancer cells expressing a shRNA targeted to either the IIA or IIB heavy chain isoform. While there are several methods available to measure changes in the biophysical characteristics of the ECM, we wanted to use a method which allows for the measurement of global stiffness changes as well as a dynamic response from the sample over time. The stretch conditioning protocol used allows the direct measurement of ECM stiffness. Using various treatments, it is possible to determine the contribution of various construct and cellular components to the overall construct stiffness. Using this assay, we show that both the IIA and IIB heavy chain isoforms are necessary for efficient matrix remodeling by MDA-MB-231 breast cancer cells, as loss of either isoform changes the stiffness of the collagen constructs as measured using our conditioning protocol. Constructs containing only collagen had an elastic modulus of 0.40 Pascals (Pa), parental MDA-MB-231 constructs had an elastic modulus of $9.22 \mathrm{~Pa}$, while IIA and IIB KD constructs had moduli of 3.42 and $7.20 \mathrm{~Pa}$, respectively. We also calculated the cell and matrix contributions to the overall sample elastic modulus. Loss of either myosin isoform resulted in decreased cell stiffness, as well as a decrease in the stiffness of the cell-altered collagen matrices. Finally, we measured the migration ability of these cells in a 3D model. Loss of myosin IIB causes a 50\% reduction in migratory speed while loss of IIA results in a $25 \%$ reduction compared to parental controls. Track displacement and track total length were also altered in IIA and IIB KD cell lines. These 
results indicate that the IIA and IIB heavy chains play distinct and non-redundant roles in matrix remodeling and cell migration. 


\section{INTRODUCTION}

Breast cancer is a widespread disease that remains a leading cause of death in the US, despite public education and research initiatives in recent years. With 232,340 new cases of invasive disease estimated in 2013 , and 39,620 expected deaths, breast cancer is the second leading cause of cancer related deaths in women [1]. An initial sign of breast cancer is the presence of a palpable lump in the breast [2]. This lump, or stiffening of the breast tissue, corresponds to up to a ten-fold increase in the rigidity of the extracellular matrix (ECM) of the tissue [3]. The majority of cancer-related deaths result from metastatic disease in such vital organs as the lungs, liver or brain [4]. Metastasis is a multi-step process that allows tumor cells to break off from the primary tumor and colonize distant sites in the body. Briefly, cells leave the primary tumor, invade into and migrate through local normal tissues before intravasating into nearby blood vessels or lymphatic vessels and traveling to distant sites. The cells then extravasate from the blood or lymph vessels and colonize the secondary site [5]. Changes to cell and/or tissue mechanics, such as the increased rigidity of the breast during cancer tumorigenesis, may have an influence on cell signaling, proliferation, invasion, migration, and metastasis [2, 6-8], and can therefore have a vast impact on how cancer is diagnosed and treated.

Tissues maintain a balance of overall stiffness by a phenomenon known as mechanoreciprocity. This involves a feedback loop between the cells and their surrounding matrix to maintain a particular rigidity $[2,9,10]$. In some diseases, including many solid cancers, this homeostasis is lost and promotes disease progression [2, 11]. This loss of homeostasis can be the result of changes in ECM content and cross-linking $[3,12]$, as well as the increased cell pressure caused by the high cell density within a 
growing tumor $[6,13]$. In fact, these two facets of tissue stiffness can feed into each other. Tumor cells excrete factors that activate stromal cells, including fibroblasts, inducing them to deposit ECM components and secrete crosslinking factors such as lysyl oxidase. The resultant increased matrix rigidity in turn stimulates cell proliferation, which increases tumor cell density and pressure [2, 6, 7, 9, 13]. During the latter stages of disease progression, ECM stiffness and reorganization influences cancer invasion and metastasis $[2,6,8,12,14-16]$. Breaking the link between increasing ECM stiffness and cell proliferation and invasion could be a powerful therapeutic target, especially considering that the increased matrix stiffness can alter the efficiency of chemotherapeutic agents [17]. This interplay between matrix rigidity and cell signaling and growth is dependent on mechanosensing in the cells, a process which requires the force generation power of nonmuscle myosin II as part of the transmission and response to the force signal from focal adhesions and integrins at the cell surface [18-22].

Changes in ECM stiffness influence cell migration and metastasis as well as tumor growth. Specific alterations in the surrounding matrix, especially physical arrangement of collagen fibers, promote cell migration [12]. Cell migration plays a central role in cancer metastasis and has been of great interest in the literature. Myosin II is involved in a number of forms of cell motility, including leukocyte migration during the inflammatory response and growth cone-steering in neurite migration [14, 18, 23-30]. Given myosin II's role in the migration of these other cell types, it likely plays a role in the migration of tumor cells as well. The viscoelastic properties of a cell could also have a significant impact on a cell's ability to migrate and metastasize, and are influenced by matrix stiffness changes $[10,31]$. The deformability of cells influences how cells migrate through the matrix and 
whether they can squeeze through the pores already existing in the matrix or must resort to proteolytic mechanisms [31, 32]. Cell elasticity also impacts later stages in the metastatic process: specifically, how cells travel through the bloodstream. As metastatic cells flow through the circulatory system, they can become trapped in small capillary beds. Cancer cells are larger than red blood cells, and are more likely to become trapped in the capillary beds of organs such as the lungs [33]. Red blood cells are able to traverse capillary beds due to their elasticity and deformability [34]. A more deformable cell may be able to metastasize to different sites in the body, while a less deformable cell may become trapped earlier in the circulation, yielding different metastatic profiles for cells with varying elastic properties. Once a circulating tumor cell is trapped, it either extravasates from the vessel or proliferates within the vessel [35]. Myosin II contractility is necessary for cell stiffness, and changes in the myosin II isoform expression of cells may affect their viscoelastic properties, migration potential, and metastasis [21, 36-40].

There are three isoforms of nonmuscle myosin II: A, B, and C. Nonmuscle myosin Il functions as a hexamer with a pair of heavy chains and two pairs of light chains, regulatory and essential. It is an ATPase capable of converting chemical energy into mechanical work, which is integral to its role in mechanosensing $[18,41]$. In addition to its role in mechanotransduction, it has also been shown to be involved in cytokinesis and other cellular processes [42-44]. Force generation is also needed in order for cells to reorganize their surrounding matrix, which contributes to mechanical homeostasis $[2,6$, 9]. Finally, myosin contractility is needed for multiple types of cell migration, including lymphocyte invasion, neuron migration during development, and tumor cell migration [14, $23,26,45-50]$. While we know that myosin II is involved in these processes, limited 
research has been done looking into the specific involvement of this motor protein in cancer progression. It has been shown that upregulation or overactivation of myosin IIA is associated with poor prognosis in esophageal [51] and lung cancer [52]. Additionally, in gastric cancer, a decrease in expression of Let-7f, a microRNA that directly binds the 3'UTR of the myosin IIA gene, is associated with an increase in myosin IIA expression and the invasive potential of gastric cancer cells [53]. Finally, tumor tissue in a carcinogen induced murine hind limb model of cancer has increased levels of both myosin IIA and IIB compared to tumor associated normal tissue [54]. Given these changes in myosin II regulation in various cancers, and its role in mechanoreciprocity, it could be a strong potential target to break the ECM stiffness/cancer progression feedback loop.

To investigate the role of nonmuscle myosin II isoforms in tumor cell driven remodeling of the ECM, we generated stable myosin IIA and IIB knockdown (KD) MDAMB-231 cell lines. The morphology was characterized in both two- and three- dimensional culture model systems. We then tested the cell lines for their ability to remodel and constrict a 3D collagen matrix. Complementing the gel compression measurements, we used mechanical testing protocols to measure the stiffness and elasticity of cell populated collagen matrices. This assay allows the direct measurement of biophysical characteristics of the matrix and is similar that used by Wakatsuki, et al [40]. Here we show that loss of myosin IIA blocks the ability of the cells to compress a matrix and results in a matrix with decreased stiffness compared to parental or IIB KD modified matrices. The IIB KD cells are able to compress the collagen gels, but the collagen constructs containing these cells have a different elastic modulus profile than parental cells, indicating that the changes they make to the collagen matrix are not the same as those 
made by the parental cells. The viscoelastic properties of cells influences their migration capabilities, therefore we measured cell stiffness directly using cell poking $[2,16,55,56]$. To investigate the roles of the myosin II isoforms, A and B, in cancer cell migration, we developed a 3D model system using a "mini-tumor" approach. Here we show that loss of either the IIA or the IIB isoform has a distinct effect on the migration patterns of the cells. These results indicate that nonmuscle myosin II is involved in matrix remodeling and mechanical homeostasis, making it a potential therapeutic target for blocking the effects of matrix stiffness on tumor proliferation and progression.

\section{Materials and Methods}

\section{Cell culture}

MDA-MB-231 (ATCC, HT-B26) cells were grown and maintained in Minimal Essential Media (MEM) supplemented with 10\% FCS, $100 \mathrm{U} / \mathrm{ml}$ penicillin, and $100 \mu \mathrm{g} / \mathrm{ml}$ streptomycin (media components were purchased from Sigma Aldrich) in a $37^{\circ} \mathrm{C}$ humidified $5 \% \mathrm{CO}_{2}$ tissue culture incubator.

\section{Generation of Myosin II Knockdown Cell Lines}

Lentiviruses were produced in $293 \mathrm{~T} / 17$ cells as outlined by Tiscornia, et al. [57] using $2^{\text {nd }}$ generation transfer plasmids. Myosin IIA Heavy Chain shRNAs (Cat \# RHS4533) and IIB Heavy Chain shRNAs (Cat \# RHS4531) were obtained from Openbiosystems (Waltham, MA, USA). After screening all clones, myosin IIA shRNA clone \#29467 and myosin IIB shRNA clone \#123076 were determined to be isoform specific and produce the most efficient myosin II knockdown. These clones were used in all experiments. For viral infections, MDA-MB-231 cells were seeded at a density of $4 \times 10^{5}$ cells and allowed to adhere and spread overnight. Two $\mathrm{mL}$ of viral stock was added to each culture and virus 
incubated with cells for 72 hours. Cultures were washed with MEM+10\% FCS and allowed to recover for 1 day. For selection and maintenance of MDA-MB-231 cell lines, cultures were fed with MEM+10\%FCS containing $5 \mu \mathrm{g} / \mathrm{mL}$ puromycin (Sigma Aldrich). Myosin IIA and IIB KD was verified using Western Blot analysis.

\section{Immunofluorescence staining}

For indirect immunofluorescence staining, MDA-MB-231 control (parental) and MDA-MB231 myosin II KD cells were fixed and stained for actin and myosin II as described previously [58]. Cells were labeled with affinity-purified rabbit anti-myosin heavy chain IIA or IIB antibody (final dilution 1:1000) as well as TRITC-phalloidin (Sigma-Aldrich, St. Louis, MO, USA Cat \# P1951). Alexa 488 goat $\alpha$-rabbbit secondary antibody (Invitrogen, Grand Island, NY, USA Cat \# A11070) was used at a final dilution of 1:1000. MDA-MB231 cells were mounted in $90 \%$ glycerol/10\% PBS containing $0.1 \mathrm{M} n$-propyl gallate (Sigma-Aldrich, St. Louis, MO, USA Cat \# P3130). Imaging was performed using a Zeiss LSM 510 confocal microscope. A Plan-Apochromat 63x/1.40 Oil DIC M27 objective was used and composite images were constructed from $0.3-\mu \mathrm{m}$ optical sections. To quantify the fluorescent staining, cells were stained as outlined above, and imaged using a ZEISS Axiovert $40 \mathrm{CFL}$ microscope with a LD A-Plan 20X objective. Quantification was performed using Image $\mathrm{J}$ software on at least 25 cells per experiment, across three experiments.

\section{D Morphology}

Methods for pouring collagen gels were performed as described in detail previously [58, 59]. Collagen gels were made by suspending $1 \times 10^{6}$ cells/ml of MDA-MB-231 controls (parental) or MDA-MB-231 myosin IIA or myosin IIB KD in a collagen/MEM solution 
containing $1.0 \mathrm{mg} / \mathrm{ml}$ Type I rat tail collagen. Collagen/cell suspension $(1 \mathrm{ml})$ was poured into Teflon casting molds with a central mandrel and transferred to a $37^{\circ} \mathrm{C}$ incubator for 1 hour to initiate collagen polymerization. The collagen gel forms $(3 \mathrm{~mm}$ thick, $3 \mathrm{~cm}$ diameter) between the inner wall of the Teflon cylinder and the central mandrel giving rise to a collagen/cell matrix in the shape of a ring (henceforth referred to as a construct). Teflon casting molds were then filled with MEM-10\% FCS and incubated for 4 days in a humidified incubator at $37^{\circ} \mathrm{C}$ with $5 \% \mathrm{CO}_{2}$. At the appropriate time, collagen gels were removed from the molds, fixed, permeabilized and stained as described for 2D immunofluorescence. Pieces of the collagen gels were cut and processed for staining with TRITC-Phalloidin and affinity purified myosin IIA or IIB antibodies as described above. Alexa 488 goat $\alpha$-rabbbit secondary antibody was used at a final dilution of 1:1000. Prior to being mounted, gel pieces were soaked overnight in 9:1 glycerol:PBS containing $0.1 \mathrm{M}$ n-propyl gallate. Multi-Photon Laser Scanning Microscopy (MPLSM) was used to image stained constructs for gel compression studies. For 3D cell morphology, a Zeiss LSM 510 was used with an EC Plan-Neofluar 40x/1.30 Oil DIC M27 objective. Composite micrographs were constructed from $0.5-\mu \mathrm{m}$ optical sections. Analysis of cell morphology was performed using IMARIS image analysis software (Version 8.0 Bitplane, Zurich, $\mathrm{CHE}$ ). The Filaments function was used to measure the average number of cell protrusions. To calculate the sphericity of the cell bodies, the Surfaces function was used. Surfaces contours were manually drawn and the sphericity calculated by the software. Sphericity compares the surface area of the object, in this case a cell body, to the surface area of a sphere of the same volume. If the object is a perfect sphere, the sphericity would be 1. Elongation factor was calculated using the measurements function in IMARIS. We 
defined elongation factor as the longest dimension of the object, the cell body, divided by the shortest. The more elongated the cell body, the higher the elongation factor. These morphology characteristics were measured on cells across three separate experiments, with more than 18 cells for each cell type analyzed per experiment. One-way analysis of variance (ANOVA) with a Tukey post-test was performed in GraphPad Prism (GraphPad Software, Inc., La Jolla, CA, USA) to determine the statistical significance of the differences seen.

\section{Gel Compression}

Collagen gel constructs were poured as described above. While in culture, cells organize and compress the collagen, reducing its volume approximately 2 to 5 fold. For gel compression studies (gel thickness), collagen gels were washed with PBS, fixed and removed from Teflon molds after 1 or 4 days of incubation. These time points were chosen to allow the cells sufficient time to compress the matrix. Allowing the gels to incubate for longer periods of time (past one week) does not result in enhanced matrix compression, and the cells within the construct begin to die. The collagen/cell matrix, which is in the shape of a ring, was cut open and three random non-adjacent pieces of the collagen gel cut from each MDA-MB-231 construct, stained with TRITC-Phalloidin and Hoescht 33258 dye (Sigma-Aldrich, St. Louis, MO, USA Cat \# 861405), and mounted as outlined above. To determine the thickness of gels cast with only collagen, $40 \mu \mathrm{l}$ of $1 \mu \mathrm{m}$ fluorescent beads (Polysciences, Warrington, PA, Cat\# 24062) were added to the collagen/MEM solution prior to pouring constructs. Multi-Photon Laser Scanning Microscopy (MPLSM)

was used to measure the full thickness of all collagen constructs. For all experimental conditions, constructs were poured in duplicate and a minimum of five measurements 
were taken from each piece, for a total of 30 measurements per cell type per experiment. The data shown are averaged from three separate experiments. Construct thickness was compared between gels cast from collagen alone, parental and KD MDA-MB-231 cell lines. For experiments using blebbistatin to inhibit myosin II, constructs were fed daily with MEM+10\% FCS containing $50 \mu \mathrm{M}$ blebbistatin ((S)-(-)-blebbistatin, Toronto Research Chemicals) and fixed at 1 and 4 days. Constructs were then processed and measured as described above. Statistical significance was calculated in GraphPad Prism 6 using one-way ANOVA and a Tukey post-test.

\section{Isometric Tension and Mechanical Measurements}

Constructs were poured as described above. After 4 days of incubation, the central mandrel was removed from the Teflon casting mold and the MDA-MB-231 populated construct gently removed from the mandrel before being looped over a triangular hook connected to an isometric force transducer (Harvard Apparatus model 52-9545, South Natick MA) as described previously $[58,59]$. The ring is then looped over a horizontal bar which is connected to a stepper motor controlled by a micro-stepping driver as initially described by Kolodney and Wysolmerski [60]. The apparatus used in this study, is very similar to that used by Wakatsuki et al [40], which includes a schematic of the apparatus and construct pouring method. The collagen gels were placed in a $50 \mathrm{ml}$ thermo-regulated Organ Bath (Harvard Apparatus, Holliston, MA, USA Cat\# 760165) containing 20 mM Hepes-buffered MEM/0.4\% bovine serum albumin (Sigma Aldrich). Organ baths were maintained at $37^{\circ} \mathrm{C}$ for the duration of experiments. The triangular hook and stationary horizontal bar over which the construct was looped were set to hold the collagen ring at its original length of $15 \mathrm{~mm}$, which corresponds to half the circumference of the central 
mandrel. This configuration allows us to apply a defined stretch over a specific time period and to relax the constructs to their original length at the same rate. For mechanical measurements, constructs were hung and allowed to establish a stable basal force. After establishing a basal force, constructs were stretched to $10 \%$ strain $(1.5 \mathrm{~mm})$ at a rate of $0.5 \mathrm{~mm} / \mathrm{min}$, and immediately relaxed to their original length at the same rate. After this initial stretch, constructs were allowed to recover for at least $60 \mathrm{~min}$, or until a stable basal line tension developed. $2 \mu \mathrm{M}$ cytochalasin $\mathrm{D}$ was added to the organ bath to depolymerize MDA-MB-231 actin filaments and abolish basal tension. After basal line tension was eliminated ( $\sim 45$ minutes) constructs were then subjected to another $10 \%$ strain $(1.5 \mathrm{~mm})$ at a rate of $0.5 \mathrm{~mm} / \mathrm{min}$, and immediately relaxed to their original length at the same rate. Constructs were allowed to recover for 1 hour before being removed from the apparatus. Recovery was included in the mechanical testing for thoroughness as failure in long-term elastic recovery could indicate changes in the properties of the samples not measured by the elastic modulus calculations; alterations in long-term recovery of the samples tested here were not seen. After being removed from the apparatus, samples were snap frozen for determining DNA and myosin II isoform content. This protocol allowed us to determine how MDA-MB-231 cells actively changed the mechanical properties of the collagen matrix after 4 days in culture. It also allows for determination of how elimination of the active actin contractile cytoskeletal contribution alters construct stiffness. To determine the stiffness of the cell altered collagen matrix alone, MDA-MB-231 collagen gels were treated with deoxycholate and subjected to a stretching protocol. This treatment also allows us to determine if other cell components besides the actin contractile cytoskeleton, such as microtubule networks or cell-matrix attachments, contribute to the overall 
construct stiffness. For deoxycholate experiments, a separate set of constructs, cast on the same day and with the same collagen solution as the initial and cytochalasin D treated constructs, were hung on the apparatus and subjected to the initial stretching protocol outlined above. After 45 min recovery, deoxycholate was added to the organ bath at a final concentration of $0.5 \%$ and constructs incubated in the presence of the detergent for an additional 60 min before being subjected to another $10 \%$ strain. For all experiments, constructs were hung in duplicate for each treatment type. During each stretching protocol, isometric tension generated by constructs was recorded every second at $5 \mathrm{~Hz}$ for the duration of an experiment. At the end of each experiment, constructs were removed from the apparatus and snap frozen for DNA and myosin II isoform content analysis. In optimizing stretch parameters, total strains of $5,10,15$, and $20 \%$, and strain rates of $0.2,0.5,0.7$, and $0.9 \mathrm{~mm} / \mathrm{min}$ were tested.

\section{Estimation of cross-sectional area}

Collagen constructs were laid flat on a glass plate and collagen construct width was calculated by taking high resolution digital photographs and measuring the number of pixels across the width of the construct. The thickness of the specimens was determine by Multi-Photon Laser Scanning Microscopy as outlined above (gel compression).

\section{Measurement of Cell Concentration and DNA Analysis}

The final cell concentration within collagen constructs was calculated from standard curves generated using MDA-MB-231 samples of known cell number in increments from 100,000 to 5 million cells. Frozen construct samples were resuspended in $750 \mu \mathrm{L}$ of $0.1 \%$ SDS in PBS and sonicated until homogenous. Samples were diluted using $0.1 \%$ SDS in PBS at 1:10, 1:50 and 1:100 dilutions and $100 \mu \mathrm{L}$ of each dilution loaded into a microwell 
plate (Nunc Part No. 237017). Hoescht 33258 stain was added to each well at a concentration of $0.09 \mu \mathrm{g} / \mathrm{mL}$ per well and the plate was analyzed using the Hoescht 33528 protocol on a Modulus Microplate plate reader (Turner Biosystems, Model number 9300002).

\section{Calculation of Elastic Modulus}

Tension readings were converted from dynes to millinewtons $(\mathrm{mN})$ and plotted against percent strain using Sigmaplot (Version 8.02, Systat Software, San Jose, California, USA). Hysteresis curves were generated by plotting the force readings during stretching and unloading against strain as a function of time. Because each strain is reached twice, once during stretching and once during unloading, the resulting graph starts from zero, reaches $10 \%$ strain, and then returns to zero. The upward sweep of each curve is the tension produced during stretching, and the downward sweep is tension during unloading of the sample. To measure the elastic modulus of the constructs, the cross-sectional area must be determined. The cross-sectional are is defined as the area of the sample where the force is applied; in this case, the thickness and the width of the construct were calculated as outlined above. Tension readings, in $\mathrm{N}$, were divided by the cross-sectional area, in $\mathrm{m}^{2}$, to determine the stress on the sample in Pascals $\left(\mathrm{Pa} ; 1 \mathrm{~Pa}=1 \mathrm{~N} / \mathrm{m}^{2}\right)$. When the stress in $\mathrm{Pa}$ is plotted against strain, the slope of the line during the stretch portion of the curve is the elastic modulus of the sample. This slope was calculated using the Linear Regression tool in SigmaPlot, with a confidence interval of $95 \%$. Using the Rule of Mixtures (below), we calculated the contribution of individual components of a sample to the total elastic modulus. For the collagen constructs, there are two main components: the matrix itself and the cells within the matrix. 


$$
E_{\text {construct }}=f E_{\text {cells }}+(1-f) E_{\text {matrix }}
$$

Where $\mathrm{E}_{\text {construct }}$ is the elastic modulus of the entire construct, determined using the initial stretch of the untreated construct; $\mathrm{E}_{\text {matrix }}$ is the elastic modulus of the matrix component of the constructs, determined using the DOC treated stretch; and $f$ is the volume fraction. Volume fraction is defined as the volume of the component of interest, in this case the volume of the cells, divided by the volume of the complete sample. To calculate the cell volume, samples were stained with TRITC-Phalloidin and imaged using MPLSM for the full depth of the sample. Using, the Surface function of IMARIS software, the volume of the TRITC channel was calculated. The total volume was calculated using the known frame size of the z-stacks taken. The volume fractions were determined for two full zstacks for each construct and were consistent between constructs for each cell type. After the elastic modulus of the cell component was determined, the average elastic modulus for individual cells was calculated by dividing $\mathrm{E}_{\text {cells }}$ by the total number of cells in the construct. In addition to the elastic modulus, we calculated the elastic recovery of samples. For the purposes of this study, elastic recovery is defined as the slope of the graph during the initial recovery after stretching (the first 30 time points after unloading begins). These experiments were performed three separate times, and the statistical significance was calculated using a one-way ANOVA with a Tukey post-test.

\section{Cell Poking}

Cell poking measurements were performed as outlined previously [56]. Briefly, cells are seeded onto a glass coverslip and indented using a probe controlled by a motor. The indentation depth and elastic recovery, or the amount of time a cell needs to return to the original cell shape, are used to calculate cell stiffness. The position of each cell poked 
was recorded. After cell poking measurements were completed, cells were fixed in $4 \%$ paraformaldehyde, treated with $10 \mathrm{mM}$ sodium borohydrite for 2 minutes to reduce free aldehydes, permeabilized in stabilizing buffer containing 0.5\% Triton X-100, 0.6\% DOC, pH6.5 for two 10min incubations and then stained as described above. The individual cells poked were imaged using laser scanning confocal microscopy and myosin content, actin content, cell surface area and cell volume were measured using Image $\mathrm{J}$. Experiments were performed three separate times, and statistical significance was calculated using ANOVA with a Tukey post-test.

\section{D Migration}

Two different migration assays were used, 1) a plug model, where cells migrate outwards from a mass of cells into a cell-free collagen matrix and 2) a dispersed model, where cells are suspended as single cells in a collagen matrix and migration within the matrix observed. For the plug migration model, cells were combined with type I rat tail collagen solution $(1 \mathrm{mg} / \mathrm{mL})$ at a density of $2 \times 10^{6}$ cells $/ \mathrm{mL}$ and poured into silicone templates (see Fig. 4A). Constructs were allowed to incubate for 24 hours, by which time they have greatly constricted the collagen matrix and formed a collagen plug, or "mini-tumor". The cellularized plug was then removed from the template, and re-embedded into a collagen matrix $(1 \mathrm{mg} / \mathrm{mL})$. For the dispersed model of migration, cells were suspended in collagen at a concentration of $1 \times 10^{6}$ cells $/ \mathrm{mL}$ and allowed to spread for 24 hours. For both models, the migrating cells were then imaged using live cell, time-lapse microscopy on an inverted Zeiss 510 microscope with an environmental chamber. Z-series were taken at $2 \mu \mathrm{m}$ steps every 15 minutes at multiple points $(>4)$ per sample over a 24 hour period. IMARIS software was used to reconstruct the 3D movies and the Spots function used to calculate 
cell migration speed, displacement and distance traveled. These experiments were performed three separate times, and the statistical significance was calculated using a one-way ANOVA with a Tukey post-test.

\section{Collagen Isolation}

Rat tails from previous euthanized animals were obtained from animal quarters. Animals were euthanized under an approved West Virginia University Institutional Animal Care and Use Committee protocol and the tails removed by veterinarian staff. Immediately upon receiving the tails, they were sterilized with $70 \% \mathrm{EtOH}$. In a sterile environment, the tails were skinned by snipping off the tip, then making an incision with a scalpel the length of the tail before peeling back the skin. Collagen bundles were then severed at each end of the tail with a scalpel, then pulled from the tail using hemostats. Collagen fibrils were placed in sterile $4^{\circ} \mathrm{C}$ PBS on ice until collagen from 4-5 large tails had been removed (at least $5 \mathrm{~g}$ of collagen). Any excess tissue was removed from the collagen fibrils before placing the collagen in $70 \% \mathrm{EtOH}$ for one hour on ice. Fibrils were then washed twice more with $70 \% \mathrm{EtOH}$ before being washed once each with PBS and sterile water. After the collagen was washed, the fibrils were placed in $300 \mathrm{~mL}$ of sterile $20 \mathrm{mM}$ Acetic Acid. The collagen solution was then stirred at a slow rate for 48 hours at $4^{\circ} \mathrm{C}$, occasionally mixing with a sterile pipet to ensure complete mixing. After the extraction period, the collagen was centrifuged at $16,000 \times \mathrm{xg}$ for 90 minutes at $4^{\circ} \mathrm{C}$. Collagen concentration was determined using SDS-PAGE and stored at $4^{\circ} \mathrm{C}$, protected from light. 


\section{RESULTS}

\section{Knockdown of Myosin II Isoforms in MDA-MB-231 Cells}

It has been established in the literature that MDA-MB-231 cells express the IIA and IIB isoforms of nonmuscle myosin II, but express low levels of IIC not detectable by Western blot [61-63]. In order to test the contribution of each of the major myosin II isoforms in MDA-MD-231 cells, we performed knockdown (KD) of myosin IIA and IIB and assessed what effect myosin KD had on cell morphology (2D and 3D), actin organization, and the ability of MDA-MB-231 cells to compress and organize 3D collagen matrices. Lentiviral shRNA constructs against the two isoforms were screened for specificity and efficient myosin II KD. As shown in Figure 1, each shRNA construct achieved greater than $85 \% \mathrm{KD}$ of their respective isoforms, while only minimally affecting the non-targeted isoform. Efficient knockdown of myosin isoforms was verified using immunofluorescence (S1 Figure).

We next sought to determine if loss of either myosin IIA or IIB affects general cell morphology as well as actin and myosin II distribution. Figure 2 illustrates representative immunofluorescent images of parental controls and myosin IIA and IIB KD MDA-MB-231 cells in 2D culture. F-actin in parental MDA-MB-231 cells was localized to lamellapodia and central stress fibers (Fig. 2 A\&C). Myosin IIA co-localized to the underlying actin filaments in lamellapodia and stress fibers (Fig. 2B) while myosin IIB was localized to stress fibers and concentrated in the perinuclear region (Fig. 2D). Knockdown of myosin IIA caused a disruption in the actin stress fibers of cells, exhibiting prominent stress fibers at the periphery of the cell, and fewer centrally located fibers (Fig. 2E). Residual myosin IIA (Fig. 2F) was detected at low levels in KD cells where it localized to the actin stress 
fibers. Knockdown of myosin IIA appears to alter the distribution of myosin IIB, which seems to assume a microtubule like distribution pattern (Fig. 2 G-H). We speculate this might result from IIB binding to a microtubule associated protein. Loss of myosin IIB (Fig. $2 \mathrm{I}-\mathrm{L})$ resulted in formation of shorter, thicker stress fibers heavily decorated with myosin IIA (Fig.2 I-J). These fibers were randomly distributed throughout the cytoplasm. In contrast, KD of myosin IIB for the most part abolished myosin IIB staining associated with underlying stress fibers (Fig. 2L). Any remaining myosin IIB exhibited a perinuclear localization (Fig. 2L). In 2D, MDA-MB-231 cells showed a variety of morphologies and shapes.

In attempt to generate a microenvironment similar to what cells encounter in vivo, MDA-MB-231 cells were cast within 3-D collagen matrices. MDA-MB-231 parental, IIA, and IIB KD cell lines suspended in type 1 rat tail collagen were poured into Teflon casting molds and incubated for 4 days. Over this time period cells spread, organize and compress the collagen matrix. Since neither the cells nor collagen are able to adhere to Teflon, the influence of the casting mold on matrix organization is minimized. Therefore, MDA-MB-231 cell-matrix and cell-cell interactions are primarily responsible for generating the 3-D organized matrix within the Teflon casting mold. After 4 days, collagen constructs were fixed and stained for actin and myosin IIA or myosin IIB.

Figure 3 shows representative images illustrating the morphology and the actin/myosin II distribution of MDA-MB-231 cells in 3D matrices. Parental (Fig. 3 A-F), myosin IIA KD (Fig. 3 G-L) and myosin IIB KD (Fig. 3 M-R) cells exhibit distinct morphology in 3D. Parental cells (Fig. 3 A-F) exhibited a rounded or pyramidal like cell body with multiple cell processes extending in various directions and focal planes. Actin 
(Fig. 3 A\&D) was localized to the cytoplasm and cell processes. Both myosin IIA and IIB

(Fig. 3, B\&C and E\&F, respectively) co-localize to the underlying actin filaments in the cell body and processes, and also exhibit diffuse staining throughout the cytoplasm. Myosin IIA KD cells (Fig. 3 G-L) have a more rounded cell body with numerous slender cell processes extending into several focal planes of the 3D construct. Lack of myosin IIA staining (Fig.3 H\&l), in conjunction with western blot analysis (Fig. 1B), confirms the efficient myosin IIA KD and shows that loss of IIA had little effect on myosin IIB localization (Fig. $3 \mathrm{~K} \& H$ ). In contrast, IIB KD cells within the collagen matrix are long slender cells that lack cell processes, confining IIB KD cells to a single focal plane. Lack of myosin IIB staining (Fig. 3Q), in conjunction with western blot analysis (Fig. 1B), showed IIB KD had little effect on IIA distribution. The changes in cell morphology in 3D were quantified using IMARIS software (Fig. 4). Figure 4A shows the average number of protrusions per cell. Parental cells had 6.7 protrusions per cell, while IIA KD cells had 12.9, and IIB KD cells had 2.9 protrusions. IIA KD cells had significantly more protrusions per cell than either the parental or IIB KD cells. We also calculated the sphericity (Fig. 4B) and elongation (Fig. 4C) of the cell bodies. IIA KD cells had slightly more spherical cell bodies, and IIB $\mathrm{KD}$ cells had slight more elongated cell bodies, though these differences were not statistically significant. These results suggest that myosin II isoform may regulate how cells are able to interact and organize their surrounding matrices.

\section{Myosin II Isoforms and 3D Collagen Gel Compression}

Myosin II has been proposed to be critical for mechanotransduction [41], and for generation of cellular forces essential for matrix remodeling. To measure the ability of MDA-MB-231 cells to organize and compress 3D collagen gels, we developed a gel 
compression assay. MDA-MB-231 cells were mixed in type I collagen and cast into a Teflon casting mold and allowed to organize and compress the collagen gel for 1 to 4 days, before being fixed and removed from the molds. At this point, the cells have compressed the collagen matrix into a tight ring around the central mandrel of the casting mold. The ring is cut open and the thickness of the collagen constructs measured using microscopy. For determining the thickness of gels cast with only collagen, $1 \mu \mathrm{m}$ fluorescent beads were added to the collagen/MEM solution prior to casting constructs. Construct thickness was compared between gels cast from collagen alone, parental, and myosin KD MDA-MB-231 cell lines.

Examples of representative z-stacks depicting the thickness of collagen constructs generated from collagen alone, parental and myosin IIA and IIB KD MDA-MB-231 cell lines are shown in Figure 5A. Comparing the measured thickness of these different constructs allowed us to calculate to what extent control and KD cells compress a collagen gel. Collagen constructs cast from collagen alone were approximately 1024.7 $\mu \mathrm{m}$ thick 1 day post casting, and after 4 days were measured to be $1023.7 \mu \mathrm{m}$ thick (Fig. 5 A,B). Parental cells were able to compress the matrix by $50 \%(540.6 \mu \mathrm{m}) 1$ day post casting, and $57 \%(442.1 \mu \mathrm{m}) 4$ days post casting, compared to constructs containing collagen alone. Although the majority of the matrix organization/compression occurs within 24 hours, the process continued for the 4 day duration of an experiment. Myosin IIA KD cells were unable to effectively constrict the collagen construct (Fig 5B). Myosin IIA KD cell were only able to compress the matrix $15.2 \%(870.2 \mu \mathrm{m})$ and $16.1 \%(858.9$ $\mu \mathrm{m}) 1$ and 4 days post casting compared to constructs cast from only collagen). Parental cells generated $36 \%$ and $40 \%$ more matrix compression on day 1 and day 4 , respectively, 
compared to the myosin IIA KD cells. These differences were statistically significant $(p<$ 0.0001). Interestingly, we found that the IIB KD cells behaved similarly to parental cells in their ability to organize and compress the collagen constructs. Myosin IIB KD MDA-MB231 cells compressed the matrix 53\% (483.0 $\mu \mathrm{m})$ and $64 \%(369.9 \mu \mathrm{m})$ after 1 and 4 days, respectively compared to constructs cast from only collagen. This extent of compression was similar to the parental control $50 \%$ and $57 \% 1$ and 4 days post casting (Fig. 5B). We speculate that the loss of matrix remodeling exhibited by the myosin IIA KD cells could be due to the loss of the force generating capacity needed to physically modify the matrix or the loss of myosin IIA involvement in integrin signaling $[64,65]$. Since loss of myosin IIB did not cause significant disruption in matrix compression, our data suggests that myosin II isoforms do not have redundant roles in this cellular process, but rather have separate functions

In an attempt to inhibit total myosin II function we also measured the ability of parental cells treated with the small molecule myosin II inhibitor blebbistatin to compress a collagen construct. Parental cells treated with blebbistatin were only able to compress the gel $40 \%(583 \mu \mathrm{m})$ after 4 days compared to constructs cast from only collagen (data not shown). Blebbistatin treated constructs have a decreased ability to alter the matrix, however, it is not completely ablated. This suggests that cells may be using a myosin II independent mechanism or we were unable to completely inhibit myosin due to blebbistatin absorbing to the collagen matrix or its degradation in aqueous media.

\section{Myosin II Isoform Involvement in Isometric Tension of Collagen Constructs}

While the gel compression assays are a measure of the amount of matrix remodeling cells are capable of, it does not directly measure changes in the matrix itself. 
Because matrix stiffness can also independently affect tumor progression, we sought to develop a way to directly measure matrix rigidity and elasticity. To begin to measure this, we first needed a method to measure changes in tension and force production in the collagen constructs as a whole. Using our isometric tension recordings apparatus we were able to measures the force produced by collagen constructs both at rest and in response to physical strain. Collagen constructs were poured into the Teflon casting molds, removed after 4 days and hung from isometric force transducers, as described in Wakatsuki, et al [40]. After establishing a basal force, constructs were stretched to $10 \%$ strain $(1.5 \mathrm{~mm})$ at a rate of $0.5 \mathrm{~mm} / \mathrm{min}$ and immediately relaxed to their original length at the same rate. The resulting tension was measured and plotted against strain in hysteresis curves. In these graphs, the upward sweep of the curve represents the tension produced by the construct during stretching, while the downward portion is the recovery of the sample during unloading. These hysteresis curves are used to gain insight into the stiffness and elasticity of the constructs.

Figure $6 \mathrm{~A}$ shows the hysteresis curves, plotted as $\mathrm{mN}$ versus percent strain, for collagen alone (blue line), parental (black line), myosin IIA KD (red line), and IIB KD (green line) MDA-MB-231 collagen constructs during stretching and unloading from a single, representative experiment. Parental samples (the black line in Fig. 6A) show a marked increase in stress during the period of stretching, a 10-fold increase in tension at the maximum stretch. Comparing the parental samples to the collagen alone (the blue line in Fig. 6A), it is evident that the cells are significantly altering the collagen matrix. The collagen alone constructs are very loose compared to the much tighter network generated by parental cells. The loose, unorganized matrix produces a decreased force signature in 
response to strain. The myosin IIA KD and IIB KD samples (the red and green lines in Fig. 6A, respectively), also show a decreased response to physical strain when compared to the parental samples, indicating that they do not respond to physical stress in the same way as the parental cells. Interestingly, the MDA-MB-231 samples do not return to the same baseline tension after unloading, indicating the collagen constructs are not perfectly elastic. The changes in collagen construct tension between the various cell lines correspond well to the differences seen in the gel compression assay (Fig. 5). Parental cells are able to compress the collagen and generate a significant force in response to increased strain, while myosin IIA KD cells are unable to properly modify their surrounding matrix resulting in a 2.4 fold decrease in peak force generation in response to applied strain. Myosin IIB KD cells exhibit a force response to strain similar to that seen in parental cells, a 10 fold increase from baseline at the maximum stretch. The distinct tension profiles in response to strain for these cell lines suggest differences in the structural arrangement of the matrix, resulting in lower force generation for less organized, looser constructs (myosin IIA KD cells). This interpretation is in agreement with data obtained from gel compression assays (Fig. 5).

The isometric tension measurements examined thus far measure the collagen construct as a whole, i.e. cells and the microenvironment generated by modifying their surrounding matrix. By eliminating certain components of the constructs, we can determine what role(s) each component plays in matrix organization and tension generation. For example, treating the constructs with cytochalasin $\mathrm{D}$, an actin disrupting agent, before subjecting the construct to mechanical testing allowed us to compare the applied strain response produced in cells with an intact actin cytoskeleton (active 
contractile cell) with those from which the actin cytoskeletal contributions of the cell have been eliminated. This treatment provided information about the active contractile force generated by the cells within the construct. Furthermore, treating constructs with the nonionic detergent deoxycholate uncoupled cell membrane matrix interactions (by dissolving the entire cell) leaving only the collagen construct, devoid of cells, to respond to the applied strain. The cell bodies themselves and their attachments to the matrix may contribute to force generated simply because their attachments act as an anchor, prohibiting the collagen fibers from stretching as far as they could without these attachments. The force produced in response to strain after removing cells with detergent allowed us to measure only the inherent contribution of the matrix to the construct rigidity and elasticity.

Figure 6B shows representative hysteresis curves of untreated parental control constructs, as well as parental constructs treated with cytochalasin D and dexoycholate. Cytochalasin D treated constructs (red line in Fig. 6B) have a much lower baseline tension compared to untreated controls, 0.19 versus $0.59 \mathrm{mN}$. Treatment with deoxycholate reduces the baseline even lower to $0.12 \mathrm{mN}$. As shown in Figure $6 \mathrm{~B}$, parental cells generate a peak force of $5.8 \mathrm{mN}$ in response to applied strain. Disruption of actin filaments resulted in a 1.5 fold (to $3.8 \mathrm{mN}$ ) reduction in force at max stretch, indicating an intact actin/myosin cytoskeleton was needed to generate force in response to applied strain. Incubation of constructs in the presence of deoxycholate further reduced the peak force response by 1.3 fold (to $2.9 \mathrm{mN}$ ). Parental control constructs cast with MDA-MB-231 cells containing both myosin IIA and IIB generate a peak strain tension 8 fold higher $(5.8 \mathrm{mN})$ than constructs cast with collagen alone $(0.75 \mathrm{mN})$. Both myosin IIA KD (Fig. 6C) and IIB 
KD (Fig. 6D) showed a similar pattern of changes in tension production after treatment with cytochalasin D or deoxycholate as did the parental constructs. The myosin IIA KD constructs (Fig.6C) generated a 2.4 fold lower peak force than control constructs indicating the IIA KD cells were unable to stiffen the matrix in a manner comparable to parental cells. After treatment with cytochalasin D and deoxycholate (Fig. 6C, red and green curves, respectively), the hysteresis curves indicate the matrix has been organized by the IIA KD cells to impart a structural rigidity to the construct 2.5 fold stiffer than constructs cast from collagen alone; though the IIA KD generated matrix is still 2.9 fold lower than parental controls. This implies that even though the constructs are looser and larger (width and depth) than controls, the IIA KD cell still have the ability to modestly compress and organize the matrix. Myosin IIB KD (Fig. 6D) constructs more closely approximate parental control responses, however, the hysteresis curves show that myosin IIA alone (the remaining isoform in IIB KD cells) is not capable of generating the same matrix stiffness as exhibited by parental controls (Fig. 6B).

These results, in conjunction with the gel compression studies, indicate that both myosin IIA and IIB are needed for MDA-MB-231 cells to respond to applied stress and organize 3D matrices. Our data points to myosin IIA as the prominent myosin II isoform regulating matrix organization/compression, since loss of IIB has only minimal effects on 3D matrix compression and stiffness. However, myosin IIB is unable to completely compensate for the loss of myosin IIA, indicating that both isoforms are necessary for these cell processes. 


\section{Myosin II Involvement in Matrix Rigidity and Elasticity}

In order to calculate the elasticity of a sample, the stress generated by the construct, rather than the recorded tension, must be determined. Stress is defined as force divided by the cross-sectional area of the sample and is reported as Pascals ( $1 \mathrm{~Pa}$ is equal to $1 \mathrm{~N} / \mathrm{m}^{2}$ ). The cross-sectional area of the samples in this study was calculated using the width of the collagen construct multiplied by the thickness of the construct which corresponds to the area of the construct the strain is acting upon. The cross-sectional areas for the various cell lines differ due to differences in their ability to alter and compress the matrix. Figure 7A shows representative hysteresis curves corrected for the differences in cross-sectional area for parental, myosin IIA and IIB KD MDA-MB-231 cells. The differences between cell lines are highlighted when the cross-sectional area is taken into account. This is especially evident in the IIA KD constructs (the red line in Fig. 7A), which exhibits a $64 \%$ reduction in peak force in response to mechanical testing compared to parental constructs and a 50\% reduction when compared to myosin IIB KD constructs. These results show myosin II is an essential player in development of matrix stiffness and suggest myosin IIA is more involved in matrix organization than IIB.

Once the stress (force/cross-sectional area) has been calculated it is used to determine the elastic modulus of the construct. Constructs are subjected to mechanical testing and hysteresis curves plotted as Pa versus strain. The slopes of these hysteresis curves are used to calculate the elastic modulus of the sample. This calculation comes from the following equation:

$$
\sigma=E \varepsilon
$$


Where $\varepsilon$ is the strain on the sample, $\sigma$ is the stress of the sample, and $E$ is the elastic modulus of the sample. Because the elastic modulus is defined as stress ( $\mathrm{Pa}$ ) divided by strain (unitless) it has units in $\mathrm{Pa}$. The stress-strain curves for representative experiments of all cell types, as well as collagen alone, are presented in Figure 6A. Similar to the results obtained from the force versus strain curves (Fig. 6), we found major differences in the mechanical properties between constructs cast with collagen alone and constructs cast with MDA-MB-231 cells. Table 1 shows the calculated Construct elastic modulus (organized/compressed collagen matrix containing cells) and Matrix elastic modulus (samples treated with detergent to remove the cells) for parental, myosin IIA and myosin IIB KD MDA-MB-231 cells. Parental constructs had an elastic modulus of $9.22 \mathrm{~Pa}, 208-$ fold greater than for constructs cast from collagen alone (0.40 Pa). Myosin IIA KD cell constructs had an elastic modulus of $3.42 \mathrm{~Pa}$, a 2.7 fold decrease from parental controls and 8 fold increase over collagen alone. Myosin IIB KD constructs had an elastic modulus of $7.20 \mathrm{~Pa}$, more closely approximating parental control constructs. These numbers are in agreement with the differences in the ability of cells to compress the collagen gel as measured by gel compression (Fig. 5B).

Table 1. Elastic modulus of collagen constructs seeded with MDA-MB-231 cells.

\begin{tabular}{|c|c|c|c|c|}
\hline Cell Type & Construct Modulus (Pa) & P Value & Matrix Modulus (Pa) & P Value \\
\hline Parentals & $9.22 \pm 0.61$ & NA & $4.38 \pm 0.50$ & NA \\
\hline IIA KD & $3.42 \pm 0.34$ & $<0.001$ & $2.39 \pm 0.37$ & $<0.05$ \\
\hline IIB KD & $7.20 \pm 0.78$ & ns & $4.73 \pm 0.53$ & ns \\
\hline Collagen & $0.40 \pm 0.03$ & $<0.0001$ & $0.40 \pm 0.03$ & $<0.001$ \\
\hline
\end{tabular}


It is also important to understand construct mechanics during recovery (unloading) from the elastic strain. For the purposes of this study, we defined elastic recovery as the slope of the hysteresis curve during the initial 30 seconds of sample unloading. As shown in Table 2, the differences between cell types are evident and in agreement with our gel compression data and the elastic modulus: parental cell constructs had an elastic recovery of $38.61 \mathrm{~Pa}$, IIA KD constructs $15.89 \mathrm{~Pa}$, and IIB KD cells 31.86 $\mathrm{Pa}$ (Table 2). The difference between collagen alone and collagen containing cells is evident here as well; IIA KD constructs, which are unable to efficiently alter the matrix, produce a 8.3 fold greater elasticity than collagen constructs alone, which exhibited an elastic recovery of $1.92 \mathrm{~Pa}$.

Table 2. Elastic recovery of collagen constructs seeded with MDA-MB-231 cells.

\begin{tabular}{c|cccc} 
Cell Type & Construct $(\mathbf{P a})$ & $\mathbf{P}$ Value & Matrix (Pa) & P Value \\
\hline Parentals & $38.61 \pm 1.05$ & NA & $19.65 \pm 1.32$ & NA \\
IIA KD & $15.89 \pm 2.19$ & $<0.001$ & $10.70 \pm 1.56$ & $<0.01$ \\
IIB KD & $31.86 \pm 4.40$ & ns & $18.77 \pm 1.55$ & $n$ ns \\
Collagen & $1.92 \pm 0.11$ & 0.0001 & $1.92 \pm 0.11$ & $<0.00018$
\end{tabular}

The elastic recovery, here defined as the slope of the initial recovery of the construct after stretching, was calculated for each cell type. Shown are the averaged ( \pm SEM) elastic recovery for constructs across three experiments.

\section{Myosin II Isoforms Play Different Roles in Matrix Arrangement and Cellular Response to Strain}

The elastic moduli calculated above represent the collagen construct as a whole (Construct Modulus), both matrix and cell component, and that of the cell modified matrix alone after cells are removed using detergent (Matrix Modulus). While cells may be 
arranging the matrix in a similar way, the cells' response to physical stress may be different, especially if myosin II isoforms play different roles in matrix interactions and cellular force generation. Using the Rule of Mixtures it is possible to separate the contribution of the matrix and cells to overall construct elasticity. The Rule of Mixtures states that:

$$
E_{\text {construct }}=f E_{\text {cells }}+(1-f) E_{\text {matrix }}
$$

In the above equation $E_{\text {construct }}$ is the elastic modulus of the untreated samples, $E_{\text {matrix }}$ is the elastic modulus of the constructs treated with deoxycholate (Fig 7B) and $f$ is the volume fraction. The volume fraction is defined as the volume of the component of interest (cells), divided by total volume of the construct. For this study, the volume of the cell component of the constructs was calculated using microscopy and divided by the total volume of the image frame. Myosin IIA KD cells had a smaller volume fraction than IIB KD or parental cells ( 0.014 for the IIA KD cells versus 0.017 and 0.02 for the parental and IIB KD cells, respectively) because the total volume of the construct is greater due to the fact that the IIA KD cells are unable to constrict the matrix $(821 \mu \mathrm{m}$ for the IIA KD cells versus $481 \mu \mathrm{m}$ for the parental cells). However, the overall cell volume between the cell types is not significantly different (about $9 \times 10^{6} \mu \mathrm{m}^{3}$ ). For calculations such as this, it is important that the cells be evenly distributed throughout the matrix. As can be seen in Figure 5A, these cells are well distributed and not clustered in one region of the construct. For parental constructs, the cell modulus was determined to be $286.26 \mathrm{~Pa}$. Myosin IIA KD cells had a modulus of 52.89 PA, and IIB KD cells had a modulus of 107,43 Pa (Table 3). The parental cell elastic modulus was 5.4-fold greater than myosin IIA KD total cell elastic modulus and 2.4 fold greater than myosin IIB KD cells. This is consistent with the changes 
in matrix remodeling ability of the different cell lines, again suggesting that myosin IIA assumes a greater role in organizing/compressing the microenvironment than myosin IIB. Table 3. Calculated elastic modulus of MDA-MB-231 cells within collagen constructs.

\begin{tabular}{c|cccc} 
Cell Type & Total Cell Modulus (Pa) & P Value & Single Cell Modulus $(\boldsymbol{\mu P a})$ & P Value \\
\hline Parentals & $286.26 \pm 30.99$ & NA & $189.25 \pm 20.68$ & NA \\
IIA KD & $52.89 \pm 17.28$ & $<0.01$ & $36.78 \pm 13.38$ & $<0.01$ \\
IIB KD & $107.43 \pm 23.47$ & $<0.01$ & $79.84 \pm 24.48$ & $<0.05$
\end{tabular}

The Construct and Matrix moduli of constructs from each experiment were used to calculate the Total Cell Modulus. This was then divided by the cell number, determined by a DNA assay for each experiment, to calculate the Single Cell Modulus. Shown are the calculated total and single cell moduli, averaged across three experiments $( \pm$ SEM).

Once the elastic modulus of the cell component of the constructs has been calculated, dividing the total elastic modulus by the total number of cells in the constructs will determine the average elastic modulus of each individual cell (Single Cell Modulus; Table 3). The number of cells in each construct was determined to be between 1.3 and 1.8 million cells for each cell type. The single cell elastic modulus was calculated as 189.25 $\mu \mathrm{Pa}$ for parental cells, $36.78 \mu \mathrm{Pa}$ for IIA KD cells, and $79.843 \mu \mathrm{Pa}$ for the IIB KD cells (Table 3). Interestingly, the total cell elastic modulus calculated for the parental cells and the IIB KD cells (286.26 and 107.435 $\mu \mathrm{Pa}$, respectively, Table 3 ) show a divergence with what was predicted based on the overall construct elastic modulus (9.22 vs $7.20 \mathrm{~Pa}$ respectively; Table 1). This can be explained when comparing the matrix elastic modulus (deoxycholate treated stretches) for the two cell types. While the overall construct modulus is higher for the parentals than IIB KD), the matrix elastic modulus for the parental constructs is actually lower than that for the myosin IIB KD (4.38 Pa versus 4.73 $\mathrm{Pa}$ ). This suggests the myosin IIB KD cells arrange and compress the collagen matrix in 
a different way than parental cells, creating a stiffer construct. It is possible that IIB is restricting or inhibiting myosin IIA's ability to transmit force across the membrane and maximally organize the matrix. We speculate that upon loss of myosin IIB, myosin IIA is able to transmit force across the membrane more efficiently yielding a stiffer, more rigid matrix.

Our data also clearly shows that cells containing only myosin IIA (IIB KD cells) produce 2.2 fold greater tension within the construct than cells expressing only myosin IIB (IIA KD cells). In addition, these data suggest myosin IIA is the major force producing motor protein in the parental cells, since cells lacking IIA had a cell elastic modulus 5.1 fold less than parental cells, while those lacking IIB had an elastic modulus only 2.4 fold less. Nevertheless, both motor proteins are essential for MDA-MB-231 cells to achieve maximum tension production. Thus, calculating the elastic modulus of the total construct, the matrix, and the cells allows one to analyze the mechanical properties of the constructs in a more quantitative way than the gel compression measurements; these calculations are useful in making comparisons to elasticity and rigidity measurements under various experimental conditions or even whole tissues. Taken together, these results suggest that myosin II isoforms have separate roles in the generation and maintenance of cellular stiffness and in their ability to alter and guide matrix organization and stiffness. Myosin IIA is especially important for matrix remodeling and elasticity. These cellular characteristics, due to altered mechanoreciprocity in tumors, may have a drastic impact on tumorigenesis. 


\section{Loss of Myosin Isoforms Affects Cell Viscoelasticity}

Given myosin II's involvement in cell contractility and stiffness we set out to determine if changes in the myosin II status of cells affects their viscoelastic properties. Figure 8 shows the mean stiffness of individual parental, IIA and IIB KD MDA-MB-231 cells as measured by cell poking. Parental cells had a mean stiffness of 5.39 dynes/cm. IIA KD cells had a much lower stiffness of 4.26 dynes/cm. IIB KD cells actually had a higher cellular stiffness than parental cells at 5.81 dynes/cm. Finally, cells treated with the general myosin II inhibitor blebbistatin had a lower stiffness than either individual knockdown at 3.1 dynes/cm. The difference between parental cells and IIA KD cells was statistically significant, as was the difference between bebbistatin cells and all cell types. These alterations in cell stiffness could heavily influence how cells migrate in 3D models as well as their metastatic patterns in animal models.

Loss of a Myosin II Isoform has a Distinct Effect on the Ability of the Cell to Migrate in 3D

To determine if loss of either of the myosin II isoforms changes the ability of cells to migrate in 3D, we compared the migration of MDA-MB-231 parental and KD cell lines in the plug model and the dispersed models of 3D migration. There are many different models to study cell migration, each with their advantages and disadvantages. A popular model, called the "sandwich" model or the collagen overlay model, involves seeding cells between two different 3D substrates, such as collagen or Matrigel $[66,67]$. While this model is fairly simple and can yield insight into how cells migrate at the interface between two surfaces, it is not the most relevant model. Another model is seeding cells in an extracellular matrix (ECM), such as collagen, and tracking the individual cells as they 
randomly migrate in the 3D matrix $[14,46,68,69]$. We refer to this model as the dispersed model. This model shows how individual cells move in a 3D matrix, however, it does not recapitulate the specific situation in the body of individual cells breaking away from a tumor and migrating through the interstitial space. The cell-cell interactions at the tumorstromal interface influences migration, and dispersed migration does not allow for these interactions [47]. Due to the limitations of these migration models, we decided to use a plug, or "mini-tumor" approach to study cell migration. Briefly, cells are seeded in a collagen plug and allowed to form a "mini-tumor" before being re-implanted into a collagen matrix. Individual cells breaking away from the plug and migrating into the surrounding matrix can then be tracked (Fig. 9A). In developing the plug model, we sought to develop an assay that recapitulates the specific situation of cells migrating through a 3D ECM away from a tumor.

Two different models of 3D migration were performed, the dispersed model and the plug model. Parental cells in either model migrated at similar speeds (Fig. 9B and Table 4). However, the distances traveled by these cells were different between the two models. The average displacement, the distance between a cell's point of origin and its end point, regardless of the path taken, differed by $40 \%$, a statistically significant difference (Fig. 9C and Table 5). Also, the average total distance a cell traveled was different between the two models, though due to the large variation did not reach statistical significance (Fig. 9D and Table 6). There were also differences seen between the two models using IIA and IIB KD cell lines. IIA KD cells in the dispersed model migrated at a slightly slower rate than cells in the plug model (Fig. 9B and Table 4). IIA KD cells had slightly different displacement and total track lengths between the two 
models (Fig. 9 C-D and Tables 5-6). IIB cells migrated at higher speeds in the dispersed model, though it did not reach statistical significance (Fig. 9B and Table 4). Once again, a greater difference was seen in the distance traveled by the cells between the two models than in the speed of migration. IIB KD cells had a $50 \%$ increase in track displacement in the dispersed model of migration, a statistically significant difference (Fig. 9C and Table 5). A similar trend was seen in total track length, with cells moving a greater total distance in the dispersed model of migration (Fig. 9D and Table 6). The differences seen between the two models indicate that the plug model of 3D migration is an interesting model that could prove a useful addition to the currently available methods.

Table 4. Migration speed of MDA-MB-231 cells in 3D models

\begin{tabular}{|c|c|c|c|}
\hline Cell Type & Plug Model & Dispersed Model & Blebbistatin Treated \\
\hline Parentals & $17.9 \pm 1.95$ & $18.88 \pm 1.07$ & $6.99 \pm 0.54$ \\
\hline IIA KD & $13.4 \pm 1.33$ & $11.21 \pm 0.93$ & $4.30 \pm 0.47$ \\
\hline IIB KD & $8.29 \pm 0.94$ & $14.71 \pm 1.36$ & $7.18 \pm 0.50$ \\
\hline
\end{tabular}

The speed of migrating cells in three separate experiments was determined using the Spots function in Imaris. Data presented as average $\mu \mathrm{m} / \mathrm{hr} \pm \mathrm{SEM}$.

Table 5. Migration track displacement of MDA-MB-231 cells

\begin{tabular}{|c|c|c|c|}
\hline Cell Type & Plug Model & Dispersed Model & Blebbistatin Treated \\
\hline Parentals & $55.76 \pm 4.96$ & $91.45 \pm 6.68$ & $54.71 \pm 4.50$ \\
\hline IIA KD & $32.28 \pm 2.38$ & $53.39 \pm 2.93$ & $37.18 \pm 2.78$ \\
\hline IIB KD & $40.14 \pm 3.20$ & $81.89 \pm 8.03$ & $65.62 \pm 5.53$ \\
\hline
\end{tabular}

The track displacement, distance between a cell's beginning and end points, was calculated using Imaris software for three separate experiments. Data presented as average $\mu \mathrm{m} \pm \mathrm{SEM}$. 
Table 6. Migration track length of MDA-MB-231 cells

\begin{tabular}{|c|c|c|c|}
\hline Cell Type & Plug Model & Dispersed Model & Blebbistatin Treated \\
\hline Parentals & $346.27 \pm 36.14$ & $610.69 \pm 44.38$ & $205.37 \pm 20.87$ \\
\hline IIA KD & $462.16 \pm 51.94$ & $365.44 \pm 41.23$ & $117.98 \pm 14.66$ \\
\hline IIB KD & $274.04 \pm 37.39$ & $518.94 \pm 63.13$ & $223.18 \pm 18.96$ \\
\hline
\end{tabular}

The track length, total distance a cell traveled, was calculated using Imaris software for three separate experiments. Data presented as average $\mu \mathrm{m} \pm \mathrm{SEM}$.

The differences between the two models of migration were interesting. However, the comparisons between cell types in a single model, the plug model, provide valuable insight into the importance of myosin II isoforms in cell migration. In the plug model, the parental cells migrated at a faster rate than the IIA KD cells, though this difference did not reach statistical significance. The IIB KD cells migrated at the slowest rate of any of the cell types, and significantly more slowly than the parental cells. The IIA KD cells had a significantly smaller displacement than the parental cells, and a slightly smaller displacement than the IIB KD cells. However, the IIA KD cells migrated a further total distance than either the parental cells or the IIB KD cells. This effect can be seen in the tracks of the cells' migration patterns generated using Imaris software (Fig. 10). Parental cells moved in a consistent direction, resulting in a large displacement. IIA KD cells, however, frequently changed direction, especially in the z-direction. This led to a smaller displacement, yet larger total track length. Finally, the IIB KD cells tended to move back and forth within a single focal plane, along a single track, going in one direction until they met an obstacle (usually another cell) and then moving back along the original track 
instead of turning to maneuver around the obstacle (Fig. 10). General migration track patterns were consistent between cells of the same type across repeated experiments, indicating that the loss of myosin II isoforms confers a unique and specific migration potential and pattern. The altered migration potential of the knockdown cell lines is in accordance with previous data showing that actomyosin contractility is necessary for efficient cell migration $[46,62,70,71]$. These data show that loss of the myosin IIA and IIB isoforms have a distinct effect on the migration of the cell, indicating that the two isoforms play non-redundant roles in cellular migration.

\section{Treatment of Cells with the Myosin II Inhibitor Blebbistatin Blocks Their Migration}

Blebbistatin II is a non-specific myosin II inhibitor that binds to the ATP-binding pocket, preventing ADP/ATP recycling by the myosin molecule and inhibiting its enzymatic function [72]. It has previously been shown that treatment of vascular smooth muscle cells with blebbistatin inhibits the cell's ability to migrate [73]. We used blebbistatin to block the function of both myosin II isoforms and tracked their migration in the plug model. At a blebbistatin concentration of $50 \mu \mathrm{M}$, all myosin II function is inhibited. Indeed, in the parental and IIA KD MDA-MB-231 cells, treatment with blebbistatin significantly inhibited their ability to migrate. In both cases, their speed was decreased by over 60\% (Fig. 9B and Table 4). For the parental cells, average displacement was not significantly affected (Fig. 9C and Table 5), however average track length was decreased by one third (Fig. 9D and Table 6). These cells had an extremely frenetic migration track pattern, with extremely frequent direction changes and intertwined migration tracks (Fig. 10). The IIA KD cells saw no change in average displacement under blebbistatin treatment (Fig. 9C), but the average total track length was decreased by nearly 75\% (Fig. 9D). Blebbistatin 
treatment greatly inhibited the ability of these cells to migrate in 3D. Interestingly, it did not have the same effect on the IIB knockdown cells. The average speed of the IIB KDs was not changed after blebbistatin treatment (Fig. 8B), and in fact, the average displacement increased (Fig. 9C) while the total track length was not significantly altered (Fig. 9D). There may be another mechanism of cell migration that is induced when myosin II activity is completely inhibited, or the IIB KD cells may be escaping blebbistatin's effect on myosin II activity.

\section{DISCUSSION}

Matrix rigidity has been shown to stimulate tumor growth and metastasis $[2,6,7]$. It is known that actomyosin contractility is needed for tension induced cell proliferation in epithelial monolayers [74] as well as ROCK induced tissue changes and cell hyperproliferation in an induced ROCK model of murine cancer [39]. However, the importance of cell motor proteins, such as myosin II, in this process has previously not been directly investigated. Here we show that the myosin II isoforms, IIA and IIB, are involved in cell mediated matrix reorganization, cellular stiffness, cell mediated changes to matrix stiffness, and cell migration. Loss of myosin IIA especially has a drastic impact on cell mediated matrix reorganization and cell migration. This could be part of the explanation as to why myosin IIA upregulation has been shown to be correlated with poor prognosis in several types of cancer [51-53] if IIA is needed for matrix alterations that are important for tumor development and later invasion and metastasis [12, 75].

In this study, we measured the matrix remodeling ability of cells with a collagen gel compression assay using Teflon molds. This is similar, on the surface, to the gel contraction assay that has been used for a variety of cell types as a measure of cell 
mediated matrix reorganization [76]. In fact, Yu et al. [77], found that the phosphorylation state of myosin light chain did not have an effect on cancer cells' ability to alter the matrix in the gel contraction assay. However, there are several differences between the gel contraction assay as used in past studies, and the gel compression assay used here that make the two difficult to compare. In a typical gel contraction assay, cells are suspended in a 3D matrix, usually collagen, and poured into a multi-well plate. After the collagen has solidified, the gel is detached from the well and changes in the diameter of the resulting matrix disk are measured over time [76]. In such an assay, there is a strong possibility that the plastic of the multi-well plate may impact the behavior of the cells, through interaction with the collagen or the cells themselves. In the development of the assay used here, Teflon was chosen specifically because it is less likely to interfere with the cell mediated alterations to the matrix than a substrate such as plastic, which can interact with collagen. In the gel contraction assay, once the gel is detached from the bottom of the plate it may roll in on itself or undergo other physical contortions that alter the diameter measurements. Also, changes in the thickness of the gel are not measured in the gel contraction assay, generally only changes in the diameter, circumference, or area of the collagen are measured [78]. While the data presented in this paper focus on the thickness, there was a significant difference in total volume of the collagen gels, and this difference is taken into account in the cell elastic modulus calculations. While we have shown these changes, we can only speculate on how changes in myosin status of the cell are translated to the matrix without further study. A likely candidate is the $\alpha 5 \beta 1$ integrin, which has been shown to be involved in the development of traction forces and myosin II activation $[18,64,65,79]$. In our gel compression assay, we show that loss of the IIA 
isoform of nonmuscle myosin II has more significant effect on the cells' ability to modify a surrounding matrix compared to loss of the IIB isoform. This effect could be due to the differences in myosin II isoform kinetics $[80,81]$ or the differences seen in isoform response to mechanical strain [82]. In addition to the known differences in isoform enzyme activity, it has been shown that myosin IIA and IIB have different activation patterns in durotaxis, the phenomenon of cells migrating from a soft matrix to a stiffer one. Raab et al. [83] showed that the IIA isoform is diffuse in mesenchymal stem cells on soft 3D polyacrylamide matrices, but localizes to oriented stress fibers in cells in stiff matrices. This localization is followed by IIB polarization to the rear of the cell. The loss of IIA may prevent the proper localization of the IIB isoform in cells suspended in 3D matrices, blocking the cells' ability to efficiently use the remaining myosin isoform to interact with the collagen matrix.

There are several methods to measure the elasticity of cells alone or engineered cell/matrix constructs. A popular method in the literature is Atomic Force Microscopy (AFM) [84, 85]. However, AFM was designed for high-resolution imaging of the topography of specimens. For this purpose, the cantilevers used in AFM are extremely compliant and the tip size is typically in the nanometer range [86]. For many studies using AFM to measure stiffness of biological specimens, a glass bead is attached to the end of the tip to prevent the small tip from puncturing cells or slipping into the pores of a 3D matrix, which would confuse the measurements $[84,85]$. However, the weight of the glass bead alters the spring constant of the cantilever, and this change must be precisely corrected for in calculations. AFM has also been used to measure elasticity of whole tumors [85]. In the case of large specimens such as this, AFM must take many 
measurements of small sections of the sample and then the average elastic modulus is calculated. Using AFM, it is also difficult to measure changes in sample elasticity over time or in response to various treatment or condition. In developing the force conditioning model used here, we strove to design the stretching protocol in such a way that we could measure the global response of collagen constructs to stress over time. Putting the entire sample under strain allows us to calculate how the constructs, and the cells within them, dynamically respond to physical stretching. Additionally, the protocol is non-destructive, allowing for multiple stretches of the same sample under different treatment conditions. Combined with the drawbacks to AFM previously discussed, we determined that the stretching assay was the better model for what we wanted to measure. Studies of whole tumors using AFM calculated an elastic modulus in the $\mathrm{kPa}$ range [85], while we calculated an elastic modulus in the Pa range. This large difference is possibly due to the more complicated matrix composition in a whole excised tumor, as well as to differences in the method of measurement.. It is also important to note that AFM measures the stiffness of a single point of a specimen in a single point in time; these numbers are often averaged, however that still does not allow for a dynamic response from cells. The stretching assays do allow for this dynamic response on a global scale. The elastic moduli calculated using the stretching assays attach a solid number to the matrix alterations that are indirectly measured in the gel compression assay, and both assays agree that myosin IIA is necessary for efficient gel compression and development of a stiff, yet elastic, matrix. The calculated cell modulus for the IIA KD (52.89 Pa for total cell modulus, 36.78 $\mu \mathrm{Pa}$ for the single cell modulus) was also significantly lower than that for parental cells 
(286.26 $\mathrm{Pa}$ and $189.25 \mu \mathrm{Pa}$ ), indicating that IIA is necessary for cellular stiffness as well as cell generated matrix changes.

The stiffness of individual cells seeded on glass or plastic substrates, as is used in AFM measurement, would likely be significantly higher than cells seeded in collagen, due to the stiffness of the substrate. Also, due to the nature of AFM measurements, the placement of the indentation tip can have a significant impact on the ultimate stiffness measurements since different cell components have different inherent mechanical properties [87]. Additionally, the spring constant of the cantilever and the geometry of the tip are important in using AFM to calculate sample stiffness [88]. This study used a relatively low starting concentration of collagen $(1 \mathrm{mg} / \mathrm{mL})$. Adding additional matrix components, such as laminin, or starting with a higher collagen concentration, could significantly increase the stiffness of the matrix, which could ultimately affect the cellular stiffness as well, due to mechanoreciprocity. Other studies using a stretching method to measure stiffness used contractile fibroblasts, which are much stiffer than epithelial cells $[37,40,89,90]$. The assay used here relied on the mammary epithelial cells alone to generate the stiffness of their surrounding matrix. The elastic modulus of a matrix containing stromal cells such as fibroblasts, which are more contractile than epithelial cells, would likely be much stiffer than a matrix containing epithelial cells alone. This speculation is supported by the fact that fibroblasts compress the collagen to a greater degree than the breast epithelial cells (data not shown). The addition of stromal cells, particularly cancer associated fibroblasts, to this assay, while beyond the scope of this work, could provide insight into how various types of cells associated with tumors contribute to the overall tumor stiffness. 
The changes in matrix stiffness between parental and myosin II KD cells were as expected from the gel compression assays, however, the cell modulus, both total and individual, for the IIB KD cells was much lower than predicted based on the gel compression or total construct modulus. The elastic modulus of the IIB KD constructs was calculated to be $7.20 \mathrm{~Pa}$, while the parental was 9.22. Based on these numbers, it was predicted that the IIB KD total cell modulus would be much closer to the parental value of 286.262 $\mathrm{Pa}(189.25 \mu \mathrm{Pa}$ for single cell modulus) than the $107.435 \mathrm{~Pa}(79.84 \mu \mathrm{Pa}$ single cell modulus) value that was calculated. Part of this unexpected result is explained in the elastic modulus values of the two different matrices (the deoxycholate treated samples). For those stretches, the IIB KD modulus was higher than that of the parental, $4.73 \mathrm{~Pa}$ versus $4.38 \mathrm{~Pa}$, respectively. This indicates that in the IIB KD cell constructs, the matrix is responsible for a relatively large proportion of the overall elastic modulus while the cells themselves contribute little. In these cells, myosin IIA alone is sufficient to arrange a collagen matrix, but not for the cells themselves to respond to a dynamic physical strain. This could be due to the different responses of the two isoforms to mechanical loads. Myosin IIB has been shown to have different ADP release kinetics under mechanical loads, and to be more sensitive to such mechanical changes than IIA [82]. Thus, loss of IIB may prevent the cells from being able to respond to mechanical stress because the remaining IIA isoforms does not respond to mechanical loading in the same way. Here we used the rule of mixtures to calculate the contributions of the different construct components, cells and matrix, to the overall elastic modulus. This method has been used in other studies and is known to have limitations $[37,89,90]$. The calculated cell modulus using the rule of mixtures from an unidirectional strain, as used here, is somewhat cell 
distribution and orientation dependent [37]. Since the different cell types used in this study have similar, random, orientations, this effect would not have a significant bearing on the differences seen here, though it could affect the absolute calculated elastic moduli. In addition, there is a need to compensate for the voids left when the cells are removed using deoxycholate [89]. However, the effects are minimal at lower cell concentrations (below 10x106 cells $/ \mathrm{mL}$ ), where the voids do not disrupt the continuity of the matrix. The number of cells in the constructs used here is well below that threshold.

Cell viscoelastic properties are also involved in cancer metastasis, and changes in these properties could influence how cells interact with their matrices, migrate, and ultimately metastasize within the body. We tested the biophysical properties of cells lacking either the IIA or IIB myosin isoforms using cell poking. The IIA KD cells had a significantly lower mean stiffness than parental cells, indicating that the remaining isoform, IIB, is unable to generate the tension within the cell that leads to cell stiffness. IIB KD cells, on the other hand, had a higher mean stiffness than parental cells, though this difference is not significant. The differences in the physical properties of these cell lines could in part be explained by the different enzyme kinetics of the isoforms. Myosin IIB has a slower ADP release rate than IIA, and therefore spends more time bound to actin than IIA [81, 91]. Myosin IIB may be unable to quickly relocate within the cell to respond to physical strain at a defined location, as during cell poking. Based on the cell poking data and previous studies showing that metastatic cells are softer than cancer cells in the primary tumor $[55,84]$, it could be predicted that the IIA KD cells, which are significantly softer than the parental or IIB KD cells, may have a higher metastatic potential. However, when all of the data presented here is taken into account, we 
speculate that the opposite is true. IIA KD cells do not interact with the surrounding collagen matrix, as measured by gel compression and elastic modulus studies. In addition, they are unable to efficiently migrate in 3D migration models. Both of these functions are necessary for metastasis [75, 92-94].

After establishing that both myosin II isoforms are necessary for efficient cellmediated matrix reorganization, we used 3D migration assays to test the ability of these cells to migrate. We compared the migration patterns of the cells in our plug model and the widely used dispersed model of 3D migration. We determined that cells migrate differently in our plug model than they do in the dispersed model of cellular migration. This is possibly due to the lack of extensive cell-cell contacts seen in the dispersed model of migration compared to the plug model, where cells are densely packed in the collagen plugs. For the parental and IIB KD cells, track length and displacement were significantly increased in the dispersed model. This could be due to the lack of obstacles, in the form of other cells, present in the dispersed model. The different track patterns seen in the IIA and IIB KD patterns indicate that the two isoforms play non-redundant roles in MDA-MB231 cell migration.

It has previously been shown that nonmuscle myosin II isoforms are both needed for proper spreading of MDA-MB-231 cells in 2D [61]. Here we show that cells missing either the myosin IIA or IIB isoform have cytoskeletal disruptions in 2D, in agreement with previous studies [61]. We also see a difference in cell morphology in 3D after loss of either myosin II isoform. This is consistent with a previous study showing that force generation by cells is needed for cell spreading in 3D $[71,95]$. These changes in 3D morphology are related to the altered ability of the cells to interact with the collagen matrix, as discussed 
above. IIA KD cells are unable to compress a collagen matrix; their morphology in 3D is a rounded cell body with long, thin protrusions in multiple directions. Without myosin IIA, these cells are unable to spread properly in the 3D matrix, and are also unable to generate the force needed to alter the surrounding ECM and compress the gel. These two observations go hand in hand. Not only does the loss of force generation prevent the cells from compressing the collagen, it also prevents them from pushing outwards in order to spread, leading to the rounded cell body with thin protrusions. While the IIB KD cells also had altered morphology compared to the parental MDA-MB-231 cells, they were able to generate the force needed to compress the collagen gel.

Here, we showed that MDA-MB-231 cells migrate differently in our plug model of 3D migration as compared to the widely used dispersed model. There are many models of cell migration and invasion used throughout the literature, such as the dispersed model, transwell assays, and asymmetric assays in which cells are seeded between two different ECMs. Each model has its advantages and disadvantages, however we excluded transwell and asymmetric assays for our purposes and decided to focus on comparing our plug model to the dispersed model because both of these models measure the migration of cells completely suspended in collagen and allow for direct tracking of individual cell movements. The transwell assay is not compatible with such cell tracking, and the sandwich model allows the cells to from a monolayer before the top layer of matrix is added, meaning the cells will have already spread and formed matrix adhesions before they are completely surrounded by the matrix. While we showed differences in the migration of cells in the plug and dispersed models of migration, our results in the dispersed model are radically different than the average speed of $3 \mu \mathrm{m} / \mathrm{hr}$ obtained in a 
previous study of MDA-MB-231 cell invasion into Matrigel [46], though these results are consistent with previous studies of MDA-MB-231 cell migration in collagen [96]. This is most likely due to the differences in the ECM used. Different ECMs, as well as differing ECM stiffness, has been shown to alter not only the speed of cell migration, but also the mode of migration the cells use as they move through the matrix $[14,16,31,66,69,97$, 98]. Matrigel is a cell derived basement membrane composed of multiple matrix proteins, which affects cell-matrix adhesions. It is also not cross-linked. Matrix cross-linking increases cell invasion and migration [8, 99]. Finally, in the study measuring MDA-MB231 cell migration in Matrigel, the cells were only allowed to incubate in the Matrigel for 30 minutes prior to imaging, to allow the Matrigel to polymerize. After such a short time frame, the cells are not fully spread and are unlikely to be migrating efficiently [46].

We also observed differences in the migration potential of myosin IIA and IIB KD cell lines in our plug model of migration. IIA KD cells were unable to move in a sustained direction, and instead migrated in a disorganized track in a small area. Previous studies have shown that myosin IIA accumulates at the rear of migrating cells and its function is required for efficient migration [46]. IIA is also required for adhesion maturation and migration of cells on 1D fibrillar structures, micropatterned fribril-like matrix that confines the cells to moving in a single axis [71], which is consistent with our results. IIA KD cells are unable to form mature adhesions to the matrix $[71,100]$, and therefore unable to exert the force necessary to migrate. IIB KD cells also had a change in migration patterns, which is consistent with previous studies showing that loss of IIB function lowers the migration potential of melanoma cells [70] and stabilizes adhesions beneath the cell body of cells in 1D [71]. While myosin contractility in general is required to propel the cell 
forward during cell migration [46], we show here that the two main isoforms present in MDA-MB-231 cells play distinct roles in migration in a 3D collagen matrix.

In general, the results shown here indicate that myosin IIA is critical for matrix rearrangement and cell migration while loss of IIB had a less intense effect on the ability of cells to organize a matrix, though the cell elasticity is greatly affected. These differences in isoform behavior could be due to differences in their kinetics. Myosin IIB has a much higher affinity for ADP, and a slower release rate, which means it spends more of its time bound to actin than does IIA $[80,81,91]$. The two isoforms also have different means of regulation and interactions with other cytosolic proteins that alter myosin actin binding and ATPase activity that could explain the differences seen here [101-103]. Additionally, the two isoforms respond differently under mechanical loads, with myosin IIB showing enhanced mechanosensitivity [82]. Finally, it has been shown in mesenchymal stem cells that myosin IIA localizes to stress fibers of cells in stiff 3D matrices prior to IIB polarization to the rear of the cell, both of which precede migration [83]. If these observations hold true in MDA-MB-231 cells, it could provide a partial explanation for the results seen here. Cells lacking myosin IIA are unable to significantly impact their surrounding matrix or efficiently migrate in 3D collagen. If IIA localization to stress fibers is needed for proper IIB polarization, then IIB alone is unable to generate the force needed on the actin cytoskeleton to arrange the collagen. Additionally, without the IIA isoform, the cells are unable to polarize, an important step in migration. On the other hand, cells lacking the IIB isoform are somewhat able to organize the collagen matrix and migrate in 3D collagen. In these cells, the IIA isoform localizing to the stress fibers may be enough for the cells to interact with and rearrange the collagen matrix, but not for the cells themselves to 
generate tension in response to strain. This would indicate that the two main myosin II isoforms, IIA and IIB play separate roles in the generation of cellular tension and cellmatrix interactions, with IIA perhaps playing a primary role in IIB localization/activation. There are many possibilities as to why the A and B isoforms of myosin II play different roles in cell rigidity and matrix interactions, however, a more in depth study into the regulation and activity of the isoforms during matrix rearrangement is needed to fully explain the mechanisms behind these actions.

These results indicate that myosin II isoforms are significantly involved in cell processes closely involved with cancer progression and metastasis, namely, cell mediated matrix rearrangement and migration. In addition, we have developed a new method of measuring ECM stiffness and elasticity that allows for a global and dynamic response from cells and matrices, as well as precise control over matrix components. These characteristics are known to have an effect on tumor development, therefore having a better understanding of how cancer cells rearrange and interact with the matrix and affect its rigidity in vitro may lead to innovations in diagnosis and treatment that could benefit public health. While we have described the differences in matrix interaction, further research into the mechanics of how myosin II isoforms are differentially involved in this interaction is needed. 


\section{References}

1. Society AC. Breast Cancer Facts \& Figures 2013-2014. Atlanta: American Cancer Society, 2013.

2. Butcher DT, Alliston T, Weaver VM. A tense situation: forcing tumour progression. Nat Rev Cancer. 2009;9(2):108-22. PubMed PMID: 19165226.

3. Cox TR, Erler JT. Remodeling and homeostasis of the extracellular matrix: implications for fibrotic diseases and cancer. Dis Model Mech. 2011;4(2):165-78. PubMed PMID: 21324931.

4. Talmadge JE, Fidler IJ. AACR centennial series: the biology of cancer metastasis: historical perspective. Cancer Res. 2010;70(14):5649-69. PubMed PMID: 20610625.

5. Sahai E. Illuminating the metastatic process. Nat Rev Cancer. 2007;7(10):737-49. PubMed PMID: 17891189.

6. Yu H, Mouw JK, Weaver VM. Forcing form and function: biomechanical regulation of tumor evolution. Trends Cell Biol. 2010;21(1):47-56. PubMed PMID: 20870407.

7. Lopez JI, Mouw JK, Weaver VM. Biomechanical regulation of cell orientation and fate. Oncogene. 2008;27(55):6981-93. PubMed PMID: 19029939.

8. Levental KR, Yu H, Kass L, Lakins JN, Egeblad M, Erler JT, et al. Matrix crosslinking forces tumor progression by enhancing integrin signaling. Cell. 2009;139(5):891-906. PubMed PMID: 19931152.

9. DuFort CC, Paszek MJ, Weaver VM. Balancing forces: architectural control of mechanotransduction. Nat Rev Mol Cell Biol. 2013;12(5):308-19. PubMed PMID: 21508987.

10. Baker EL, Bonnecaze RT, Zaman MH. Extracellular matrix stiffness and architecture govern intracellular rheology in cancer. Biophys J. 97. United States2009. p. 1013-21.

11. Kumar S, Weaver VM. Mechanics, malignancy, and metastasis: the force journey of a tumor cell. Cancer Metastasis Rev. 2009;28(1-2):113-27. PubMed PMID: 19153673. 
12. Provenzano PP, Eliceiri KW, Campbell JM, Inman DR, White JG, Keely PJ. Collagen reorganization at the tumor-stromal interface facilitates local invasion. BMC Med. 2006;4(1):38. PubMed PMID: 17190588.

13. Kass L, Erler JT, Dembo M, Weaver VM. Mammary epithelial cell: influence of extracellular matrix composition and organization during development and tumorigenesis. Int $\mathrm{J}$ Biochem Cell Biol. 2007;39(11):1987-94. PubMed PMID: 17719831.

14. Baker EL, Srivastava J, Yu D, Bonnecaze RT, Zaman MH. Cancer cell migration: integrated roles of matrix mechanics and transforming potential. PLoS One. 2011;6(5):e20355. PubMed PMID: 21647371.

15. Irimia $\mathrm{D}$, Toner M. Spontaneous migration of cancer cells under conditions of mechanical confinement. Integr Biol (Camb). 2009;1(8-9):506-12. PubMed PMID: 20023765.

16. Parekh A, Weaver AM. Regulation of cancer invasiveness by the physical extracellular matrix environment. Cell Adh Migr. 2009;3(3):288-92. PubMed PMID: 19458499.

17. Millerot-Serrurot E, Guilbert M, Fourre N, Witkowski W, Said G, Van Gulick L, et al. 3D collagen type I matrix inhibits the antimigratory effect of doxorubicin. Cancer Cell Int. 2010;10:26. PubMed PMID: 20707917.

18. Aguilar-Cuenca R, Juanes-Garcia A, Vicente-Manzanares M. Myosin II in mechanotransduction: master and commander of cell migration, morphogenesis, and cancer. Cell Mol Life Sci. 2014;71(3):479-92. PubMed PMID: 23934154.

19. Wang N, Tytell JD, Ingber DE. Mechanotransduction at a distance: mechanically coupling the extracellular matrix with the nucleus. Nat Rev Mol Cell Biol. 10. England2009. p. 7582.

20. Wozniak MA, Chen CS. Mechanotransduction in development: a growing role for contractility. Nat Rev Mol Cell Biol. 10. England2009. p. 34-43.

21. Discher DE, Janmey P, Wang YL. Tissue cells feel and respond to the stiffness of their substrate. Science. 310. United States2005. p. 1139-43.

22. Rubashkin MG, Cassereau L, Bainer R, DuFort CC, Yui Y, Ou G, et al. Force engages vinculin and promotes tumor progression by enhancing PI3K activation of phosphatidylinositol $(3,4,5)$-triphosphate. Cancer Res. 74. United States: 2014 American Association for Cancer Research.; 2014. p. 4597-611. 
23. Geraldo S, Gordon-Weeks PR. Cytoskeletal dynamics in growth-cone steering. J Cell Sci. 2009;122(Pt 20):3595-604. PubMed PMID: 19812305.

24. Brown JA, Wysolmerski RB, Bridgman PC. Dorsal root ganglion neurons react to semaphorin $3 \mathrm{~A}$ application through a biphasic response that requires multiple myosin II isoforms. Mol Biol Cell. 2009;20(4):1167-79. PubMed PMID: 19109430.

25. Rex CS, Gavin CF, Rubio MD, Kramar EA, Chen LY, Jia Y, et al. Myosin IIb regulates actin dynamics during synaptic plasticity and memory formation. Neuron. 2010;67(4):60317. PubMed PMID: 20797537.

26. Wylie SR, Wu PJ, Patel H, Chantler PD. A conventional myosin motor drives neurite outgrowth. Proc Natl Acad Sci U S A. 1998;95(22):12967-72. PubMed PMID: 9789024.

27. Betapudi V. Life without double-headed non-muscle myosin II motor proteins. Front Chem. 2014;2:45. Epub 2014/07/30. doi: 10.3389/fchem.2014.00045. PubMed PMID: 25072053; PubMed Central PMCID: PMCPMC4083560.

28. Conti MA, Adelstein RS. Nonmuscle myosin II moves in new directions. J Cell Sci. 121. England2008. p. 11-8.

29. Elliott H, Fischer RS, Myers KA, Desai RA, Gao L, Chen CS, et al. Myosin II controls cellular branching morphogenesis and migration in three dimensions by minimizing cellsurface curvature. Nat Cell Biol. 17. England2015. p. 137-47.

30. Friedl $P$, Weigelin B. Interstitial leukocyte migration and immune function. Nat Immunol. 2008;9(9):960-9. PubMed PMID: 18711433.

31. Friedl $\mathrm{P}$, Wolf $\mathrm{K}$. Plasticity of cell migration: a multiscale tuning model. J Cell Biol. 2009;188(1):11-9. PubMed PMID: 19951899.

32. Wolf $\mathrm{K}$, Friedl $\mathrm{P}$. Extracellular matrix determinants of proteolytic and non-proteolytic cell migration. Trends Cell Biol. 21. England: 2011 Elsevier Ltd; 2011. p. 736-44.

33. Fidler IJ. The pathogenesis of cancer metastasis: the 'seed and soil' hypothesis revisited. Nat Rev Cancer. 3. England2003. p. 453-8.

34. Puig-de-Morales-Marinkovic M, Turner KT, Butler JP, Fredberg JJ, Suresh S. Viscoelasticity of the human red blood cell. Am J Physiol Cell Physiol. 2007;293(2):C597605. Epub 2007/04/13. doi: 10.1152/ajpcell.00562.2006. PubMed PMID: 17428838. 
35. Reymond N, d'Agua BB, Ridley AJ. Crossing the endothelial barrier during metastasis. Nat Rev Cancer. 13. England2013. p. 858-70.

36. Cross SE, Jin YS, Rao J, Gimzewski JK. Nanomechanical analysis of cells from cancer patients. Nat Nanotechnol. 2007;2(12):780-3. PubMed PMID: 18654431.

37. Marquez JP, Genin GM, Zahalak GI, Elson EL. The relationship between cell and tissue strain in three-dimensional bio-artificial tissues. Biophys J. 88. United States2005. p. 77889.

38. Provenzano PP, Keely PJ. Mechanical signaling through the cytoskeleton regulates cell proliferation by coordinated focal adhesion and Rho GTPase signaling. J Cell Sci. 124. England2011. p. 1195-205.

39. Samuel MS, Lopez JI, McGhee EJ, Croft DR, Strachan D, Timpson P, et al. ActomyosinMediated Cellular Tension Drives Increased Tissue Stiffness and b-Catenin Activation to Induce Epidermal Hyperplasia and Tumor Growth. Cancer Cell. 2011;19:776-91. Epub June 14, 2011. doi: 10.1016/j.ccr.2011.05.008.

40. Wakatsuki T, Kolodney MS, Zahalak GI, Elson EL. Cell mechanics studied by a reconstituted model tissue. Biophys J. 79. United States2000. p. 2353-68.

41. Clark K, Langeslag M, Figdor CG, van Leeuwen FN. Myosin II and mechanotransduction: a balancing act. Trends Cell Biol. 2007;17(4):178-86. PubMed PMID: 17320396.

42. Korn ED, Hammer JA, 3rd. Myosins of nonmuscle cells. Annu Rev Biophys Biophys Chem. 1988;17:23-45. PubMed PMID: 3293586.

43. Sellers JR. Myosins: a diverse superfamily. Biochim Biophys Acta. 2000;1496(1):3-22. PubMed PMID: 10722873.

44. Maciver SK. Myosin II function in non-muscle cells. Bioessays. 1996;18(3):179-82. PubMed PMID: 8867731.

45. Brabek J, Mierke CT, Rosel D, Vesely P, Fabry B. The role of the tissue microenvironment in the regulation of cancer cell motility and invasion. Cell Commun Signal. 8. England2010. p. 22. 
46. Poincloux R, Collin O, Lizarraga F, Romao M, Debray M, Piel M, et al. Contractility of the cell rear drives invasion of breast tumor cells in 3D Matrigel. Proc Natl Acad Sci U S A. 2011;108(5):1943-8. PubMed PMID: 21245302.

47. Provenzano PP, Eliceiri KW, Keely PJ. Shining new light on 3D cell motility and the metastatic process. Trends Cell Biol. 2009;19(11):638-48. PubMed PMID: 19819146.

48. Taddei ML, Giannoni E, Comito G, Chiarugi P. Microenvironment and tumor cell plasticity: an easy way out. Cancer Lett. 2013;341(1):80-96. Epub 2013/02/05. doi: 10.1016/j.canlet.2013.01.042. PubMed PMID: 23376253.

49. Wilson AK, Pollenz RS, Chisholm RL, de Lanerolle P. The role of myosin I and II in cell motility. Cancer Metastasis Rev. 1992;11(1):79-91. PubMed PMID: 1511499.

50. Zaman MH, Trapani LM, Sieminski AL, Mackellar D, Gong H, Kamm RD, et al. Migration of tumor cells in 3D matrices is governed by matrix stiffness along with cell-matrix adhesion and proteolysis. Proc Natl Acad Sci U S A. 103. United States2006. p. 1088994.

51. Xia ZK, Yuan YC, Yin N, Yin BL, Tan ZP, Hu YR. Nonmuscle myosin IIA is associated with poor prognosis of esophageal squamous cancer. Dis Esophagus. 2011;25(5):42736. PubMed PMID: 21951916.

52. Maeda J, Hirano T, Ogiwara A, Akimoto S, Kawakami T, Fukui Y, et al. Proteomic analysis of stage I primary lung adenocarcinoma aimed at individualisation of postoperative therapy. Br J Cancer. 2008;98(3):596-603. PubMed PMID: 18212748.

53. Liang S, He L, Zhao X, Miao Y, Gu Y, Guo C, et al. MicroRNA let-7f inhibits tumor invasion and metastasis by targeting MYH9 in human gastric cancer. PLoS One. 2011;6(4):e18409. PubMed PMID: 21533124.

54. Saha S, Dey SK, Das P, Jana SS. Increased expression of nonmuscle myosin IIs is associated with 3MC-induced mouse tumor. Febs J. 2011;278(21):4025-34. PubMed PMID: 21848673.

55. Swaminathan V, Mythreye K, O'Brien ET, Berchuck A, Blobe GC, Superfine R. Mechanical stiffness grades metastatic potential in patient tumor cells and in cancer cell lines. Cancer Res. 2010;71(15):5075-80. PubMed PMID: 21642375. 
56. Zahalak GI, McConnaughey WB, Elson EL. Determination of cellular mechanical properties by cell poking, with an application to leukocytes. J Biomech Eng. 1990;112(3):283-94. PubMed PMID: 2214710.

57. Tiscornia G, Singer O, Verma IM. Production and purification of lentiviral vectors. Nat Protoc. 2006;1(1):241-5. Epub 2007/04/05. doi: 10.1038/nprot.2006.37. PubMed PMID: 17406239.

58. Goeckeler ZM, Wysolmerski RB. Myosin light chain kinase-regulated endothelial cell contraction: the relationship between isometric tension, actin polymerization, and myosin phosphorylation. J Cell Biol. 1995;130(3):613-27. PubMed PMID: 7622562.

59. Goeckeler ZM, Bridgman PC, Wysolmerski RB. Nonmuscle myosin II is responsible for maintaining endothelial cell basal tone and stress fiber integrity. Am J Physiol Cell Physiol. 2008;295(4):C994-1006. PubMed PMID: 18701651.

60. Kolodney MS, Wysolmerski RB. Isometric contraction by fibroblasts and endothelial cells in tissue culture: a quantitative study. J Cell Biol. 1992;117(1):73-82. Epub 1992/04/01. PubMed PMID: 1556157; PubMed Central PMCID: PMCPmc2289400.

61. Betapudi V, Licate LS, Egelhoff TT. Distinct roles of nonmuscle myosin II isoforms in the regulation of MDA-MB-231 breast cancer cell spreading and migration. Cancer Res. 2006;66(9):4725-33. PubMed PMID: 16651425.

62. Beach JR, Hussey GS, Miller TE, Chaudhury A, Patel P, Monslow J, et al. Myosin II isoform switching mediates invasiveness after TGF-beta-induced epithelial-mesenchymal transition. Proc Natl Acad Sci U S A. 2011;108(44):17991-6. PubMed PMID: 22025714.

63. Betapudi V, Gokulrangan G, Chance MR, Egelhoff TT. A proteomic study of myosin II motor proteins during tumor cell migration. J Mol Biol. 407. England: 2011 Elsevier Ltd; 2011. p. 673-86.

64. Schiller HB, Hermann MR, Polleux J, Vignaud T, Zanivan S, Friedel CC, et al. beta1- and alphav-class integrins cooperate to regulate myosin II during rigidity sensing of fibronectinbased microenvironments. Nat Cell Biol. 2013;15(6):625-36. PubMed PMID: 23708002.

65. Mierke CT, Frey B, Fellner M, Herrmann M, Fabry B. Integrin alpha5beta1 facilitates cancer cell invasion through enhanced contractile forces. J Cell Sci. 2011;124(Pt 3):36983. PubMed PMID: 21224397. 
66. Brekhman V, Neufeld G. A novel asymmetric 3D in-vitro assay for the study of tumor cell invasion. BMC Cancer. 2009;9:415. PubMed PMID: 19948022.

67. Ishihara S, Haga H, Yasuda M, Mizutani T, Kawabata K, Shirato H, et al. Integrin beta1dependent invasive migration of irradiation-tolerant human lung adenocarcinoma cells in 3D collagen matrix. Biochem Biophys Res Commun. 2010;396(3):651-5. PubMed PMID: 20438698.

68. Mierke CT, Kollmannsberger P, Zitterbart DP, Diez G, Koch TM, Marg S, et al. Vinculin facilitates cell invasion into three-dimensional collagen matrices. J Biol Chem. 2010;285(17):13121-30. PubMed PMID: 20181946.

69. Wolf K, Alexander S, Schacht V, Coussens LM, von Andrian UH, van Rheenen J, et al. Collagen-based cell migration models in vitro and in vivo. Semin Cell Dev Biol. 2009;20(8):931-41. PubMed PMID: 19682592.

70. Jacobs K, Van Gele M, Forsyth R, Brochez L, Vanhoecke B, De Wever O, et al. P-cadherin counteracts myosin II-B function: implications in melanoma progression. Mol Cancer. 2010;9:255. PubMed PMID: 20860798.

71. Doyle AD, Kutys ML, Conti MA, Matsumoto K, Adelstein RS, Yamada KM. Microenvironmental control of cell migration--myosin IIA is required for efficient migration in fibrillar environments through control of cell adhesion dynamics. J Cell Sci. 2011;125(Pt 9):2244-56. PubMed PMID: 22328520.

72. Kovacs M, Toth J, Hetenyi C, Malnasi-Csizmadia A, Sellers JR. Mechanism of blebbistatin inhibition of myosin II. J Biol Chem. 2004;279(34):35557-63. PubMed PMID: 15205456.

73. Wang HH, Tanaka H, Qin X, Zhao T, Ye LH, Okagaki T, et al. Blebbistatin inhibits the chemotaxis of vascular smooth muscle cells by disrupting the myosin II-actin interaction. Am J Physiol Heart Circ Physiol. 2008;294(5):H2060-8. PubMed PMID: 18296570.

74. Nelson CM, Jean RP, Tan JL, Liu WF, Sniadecki NJ, Spector AA, et al. Emergent patterns of growth controlled by multicellular form and mechanics. PNAS. 2005;102(33):11594-9. doi: 10.1073/pnas.0502575102.

75. Provenzano PP, Inman DR, Eliceiri KW, Trier SM, Keely PJ. Contact guidance mediated three-dimensional cell migration is regulated by Rho/ROCK-dependent matrix reorganization. Biophys J. 2008;95(11):5374-84. PubMed PMID: 18775961. 
76. Vernon RB, Gooden MD. An improved method for the collagen gel contraction assay. In Vitro Cell Dev Biol Anim. 2002;38(2):97-101. PubMed PMID: 11929002.

77. Yu HJ, Serebryannyy LA, Fry M, Greene M, Chernaya O, Hu WY, et al. Tumor stiffness is unrelated to myosin light chain phosphorylation in cancer cells. PLoS One. 2013;8(11):e79776. PubMed PMID: 24224004.

78. .

79. Balcioglu HE, van Hoorn H, Donato DM, Schmidt T, Danen EH. Integrin expression profile modulates orientation and dynamics of force transmission at cell matrix adhesions. J Cell Sci. 2015. Epub 2015/02/11. doi: 10.1242/jcs.156950. PubMed PMID: 25663698.

80. Billington N, Wang A, Mao J, Adelstein RS, Sellers JR. Characterization of three full-length human nonmuscle myosin II paralogs. J Biol Chem. 2013;288(46):33398-410. PubMed PMID: 24072716.

81. Kovacs M, Wang F, Hu A, Zhang Y, Sellers JR. Functional divergence of human cytoplasmic myosin II: kinetic characterization of the non-muscle IIA isoform. J Biol Chem. 2003;278(40):38132-40. PubMed PMID: 12847096.

82. Kovacs $M$, Thirumurugan $K$, Knight PJ, Sellers JR. Load-dependent mechanism of nonmuscle myosin 2. Proc Natl Acad Sci U S A. 2007;104(24):9994-9. PubMed PMID: 17548820.

83. Raab M, Swift J, Dingal PC, Shah P, Shin JW, Discher DE. Crawling from soft to stiff matrix polarizes the cytoskeleton and phosphoregulates myosin-II heavy chain. J Cell Biol. 2012;199(4):669-83. Epub 2012/11/07. doi: 10.1083/jcb.201205056. PubMed PMID: 23128239; PubMed Central PMCID: PMCPmc3494847.

84. Li QS, Lee GY, Ong CN, Lim CT. AFM indentation study of breast cancer cells. Biochem Biophys Res Commun. 2008;374(4):609-13. PubMed PMID: 18656442.

85. Lopez JI, Kang I, You WK, McDonald DM, Weaver VM. In situ force mapping of mammary gland transformation. Integr Biol (Camb). 2011;3(9):910-21. PubMed PMID: 21842067.

86. Fischer-Cripps AC. Nanoindentation. 3 ed. Ling FF, editor. New York: Springer; 2011. 
87. Yamane $\mathrm{Y}$, Shiga H, Haga H, Kawabata K, Abe K, Ito E. Quantitative analyses of topography and elasticity of living and fixed astrocytes. J Electron Microsc (Tokyo). 2000;49(3):463-71. Epub 2000/12/07. PubMed PMID: 11108036.

88. Kirmizis D, Logothetidis S. Atomic force microscopy probing in the measurement of cell mechanics. Int J Nanomedicine. 2010;5:137-45. Epub 2010/05/14. PubMed PMID: 20463929; PubMed Central PMCID: PMCPMC2865008.

89. Marquez JP, Elson EL, Genin GM. Whole cell mechanics of contractile fibroblasts: relations between effective cellular and extracellular matrix moduli. Philos Trans A Math Phys Eng Sci. 368. England2010. p. 635-54.

90. Zahalak GI, Wagenseil JE, Wakatsuki T, Elson EL. A cell-based constitutive relation for bio-artificial tissues. Biophys J. 79. United States2000. p. 2369-81.

91. Wang F, Kovacs M, Hu A, Limouze J, Harvey EV, Sellers JR. Kinetic mechanism of nonmuscle myosin IIB: functional adaptations for tension generation and maintenance. J Biol Chem. 2003;278(30):27439-48. PubMed PMID: 12704189.

92. Conklin MW, Eickhoff JC, Riching KM, Pehlke CA, Eliceiri KW, Provenzano PP, et al. Aligned collagen is a prognostic signature for survival in human breast carcinoma. Am J Pathol. 178. United States: 2011 American Society for Investigative Pathology. Published by Elsevier Inc; 2011. p. 1221-32.

93. Pathak A, Kumar S. Biophysical regulation of tumor cell invasion: moving beyond matrix stiffness. Integr Biol (Camb). 2011;3(4):267-78. Epub 2011/01/07. doi: 10.1039/c0ib00095g. PubMed PMID: 21210057.

94. Mierke CT. Cancer cells regulate biomechanical properties of human microvascular endothelial cells. J Biol Chem. 2011;286(46):40025-37. PubMed PMID: 21940631.

95. Delorme-Walker VD, Peterson JR, Chernoff J, Waterman CM, Danuser G, DerMardirossian C, et al. Pak1 regulates focal adhesion strength, myosin IIA distribution, and actin dynamics to optimize cell migration. J Cell Biol. 2011;193(7):1289-303. PubMed PMID: 21708980.

96. Kraning-Rush CM, Carey SP, Lampi MC, Reinhart-King CA. Microfabricated collagen tracks facilitate single cell metastatic invasion in 3D. Integr Biol (Camb). 2013;5(3):606- 
16. Epub 2013/02/08. doi: 10.1039/c3ib20196a. PubMed PMID: 23388698; PubMed Central PMCID: PMCPmc3601578.

97. Shin Y, Han S, Kim H, Kim J-H, Kamm RD, Chung S. Microfluidic Study on ECMDependent Three Dimensional Morphogenesis of Breast Adenocarcinoma Cells. 15th International Conference on Miniaturized Systems for CHemistry and Life Sciences. 2011.

98. Sabeh F, Shimizu-Hirota R, Weiss SJ. Protease-dependent versus -independent cancer cell invasion programs: three-dimensional amoeboid movement revisited. J Cell Biol. 2009;185(1):11-9. PubMed PMID: 19332889.

99. Berrier AL, Yamada KM. Cell-matrix adhesion. J Cell Physiol. 2007;213(3):565-73. Epub 2007/08/08. doi: 10.1002/jcp.21237. PubMed PMID: 17680633.

100. Huang Y, Arora P, McCulloch CA, Vogel WF. The collagen receptor DDR1 regulates cell spreading and motility by associating with myosin IIA. J Cell Sci. 122. England2009. p. 1637-46.

101. Dulyaninova NG, Malashkevich VN, Almo SC, Bresnick AR. Regulation of myosin-IIA assembly and Mts1 binding by heavy chain phosphorylation. Biochemistry. 2005;44(18):6867-76. PubMed PMID: 15865432.

102. Elliott PR, Irvine AF, Jung HS, Tozawa K, Pastok MW, Picone R, et al. Asymmetric mode of $\mathrm{Ca}(2)(+)-S 100 A 4$ interaction with nonmuscle myosin IIA generates nanomolar affinity required for filament remodeling. Structure. 2012;20(4):654-66. PubMed PMID: 22483112.

103. Ford HL, Silver DL, Kachar B, Sellers JR, Zain SB. Effect of Mts1 on the structure and activity of nonmuscle myosin II. Biochemistry. 1997;36(51):16321-7. PubMed PMID: 9405067. 


\section{Figure Legends}

Figure 1. Knockdown of myosin II isoforms Greater than $85 \%$ knockdown of myosin protein content was achieved in stable cell lines expressing shRNA to myosin IIA or IIB. Myosin isoform levels were assessed for every experiment to verify the level of myosin IIA and IIB knockdown.

Figure 2. Knockdown of myosin II isoforms induces cytoskeletal changes in MDAMB-231 cells in 2D Parental (A-D), IIA KD (E-H) and IIB KD (I-L) cells were fixed, permeabilized, and immunostained with affinity purified polyclonal myosin IIA and IIB primary antibodies and Phalloidin-TRITC to visualize actin filaments and myosin localization. In parental MDA-MB-231 cells, myosin IIA (B) localizes to stress fibers and the leading edge of cells, while myosin IIB (D) had cytosolic, stress fiber, and perinuclear localization. Myosin IIA KD cells had altered actin cytoskeletal structure and were slightly larger than parental controls, while the residual IIA (E) in these cells localized to stress fibers and myosin IIB (H) localization was largely unaffected, remaining largely diffuse throughout the cytosol with some stress fiber and perinuclear localization. Myosin IIB KD cells exhibited a more irregular shape with short, prominent stress fibers, and the residual IIB in these cells exhibited a perinuclear localization (L) IIA localization was primarily to stress fibers (J), as in the parental cells.

Figure 3. Loss of myosin II isoforms induces morphological changes in 3D Cells were added to a collagen solution, poured into Teflon molds and allowed to incubate for 1 day. Constructs were washed, fixed, permeabilized, and stained with Phalloidin-TRITC and affinity purified myosin II antibodies. Cells were examined using Two Photon Microscopy. (A-F) Parental MDA-MB-231 cells in three dimensions had pyramidal cell 
bodies with multiple projections and significant staining of both IIA (B) and IIB (E) myosin isoforms, mainly diffuse throughout the cytosol. (G-L) IIA KD cells had rounded cell bodies with highly branched and elongated projections in all directions and very little residual myosin IIA (H) staining, mostly localized to the cell bodies. The IIB (K) in these cells remained diffuse throughout the cytosol. (M-R) IIB KD cells were elongated with fewer projections and tended to be localized to a single focal plan, with residual IIB (0) localized at cell edges and near the nucleus. For all cell types, myosin isoform localization in 3D was mainly cytosolic.

Figure 4. Morphological characteristics of cells lacking myosin II isoforms Collagen constructs containing cells were prepared and imaged as outlined. IMARIS image analysis software was used to quantify the observations made on cell morphology in 3D collagen gels across three separate experiments. (A) The average number of protrusions per cell were measured using the Filaments function in IMARIS. Statistical significance was calculated using one-way ANOVA with a Tukey post-test. The difference between parental and IIA KD cell types was significant $(p<0.01)$, as was the difference between IIA and IIB KD cells $(p<0.001)$. (B) The sphericity of the cell bodies was calculated using the Surfaces function in IMARIS. IIA KD cells were slightly more spherical than parental or IIB KD cells, though the difference was not statistically significant. (C) The elongation factor of the cell bodies was calculated using the measurements function in IMARIS. We defined the elongation factor as the measurement of the longest dimension of the cell body, divided by the measurement of the shortest dimension. IIB KD cells had a slightly higher elongation factor than the parental or IIA KD cells. 
Figure 5. Loss of myosin II isoforms inhibits the ability of MDA-MB-231 cells to compress a collagen gel MDA-MB-231 cells or $1 \mu \mathrm{m}$ fluorescent beads were mixed with a collagen solution and poured into a Teflon mold with a central mandrel. Constructs were incubated for 1 to 4 days to allow the cells to compress the collagen gel. MDA-MB-231 constructs were washed, fixed, permeabilized, and stained with TRITC-Phalloidin and Hoescht 33258 dye. Cells were examined using Two Photon Microscopy. (A) Z-stacks were taken from the top to the bottom of the constructs and the thickness recorded. Representative z-stacks of each cell type, stained with Hoescht 33258 dye to ensure even distribution of the cells through the depth of the collagen gel, are shown. Images were examined using IMARIS software and maximum intensity projections were generated using the Volume function. (B) Data shown are average collagen gel depth measurements (error bars are SD) from three separate experiments. Parental MDA-MB231 cells were able to constrict the collagen gel by over 40\%, as were IIB KD cells, while IIA KD cells were only able to constrict the gel by $15-20 \%$. The statistical significance was calculated using a one-way analysis of variance with a Tukey post-test on the 1 day measurements. The difference between collagen with fluorescent beads alone and parental cell and IIB KD cell constructs $(p<0.0001)$ was significant, as was the difference between the beads alone and IIA KD constructs $(p<0.01)$. These were not indicated on the bar graph for clarity. In addition, the difference between parental and IIA KD constructs was significant $(p<0.0001)$.

Figure 6. Isometric tension development of MDA-MB-231 cells Representative isometric tension tracings from a single experiment, plotted as $\mathrm{mN}$ stress versus strain, are shown for each of the following: $(A)$ readings generated by parental cells (black), IIA 
KD cells (red), IIB KD cells(green), and collagen alone during an initial $10 \%$ stretch of untreated constructs. Myosin KD cells exhibited a lower response to strain compared to parental constructs, especially IIA KD cells, while collagen alone constructs had a negligible response to the strain. (B) Parental cell constructs with no treatment (black), treated with cytochalasin D to disrupt the active actin component (red), or treated with deoxycholate to wipe out the cell completely (green). These readings are compared against collagen alone (blue). (C) IIA KD cell constructs with no treatment (black), treated with cytochalasin $\mathrm{D}(\mathrm{red})$, or treated with deoxycholate (green) are compared to collagen alone (blue). A similar pattern in treatment responses was seen to that of the parentals. Inset: The same readings set to a smaller $\mathrm{mN}$ scale to highlight the differences between the different treatments. Inset IIA KD cell construct force measurements are shown with a reduced $y$-axis scale to highlight the differences between treatment conditions. (D) IIB KD cell constructs with no treatment (black), treated with cytochalasin D (red) or treated with deoxycholate (green) are compared to collagen alone (blue) For all cell types (B-D) treatment with either cytochalasin D or deoxycholate greatly disrupted the response of the collagen constructs to stretching, with deoxycholate having a greater effect, indicating that cell components other than the actin contractile component contribute to the overall construct response to mechanical strain.

Figure 7. Matrix rigidity of MDA-MB-231 cells Representative collagen construct stress calculations from a single experiment for the initial, untreated stretch (A) and the deoxycholate treated stretch (B) plotted as Pa versus strain. For both, myosin II KD cell constructs had a decreased stiffness in response to strain. Because the stiffness calculation takes the cross section area of the constructs into account, and the IIA 
constructs are much larger, the difference between the parental and IIA KD constructs is enhanced when compared to the differences seen when the strain response is plotted as $\mathrm{mN}$ versus Strain (Fig. 6). Loss of myosin IIA had a more significant effect on force in response to strain than did loss of myosin IIB.

Figure 8. Loss of myosin II isoforms affect cell viscoelasticity as measured by cell poking. Cells were seeded on glass coverslips and their viscoelasticity measured by cell poking. Parental MDA-MB-231 cells had a mean stiffness of 5.39 dynes/cm, IIA KD a mean stiffness of 4.26 dynes/cm, IIB KD 5.81 dynes/cm, and blebbistatin treated cells a mean stiffness of 3.1 dynes $/ \mathrm{cm}$. The difference between the parental and IIA KD cell lines was significant, with a p-value of 0.003 . Cells treated with the myosin II inhibitor blebbistatin had a lower stiffness than either of the KD lines, and was significantly lower than any of the other cell types.

Figure 9. Loss of a myosin II isoform has a distinct effect on the ability of the cell to migrate in 3D (A) MDA-MB-231 cells are mixed with $1 \mathrm{mg} / \mathrm{mL}$ Type I rat tail collagen solution at a concentration of $2 \times 10^{6}$ cells $/ \mathrm{mL}$ (1), and poured into silicon templates (2-3). The collagen/cell mix is allowed to incubate for 24 hours at $37^{\circ} \mathrm{C} 5 \% \mathrm{CO}_{2}(4)$, by which time the cells have organized and constricted the collagen matrix to form a mini-tumor (5). Mini-tumors are removed from the template and re-embedded into a 3D collagen matrix (6). Cultures are placed in a tissue culture incubator for 12 hours at $37^{\circ} \mathrm{C}, 5 \% \mathrm{CO}_{2}$ (7) before beginning motility measurements performed on a Zeiss 510 Meta equipped with a temperature and $\mathrm{CO}_{2}$ controlled environmental chamber (8) . (B-D) Mini-tumors were imaged in a $37^{\circ} \mathrm{C}, 5 \% \mathrm{CO}_{2}$ humidified chamber using live cell confocal microscopy. Z-stacks were taken at $2 \mu \mathrm{m}$ steps for a total depth of $50 \mu \mathrm{m}$. Images were captured every 
15 min over a 24 hour period. Cells were tracked and speed, track displacement (the distance from a cell's starting point to end point), and track length (the total distance the cell moved) were calculated using Imaris Spots function. Migration in the mini-tumor approach was contrasted with cells treated with 50uM blebbistatin as well as cells dispersed in a collagen matrix. Cells seeded in the mini-tumor model migrated much slower than cells dispersed in a collagen matrix. Within the mini-tumor model, parental MDA-MB-231 cells migrated $30 \%$ faster than IIA KD cells and $50 \%$ faster than IIB KD cells. Blebbistatin treatment also affected the migration patterns of cells in the mini-tumor model.

Figure 10. Migration track patterns of cells migrating in the plug model. Mini-tumors were imaged in a $37^{\circ} \mathrm{C}, 5 \% \mathrm{CO}_{2}$ humidified chamber using live cell confocal microscopy. Z-stacks were taken at $2 \mu \mathrm{m}$ steps for a total depth of $50 \mu \mathrm{m}$. Images were captured every 15 min over a 24 hour period. Reconstructions were generated using Imaris Spots tracker (Bitplane) software package. Scale bars are 50um. 
Figure 1
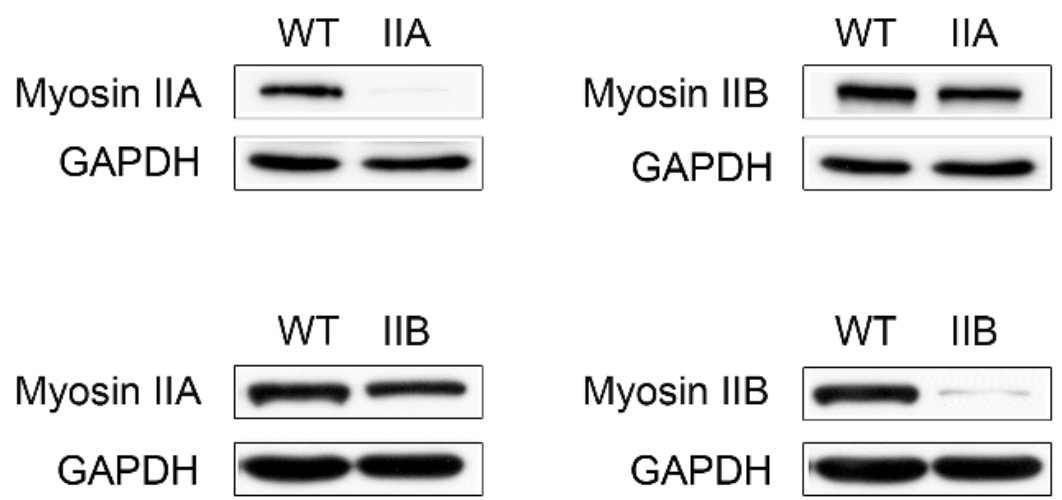
Figure 2
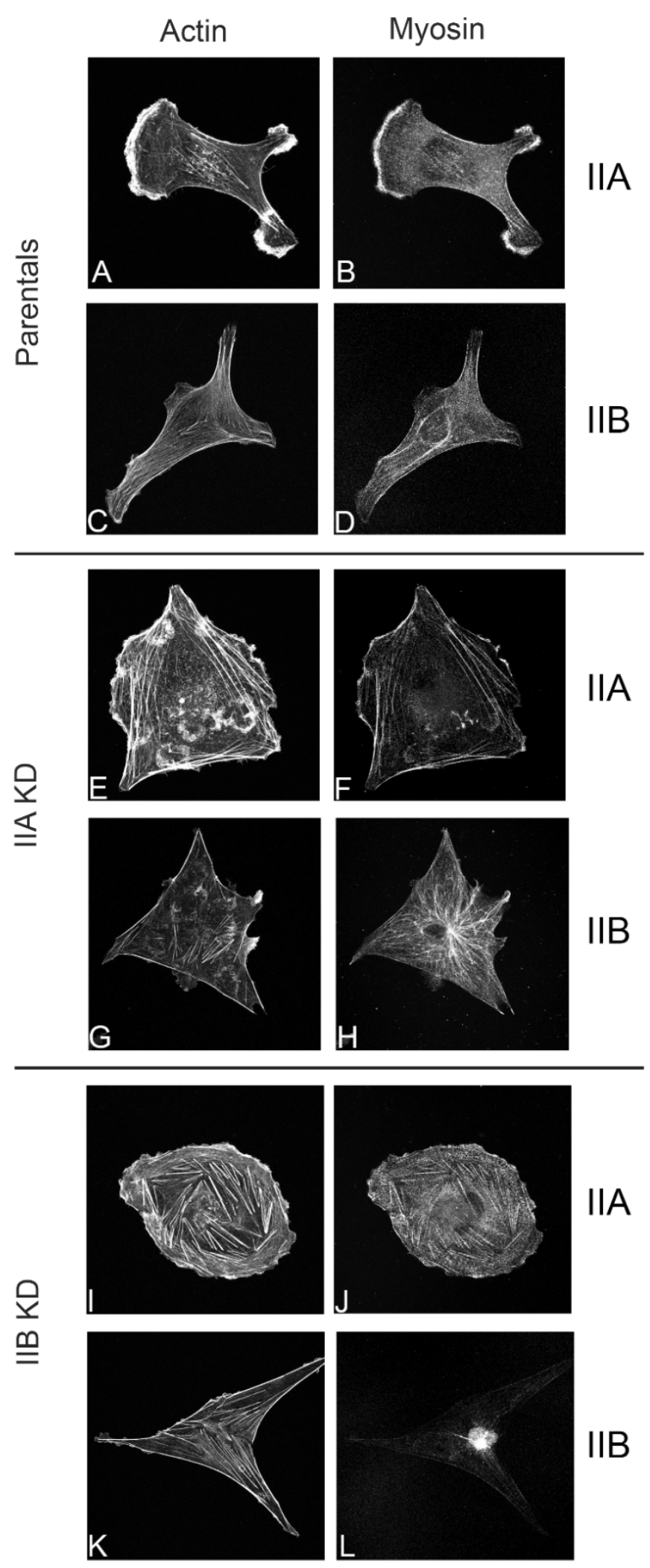
Figure 3
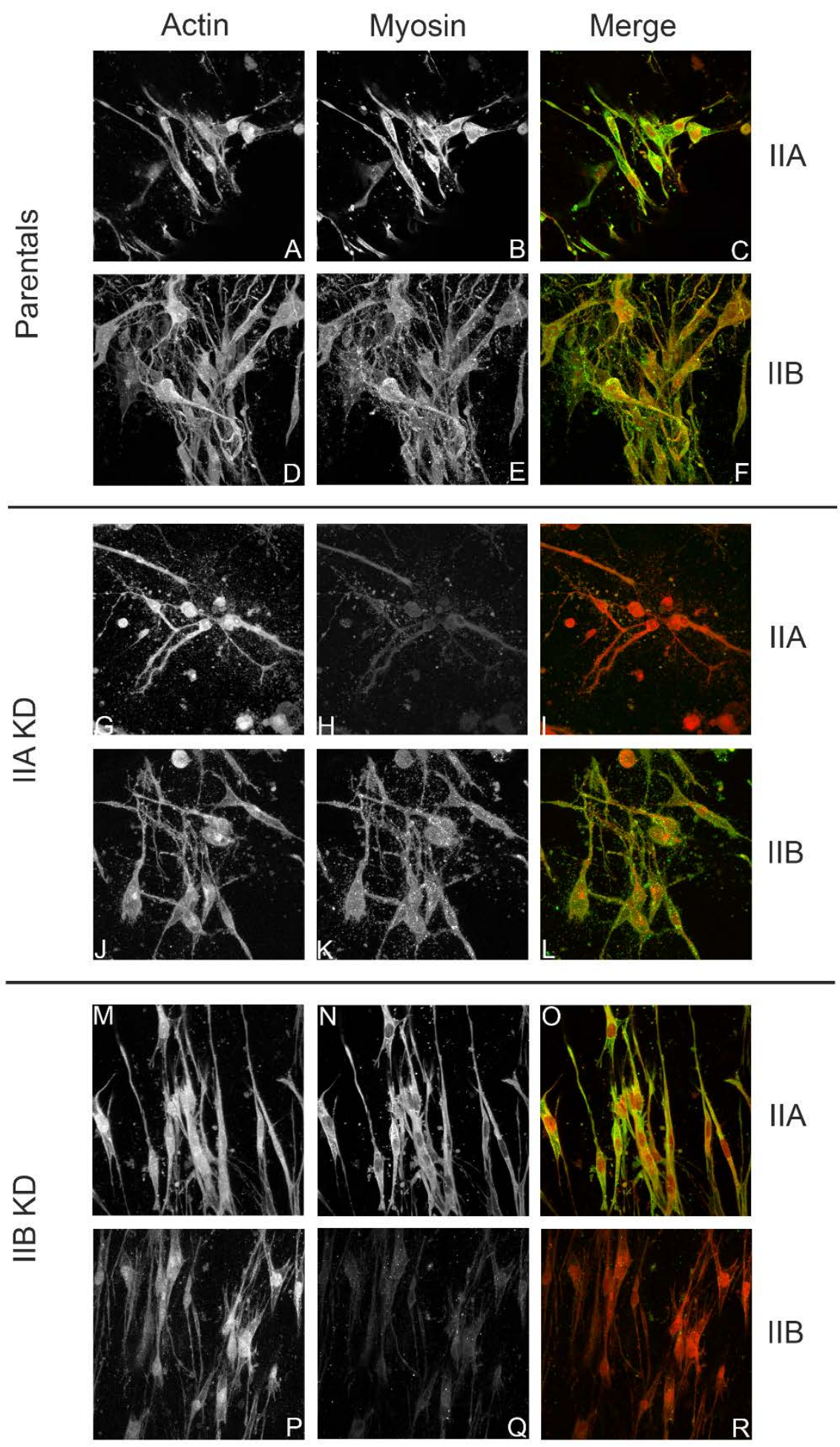
Figure 4
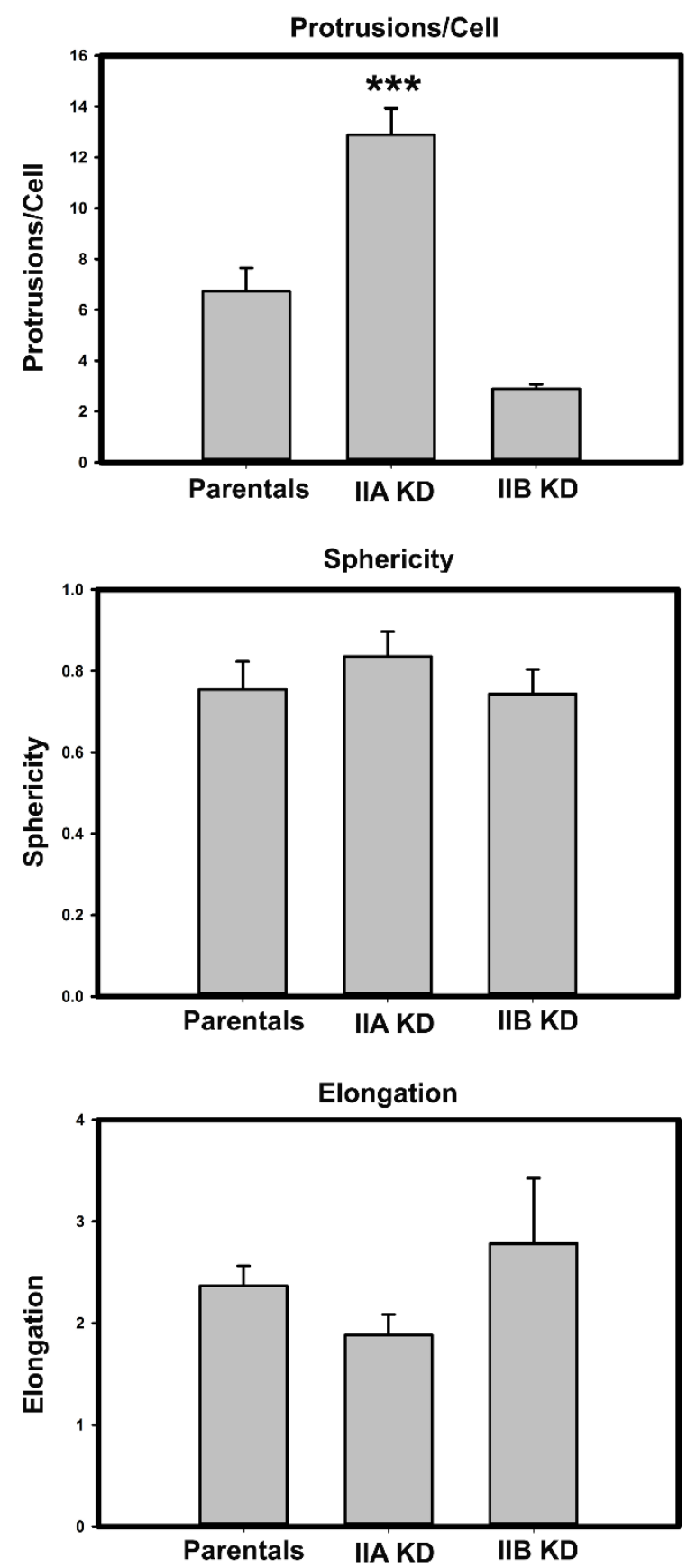
Figure 5

A

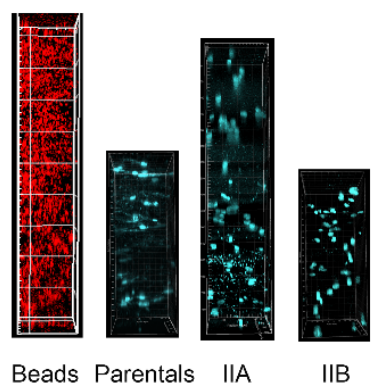

B

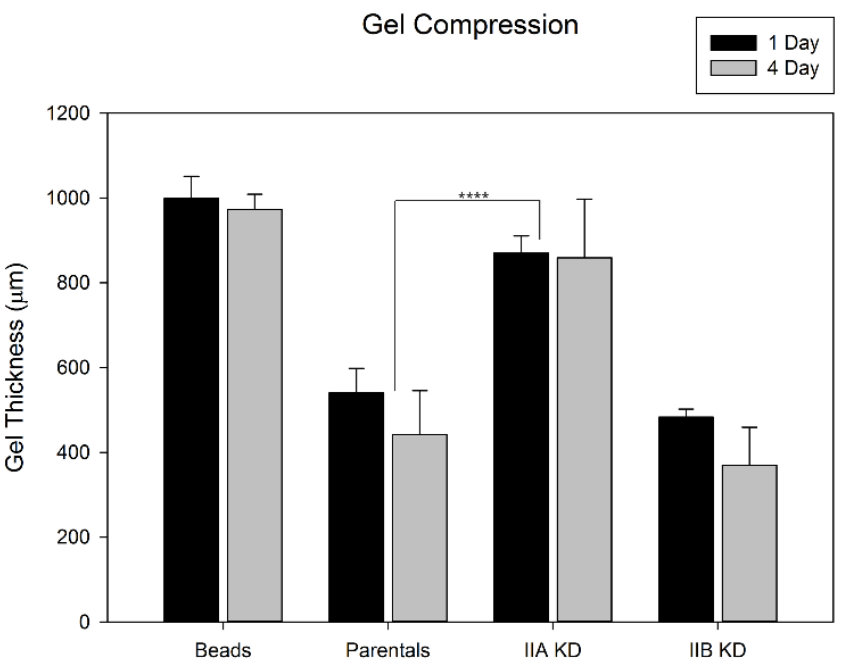


Figure 6

A

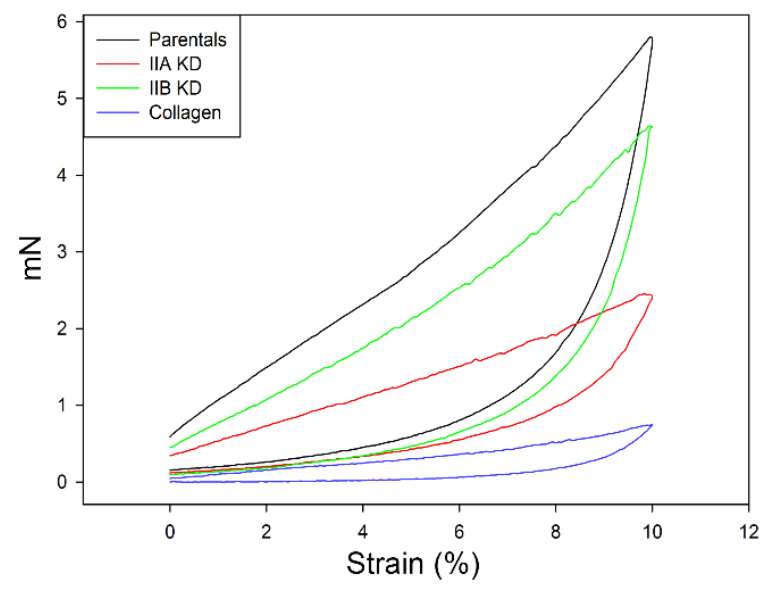

C

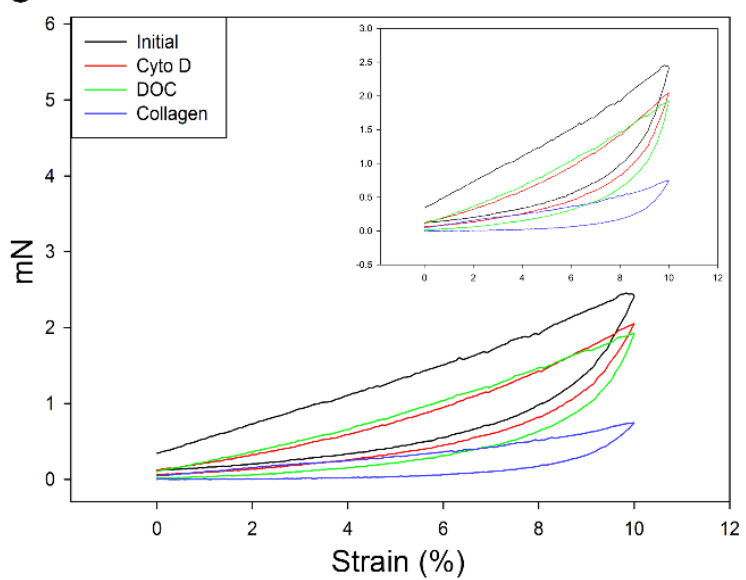

B MDA-MB-231 - Parentals

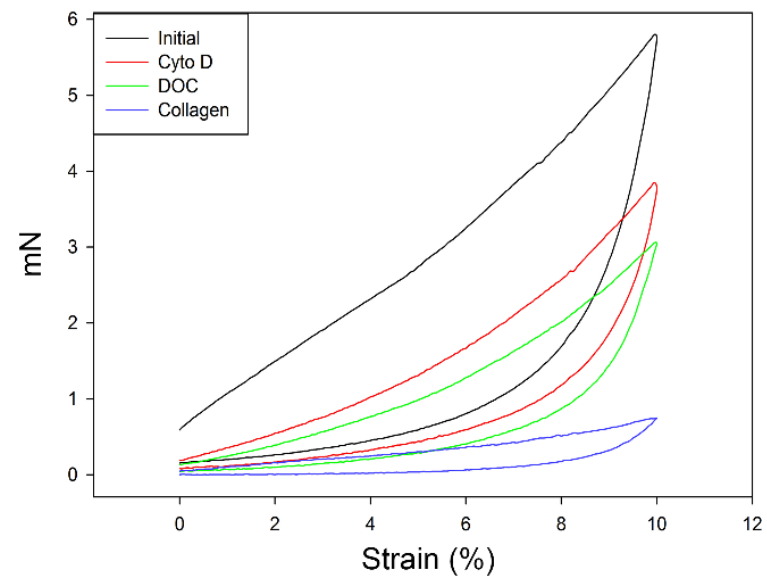

MDA-MB-23.1 -. HB.KD

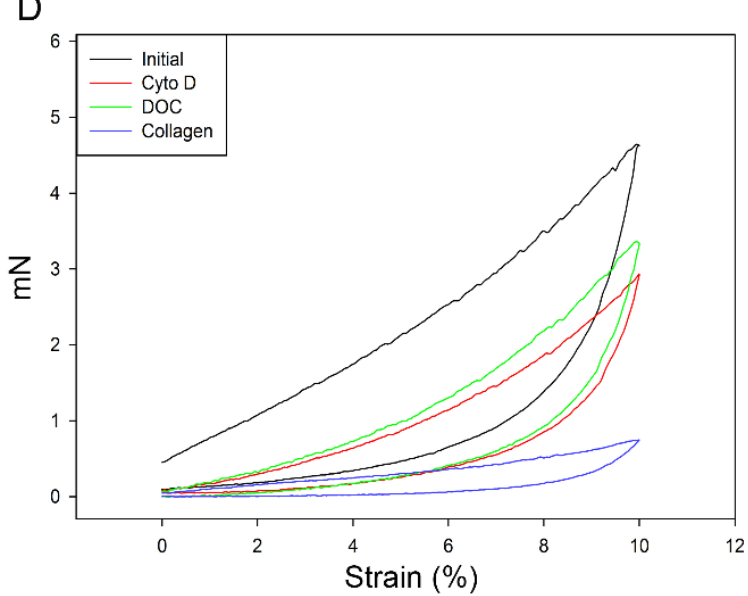


Figure 7

A

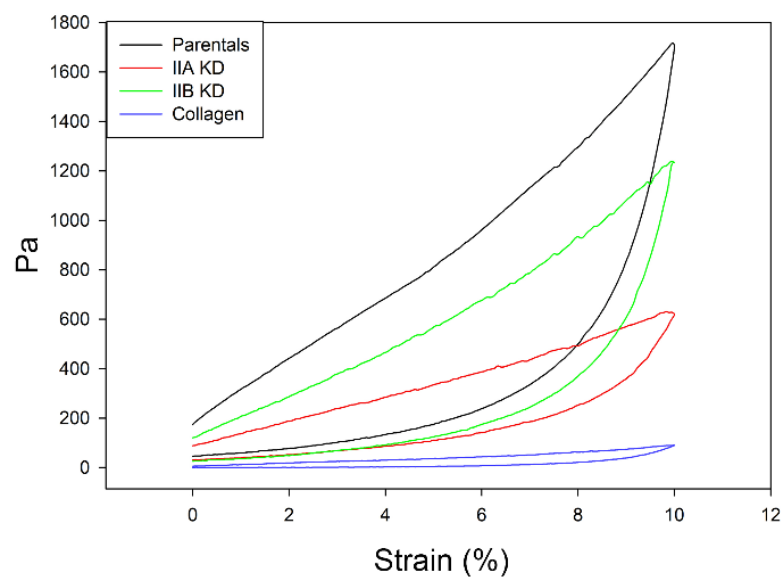

B DOC Treated Stretch

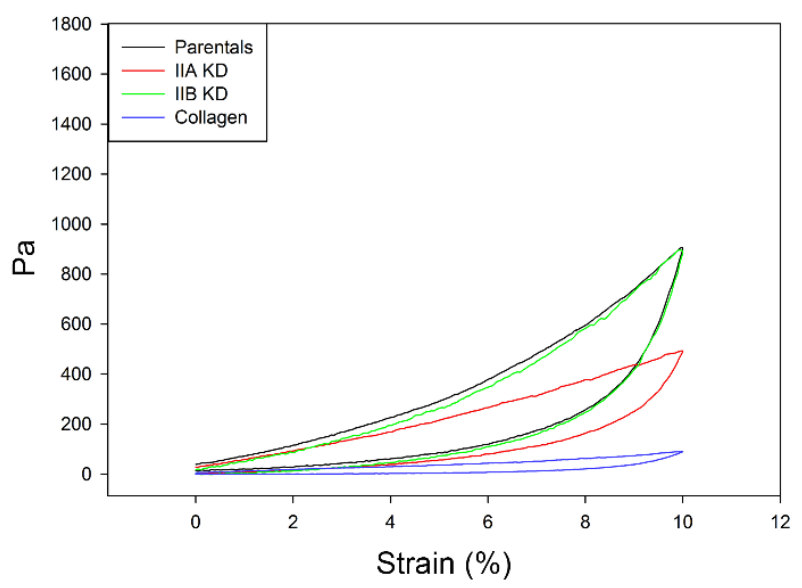


Figure 8

Cell Poking

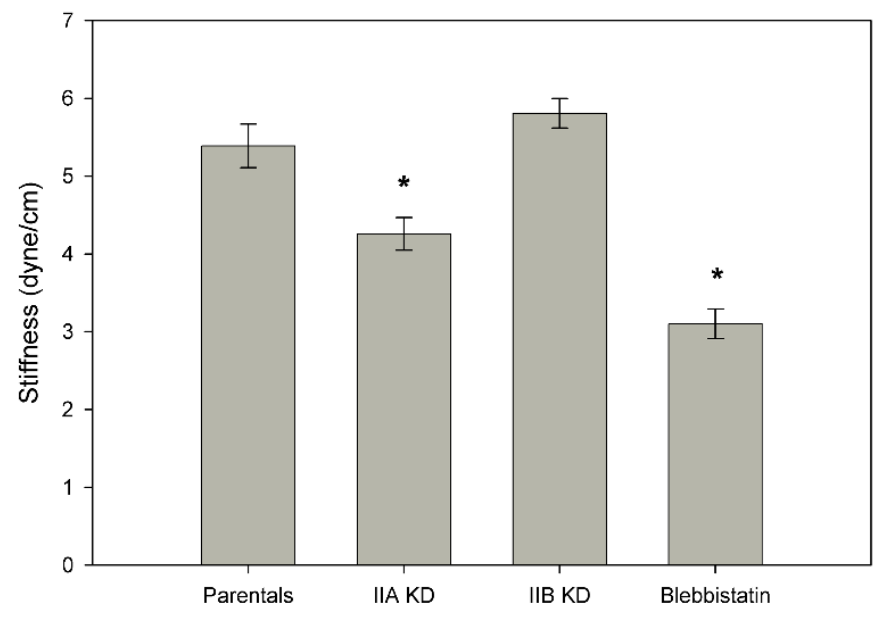


Figure 9

A

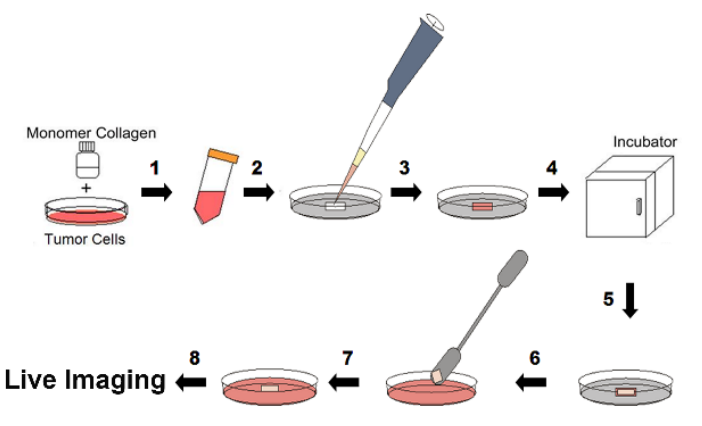

C

Track Displacement

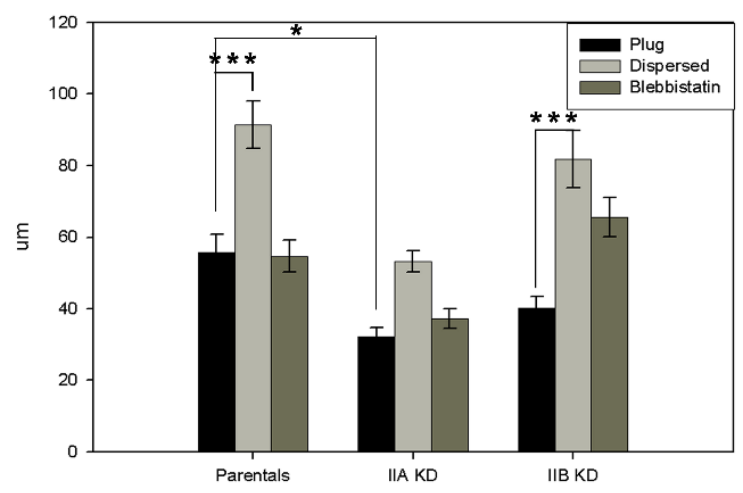

B

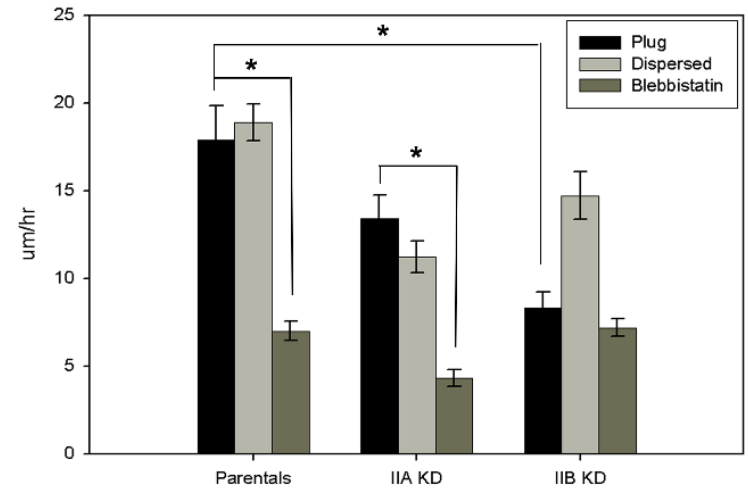

D

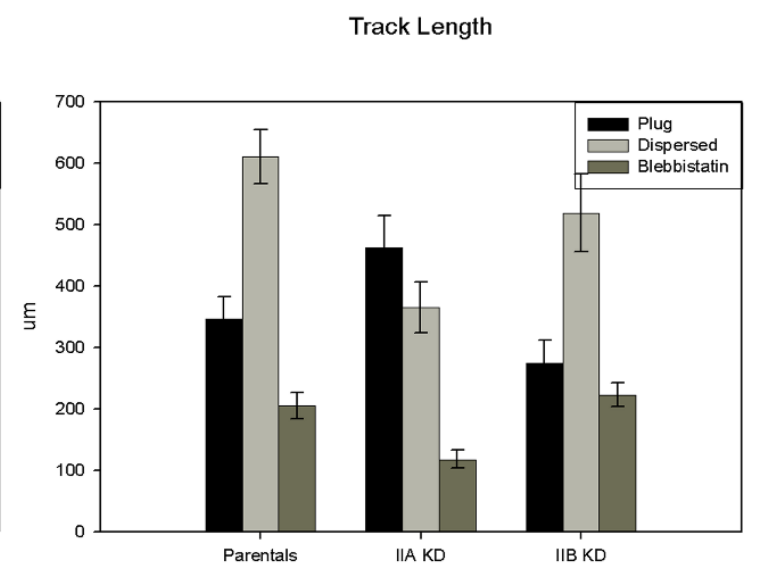


Figure 10

Parentals

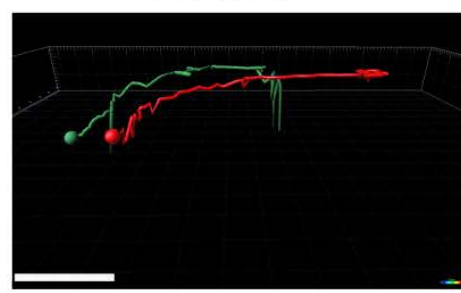

IIB KD

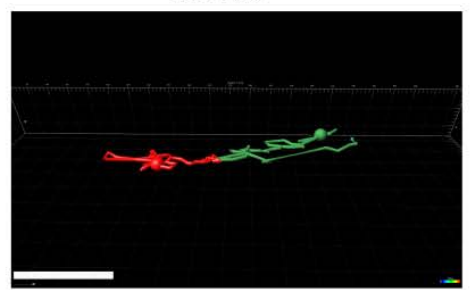

IIA KD

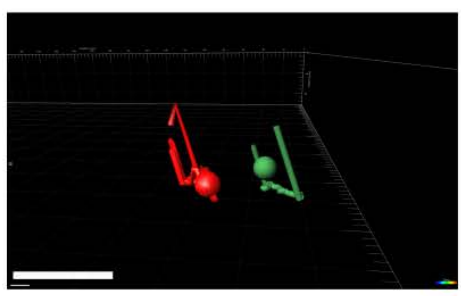

Blebbistatin

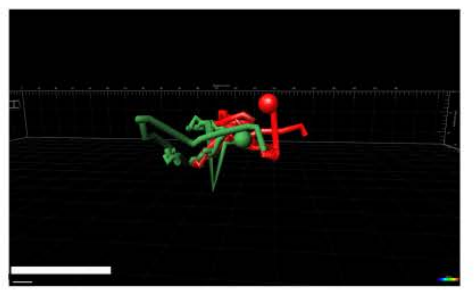


Supplementary Figure 1

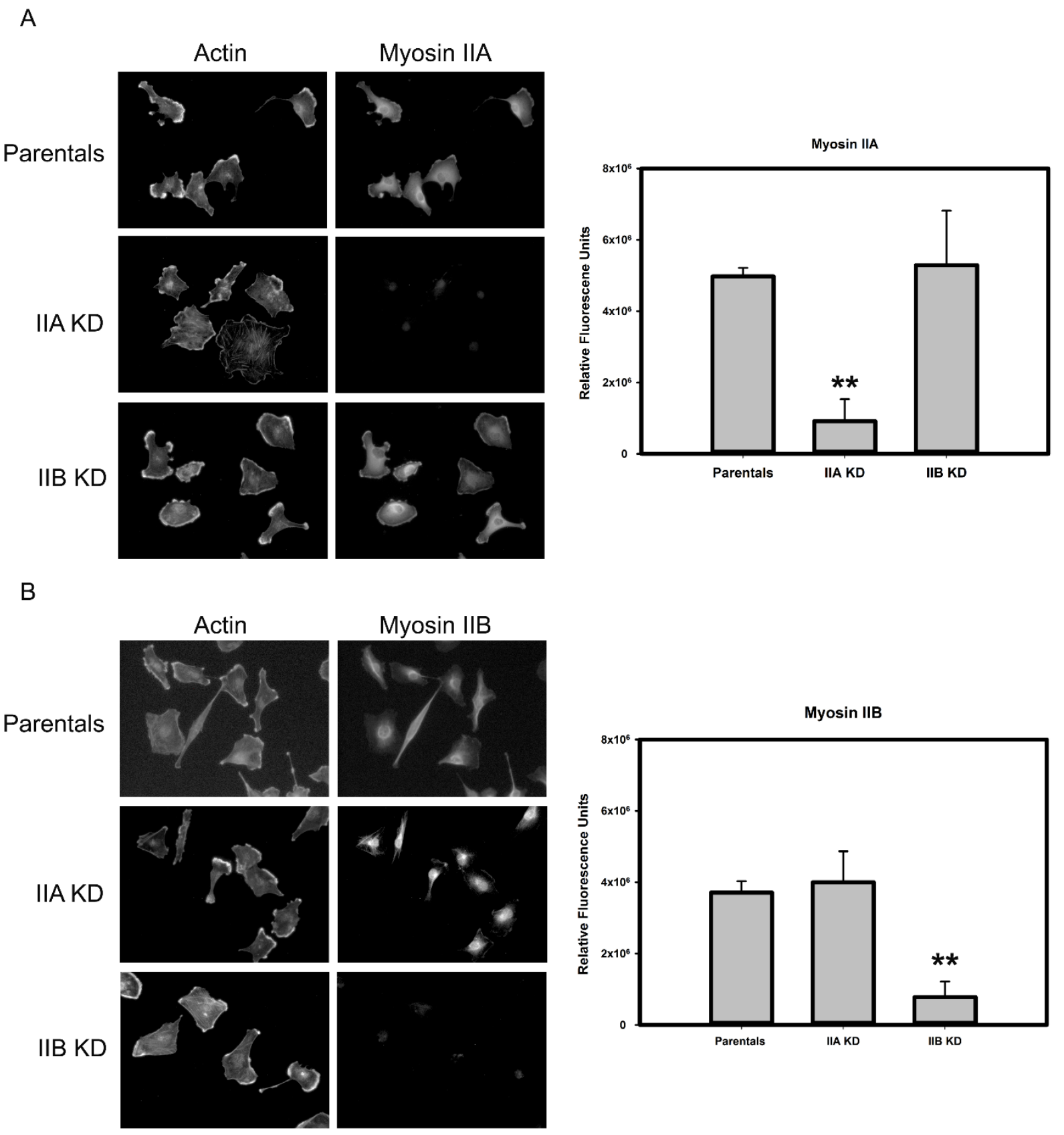


Myosin II Isoforms are Necessary for Endothelial Cell Permeability Function and Isometric Tension Generation

Bridget Hindman ${ }^{1}$, Zoe Goeckeler ${ }^{2}$, and Robert Wysolmerski ${ }^{1,2}$

${ }^{1}$ Mary Babb Randolph Cancer Center, ${ }^{2}$ Center for Cardiovascular and Respiratory Sciences

West Virginia University, Robert C. Byrd Health Sciences Center, Morgantown, WV 26506 


\section{Abstract}

Endothelial cells are a major component of blood vessels, and as such, they are involved in physiological functions related to the circulatory system. A number of these functions are dependent on the contractility of the endothelial cells, including the barrier function, an important function in maintaining the integrity of blood vessels. The main regulator of actin based contractility in nonmuscle cells is nonmuscle myosin II, which has three isoforms, $A, B$, and $C$. We therefore sought to determine if the different isoforms of nonmuscle myosin II are differentially involved in endothelial cell properties that contribute to blood vessel integrity. Using shRNA constructs, we generated myosin IIA and IIB knockdown SVEC cell populations. Cells lacking either isoform had a disrupted actin cytoskeleton and altered morphology. We tested the barrier function of SVEC monolayers using Electric Cell-substrate Impedance Sensing (ECIS). Cells lacking myosin IIA had a lower barrier function compared to parental or IIB KD cells. The ability of the cells to generate a basal isometric tension and respond to thrombin treatment, which stimulates endothelial cell contraction, was also tested. Parental cells had a high basal tension and robust response to thrombin treatment. IIB KD cells had a lower basal tension, but retained the ability to respond to thrombin. IIA KD cells, on the other hand, not only had a reduced basal tension, but also did not respond to thrombin treatment. These results indicate that nonmuscle myosin IIA is involved in the barrier function of endothelial cells and their ability to respond to thrombin. 


\section{Introduction}

Endothelial cells play a number of important physiological roles in the cardiovascular system. These cells line both the vascular and lymphatic vessels in the body and control the passage of fluids, signaling molecules such as hormones, and cells such as leukocytes between the bloodstream and the surrounding tissue through their barrier function. Endothelial cells also control blood pressure, release anti-coagulation factors to prevent the formation of blood clots, and regulate the growth of new vessels in response to physiological and pathological stimuli $[1,2]$. The induction of angiogenesis, i.e. the growth of new vessels, is one of the hallmarks of cancer. This allows tumors to receive oxygen and nutrients through the blood supply, which allows the tumors to grow larger [3, 4]. The endothelium also serves as a physical barrier during two steps of metastasis, i) during intravasation, where cancer cells leave the primary tumor and enter the bloodstream, and ii) during extravasation, where cancer cells exit the bloodstream at a distant site [4, 5]. Many studies have addressed the molecular mechanisms of cancer cell transmigration across an endothelial cell monolayer, however, the majority of these studies have focused on the cancer cell, while assuming the endothelium plays a more passive role [5]. Recent studies show that endothelial cells promote tumor cell invasion into a collagen matrix. The endothelial cells may be releasing chemotactic factors that enhance invasion, which could enhance metastasis by directing cancer cell migration towards local vasculature. Further, cancer cells alter the biomechanics of the endothelium through direct interactions or chemical signaling to enable transmigration [5-8].

Cancer cell extravasation is similar to leukocyte tissue invasion during the inflammatory response [9]. During leukocyte diapedesis, the leukocytes cause an 
increase in intracellular calcium in the endothelium, which results in the activation of myosin light chain kinase (MLCK) [10]. MLCK phosphorylates and activates nonmuscle myosin II, which stimulates cell contractility [11-14]. This increase in cell contractility puts physical strain on the junctions between endothelial cells, disengaging the cell-cell adhesions and signaling for the adhesion proteins to be internalized by the cell [15-18]. This disruption of cell-cell adhesions increases the permeability of the endothelium, allowing the leukocyte to pass between endothelial cells as it extravasates from the blood vessel into the infected or damaged tissue [10]. Cancer cells may use a similar mechanism during transmigration.

Nonmuscle myosin II is the main regulator of contractility in nonmuscle cells, and is activated by MLCK [19]. As indicated above, leukocytes induce calcium dependent activation of MLCK. In contrast, thrombin treatment of endothelial cells stimulates Protein Kinase C-dependent activation of MLCK, inducing myosin II dependent cell contraction and disassembly of adherens junctions. Thus, while the steps leading to myosin II activation in response to different stimuli can differ, the outcome is similar, induced cell contraction and weakened barrier function [18]. It has been established in the literature that tumor cells interact with the endothelium to enable their transmigration $[6,8]$. Tumor cells may stimulate myosin II dependent endothelial cell contraction, leading to gaps in the cell-cell junctions that would enable tumor cell transmigration. In fact, TGF- $\beta 1$, a chemokine associated with many cancers, induces endothelial cell contraction and disruption of adherens junctions through MLCK [7]. Whether the tumor cells stimulate calcium-dependent myosin II activation, activation through the PKC-MLCK axis, or contraction through TGF- $\beta 1$ is unknown. Understanding the precise role of the contractile 
machinery in the endothelial cells in barrier function will provide valuable insight into the metastatic process and may elucidate potential therapeutic targets.

There are three isoforms of nonmuscle myosin II heavy chain; A, B, and C. Functional myosin II molecules are hexamers composed of two myosin heavy chains and two sets of light chains, the essential and regulatory. It is the regulatory light chains that are phosphorylated by MLCK and activate myosin II activity [20]. Myosin II is involved in many cellular processes, including cell division, migration, and adhesion [21]. It is this last function, myosin's role in cell-cell adhesion, as well as its role in the contractility response that leads to increased barrier permeability, that is of particular interest in tumor transmigration and is not well understood. In some cell processes, myosin isoforms are interchangeable, one isoform can function in place of another [22]. In other cell processes, the isoforms play distinct and non-redundant roles [23-25]. Studies on myosin II in cell adhesions have previously focused on general myosin II activity, not the role of the specific isoforms [26-29]. Understanding how the separate isoforms function in cell processes associated with disease may enable the development of targeted therapies. Therefore, we sought to characterize how loss of myosin II isoforms affects the cell contractility and barrier function of endothelial cells.

In this study, we used lentiviral mediated shRNA knockdown of the two main isoforms of myosin II expressed in murine small vein endothelial cells (SVEC), myosin IIA and IIB, to evaluate the function of each in endothelial cells [11]. Changes in cell morphology, actin cytoskeleton organization, contractility, and barrier function were measured. Changes in the myosin II status of these endothelial cells affected organization of the actin cytoskeleton and cell morphology. Cells exhibited altered actin structures and 
cell shapes. Monolayers composed of cells lacking the IIA isoform did not present the typical cobblestone appearance, and exhibited a number of spindle shaped cells and less well defined cell borders. Myosin IIB knockdown cell monolayers exhibited a cobblestone appearance, however, the individual cells were larger. We show that loss of either the myosin IIA or myosin IIB isoform decreases tension generation in SVEC cell lines. Loss of the IIA isoform significantly decreased monolayer barrier function and tension generation, while loss of myosin IIB had no significant effect on barrier function and a muted decrease in tension generation. These data indicate that the myosin II isoforms are differentially involved in tension generation and endothelial barrier function, with the IIA isoform appearing to play a more vital role. Tumor cells may induce specific activation of the IIA isoform during transmigration, though further studies are needed. This could be exploited in the design of therapies targeting metastasis.

\section{Materials and Methods}

\section{Cell Culture:}

Mouse small vein endothelial cells (SVEC) were obtained from ATCC and maintained in MEM supplemented with 10\% FCS, $100 \mathrm{U} / \mathrm{ml}$ penicillin, and $100 \mu \mathrm{g} / \mathrm{ml}$ streptomycin in a $37^{\circ} \mathrm{C}$ humidified $5 \% \mathrm{CO}_{2}$ tissue culture incubator. Cells were plated on $0.5 \%$ gelatin (Sigma-Aldrich) coated flasks to maintain cell viability. Phase contrast images were taken on a Zeiss Axiovert $40 \mathrm{CFL}$ microscope.

\section{Generation of Myosin II Isoform Knockdown Cells:}

SVEC knockdown cells were generated using lentiviral shRNA constructs targeted to either the IIA or IIB isoform (obtained from Openbiosystems). Lentiviral constructs were produced in $293 T / 17$ as outlined previously [30] using $2^{\text {nd }}$ generation transfer plasmids. 
Briefly, 293/T17 cells were seeded 24 hrs prior to transfection and transfected with a total of $30 \mu \mathrm{g}$ DNA in the ratio of 3 parts transfer vector: 2 parts psPAX2 packaging vector: 1 part pMD2.G VSV-G packaging vector. Turbofect transfection reagent (ThermoScientific) was used. Media containing virus was collected every 12 hours for 3 days. Viral enriched media was centrifuged at 2000 RPM for 5 min and filtered through a $0.45 \mu \mathrm{m}$ low protein binding filter to remove cell debris and stored at $-80^{\circ} \mathrm{C}$. To generate cell lines, SVEC cells were seeded at a density of $4 \times 10^{5}$ cells/T-25 flask 24 hours before infection with shRNA lentivirus. Cells were infected with $2 \mathrm{~mL}$ of viral stock for 72 hours. Cultures were washed with $\mathrm{MEM}+10 \%$ FCS, refed and allowed to recover for 1 day. For selection and maintenance of SVEC cell populations, cultures were fed with MEM $+10 \% \mathrm{FCS}$ containing $5 \mu \mathrm{g} / \mathrm{mL}$ puromycin. Knockdown was verified using Western Blot analysis.

\section{Immunofluorescence staining:}

Cells were seeded at a density of $3.5 \times 10^{4}$ in $35 \mathrm{~mm}$ dishes 48 hours prior to fixation, fixed and permeabilized as outlined previously [13]. Affinity purified primary rabbit antibodies were prepared at a dilution of $1 \mu \mathrm{g} / \mathrm{mL}$ in blocking buffer and samples incubated for 3 hours at room temperature. TRITC-phalloidin (Sigma-Aldrich, St. Louis, MO, Cat. No. P1951) was also added in the primary antibody incubation for examination of actin filaments. The cells were washed in blocking buffer and incubated for 1.5 hours at room temperature in a 1:1000 dilution of Alexa 488 goat $\alpha$-rabbit secondary antibody (A11070 Invitrogen, Grand Island, NY, 14072) diluted 1:10 in blocking buffer. Cells were washed and coverslipped in 9:1 glycerol:PBS containing $0.1 \mathrm{M}$ n-propyl gallate. Imaging was performed using a Zeiss LSM 510 confocal microscope. For 2D morphology, a Plan- 
Apochromat $63 x / 1.40$ Oil DIC M27 objective was used and z-stacks taken at $0.3 \mu \mathrm{m}$ steps through the depth of the cell.

\section{ECIS Measurements:}

The effect of myosin II isoform depletion on monolayer permeability was measured using Applied Biophysics Model 1600R ECIS (Applied BioPhysics, Troy, NY, USA). Electrode arrays (8W10E+) were cleaned using $10 \mathrm{mM}$ cysteine and coated with $5 \mu \mathrm{g} / \mathrm{mL}$ collagen in $0.15 \mathrm{M} \mathrm{NaOH}$ and incubated overnight at room temperature. Array wells were then washed with $300 \mu \mathrm{L}$ culture media, stabilized, and equilibrated at $37^{\circ} \mathrm{C}, 5 \% \mathrm{CO}_{2}$ for two hours. Arrays were seeded with SVEC parental and knockdown cells with $4 \times 10^{5}$ cells/well in $400 \mu \mathrm{L}$ media and attached to electrode clamps. Cell lines were seeded in duplicate on each array, and duplicate arrays were measured, for a total of 4 replicates of each cell type with each experiment. Electrical resistance was measured at one minute intervals until a stable resistance was reached and maintained, which took approximately 96 hours. A lower resistance corresponds with increased monolayer permeability. Data are plotted as resistance (ohms) as a function of time. Parental and knockdown cell line tracings are an average of data from 4 individual wells \pm SEM. Shown are representative experiments of 3 replicate studies.

\section{Isometric Tension Measurements:}

Isometric tension measurements were performed as described in detail previously [13, 14, 31-33]. Briefly, parental and myosin II KD endothelial cells were mixed with $1 \mathrm{mg} / \mathrm{mL}$ Type I rat tail collagen and poured into Teflon casting molds with a central post. After 4 days of incubation in a $37^{\circ} \mathrm{C}$ humidified $5 \% \mathrm{CO}_{2}$ tissue culture incubator, the cells have compressed the collagen in a tight ring around the central posts. The collagen ring is 
removed and hung from a force transducer connected to a stepper motor. The collagen gels were placed in a $50 \mathrm{ml}$ thermo-regulated Organ Bath (Harvard Apparatus, Holliston, MA, USA Cat\# 760165) containing $20 \mathrm{mM}$ Hepes-buffered MEM/0.4\% bovine serum albumin (Sigma Aldrich). Organ baths were maintained at $37^{\circ} \mathrm{C}$ for the duration of experiments. The isometric tension generated by the collagen constructs is allowed to reach a stable baseline before the constructs are treated with 2 units $/ \mathrm{mL}$ of thrombin to stimulate cell contraction and allowed to return to baseline. Constructs were snap frozen in liquid nitrogen and stored at $-80^{\circ} \mathrm{F}$ for DNA content analysis. Tension measurements were normalized to DNA content to control for the small variations in cell number between collagen constructs.

\section{Rat tail collagen isolation:}

Fresh rat tails were obtained from animal quarters and sterilized with $70 \% \mathrm{EtOH}$. In a sterile environment, the tails were skinned and collagen bundles were severed at each end of the tail with a scalpel, before being pulled from the tail using hemostats. Collagen fibrils were placed in sterile $4^{\circ} \mathrm{C}$ PBS on ice until at least a total of $5 \mathrm{~g}$ of collagen had been collected ( 4-5 large tails). Excess muscle tissue was removed from the collagen fibrils before placing the collagen in $70 \% \mathrm{EtOH}$ for one hour on ice. Fibrils were then washed twice more with $70 \%$ EtOH before final washes of sterile PBS and water. The fibrils were then placed in $300 \mathrm{~mL}$ of sterile $20 \mathrm{mM}$ acetic acid. The collagen solution was stirred at a slow rate for 48 hours at $4^{\circ} \mathrm{C}$, occasionally mixing with a sterile pipet to ensure complete mixing. After the extraction period, the collagen was centrifuged at $16,000 x g$ for 90 minutes at $4^{\circ} \mathrm{C}$. Collagen concentration was determined using SDS-PAGE and stored at $4^{\circ} \mathrm{C}$, protected from light. 


\section{DNA Analysis:}

To measure the DNA content of collagen constructs after isometric tension measurements, frozen construct samples were re-suspended in $750 \mu \mathrm{L}$ of $0.1 \%$ SDS in PBS and sonicated until homogenous. Samples were diluted using $0.1 \%$ SDS in PBS at 1:10, 1:50 and 1:100 dilutions and $100 \mu \mathrm{L}$ of each dilution loaded into a microwell plate (Nunc Part No. 237017). Hoescht 33258 stain was added to each well at a concentration of $0.09 \mu \mathrm{g} / \mathrm{mL}$ per well and the plate was analyzed using the Hoescht 33528 protocol on a Modulus Microplate plate reader (Turner Biosystems, Model number 9300-002).

\section{Results}

\section{Generation of Myosin II Isoform Knockdown Cell Lines}

For the purposes of this study, we focused on the role of myosin IIA and IIB in endothelial cell function. The IIC isoform is less well studied because it was more recently discovered and cloned, but is known to be less prevalent than the other two isoforms [11, 34]. To generate myosin II isoform knockdown (KD) cell lines, we infected endothelial cells with lentiviral shRNA constructs targeted to either the IIA or the IIB isoform. Lentiviral constructs were obtained from Openbiosystems and several shRNA clones were screened for efficacy. A clone for each target was chosen based on the knockdown efficiency and specificity. Several clones produced efficient knockdown of the targeted isoform, but also reduced expression of the other, non-targeted isoform. Figure 1 shows the myosin II isoform expression levels in cells after shRNA mediated knockdown. Greater than 85\% KD was achieved for both IIA and IIB, with minimal effect on the nontargeted isoform. Since myosin $\mathrm{II}$ is involved in cell adhesion and cell shape determination, we speculated that changes in the myosin status of cells would alter the 
appearance of SVEC monolayers. Indeed, loss of either isoform affects morphology of cells in the monolayer. SVEC parental monolayers (Fig 1B; left panel), had a uniform, cobblestone appearance with rounded cells. IIA KD cells (Fig. 1B; middle panel) did not form uniform monolayers. Individual cells appeared larger, with less well defined cell borders. In addition, a number of the cells had a spindle like shape and grew on top of the more regularly shaped cells, even before cells reached confluence. Finally, IIB KD cells (Fig. 1B; right panel) formed a monolayer more uniform in appearance, similar to the parental cells. However, there were minor differences in morphology, especially the size of individual cells, which were larger in the IIB KD monolayers. These alterations to the monolayer, which could indicate a change in cell-cell adhesions, could have a significant effect on the barrier function of monolayers lacking myosin IIA, an essential function of endothelial cells.

\section{Myosin II Localization in Individual Endothelial Cells}

While the phase contrast images of the SVEC monolayers presented in Figure 1B are informative, we also wanted to investigate if loss of a myosin isoform affects the nuances of the cell actin cytoskeleton. Cells were stained with TRITC-Phalloidin to observe the actin networks and antibodies against the IIA and IIB myosin isoforms to examine their localization within the cell. Individual cells were stained to enable more precise imaging of cells structures. This was especially important in the IIA KD cells, where cells in a monolayer grew on top of one another, even before reaching confluence. Parental endothelial cells (top two rows of Fig. 2) had profuse stress fibers, and myosin IIA had a mainly cytosolic localization, though there was some IIA decorating the stress fibers. Myosin IIB in these cells also exhibited strong cytosolic localization with some IIB on the 
stress fibers. In IIA KD endothelial cells (middle two rows of Fig. 2), the actin cytoskeleton appeared similar to that of the parental cells. The cells had altered morphology, with an increase in protrusions at the cell edge, and they lacked the smooth, rounded polygonal shape of their parental counterparts. The remaining myosin IIA in the cells was localized in the cytosol, and the IIB was localized to stress fibers and the cytosol. Finally, IIB KD endothelial cells (bottom two rows of Fig. 2) showed no significant alterations in either actin cytoskeleton or cell shape. Myosin IIA retained the stress fiber and cytosolic localization seen in the parental cells, and the remaining IIB had a perinuclear, mictrotubule like staining pattern. This microtubule like staining pattern could be due to myosin II interaction with microtubule associated proteins [35]. This immunofluroescent localization confirmed the isoform knockdown shown by Western blot analysis and indicated that loss of one isoform does not significantly affect localization of the other.

\section{Myosin II Isoforms are Needed for Endothelial Cell Barrier Function}

A vital function of endothelial cells is their barrier function. Endothelial cells line the vasculature and therefore must maintain a tight barrier. A "leaky" vasculature is associated with a number of diseases and can cause a significant, and dangerous, drop in blood pressure [1]. Changes in vascular permeability may also promote cancer metastasis since cancer cells could have an easier time crossing the physical barrier of the blood vessel wall $[5,6,36]$. Since myosin II isoforms are involved in cell adhesion, and myosin IIA knockout mice show deficiencies in vasculature integrity [11, 37], we hypothesized that changes in myosin II isoform expression in the cells would have a significant impact on their barrier function. To test this hypothesis, we used Electric Cellsubstrate Impedance Sensing (ECIS). Cells are seeded on an electrically conductive 
array, allowed to form a confluent monolayer over the course of several days, and an electrical current is applied. If the monolayer is tight and has a high barrier function, the resistance of the cells will be high because the cells act as an insulator against the current. If the monolayer is "leaky", with a low barrier function, the resistance will be lower. For these experiments, cells were seeded at a density of $4 \times 10^{5}$ cells/well and the array was immediately clamped into the ECIS machine and measurements begun. In this way, we were able to measure changes in resistance over the course of monolayer formation. The monolayer is considered complete when a stable resistance is reached. In this study, baseline resistance was reached after 96 hours. Figure 3 shows a representative ECIS reading from a single experiment. Measurements were performed in quadruplicate for each experiment, and experiments were repeated three times. Parental SVEC monolayers (orange line) reached a baseline resistance of about 1700 ohms after 65 hours, which is similar to the resistance of human microvascular endothelial cells [38]. IIA KD cells (yellow line) had only reached a resistance of 1400 ohms and did not reach a stable plateau, even after 96 hours of incubation. Increasing measurement time longer than 96 hours required a change of culture media to prevent cell death, which disturbed the resistance readings. On the other hand, IIB KD cells (green line) had an initial resistance higher than that of the parental monolayers. This could be due to the larger size of the cells. During the initial stages of monolayer formation, before the cells begin to form intercellular junctions, resistance is greatly influenced by how much of the surface area of the array is covered by cells. Larger cells will therefore have an increased resistance than smaller cells. By the 60 hour time point, the difference between the parental and IIB KD cells is minimal, and they reach similar peaks at stable resistance. 
These data indicate that myosin II isoforms, especially IIA, are needed for the formation and maintenance of barrier function in SVEC monolayers.

Myosin II Isoforms are Needed for Isometric Tension Generation and Contractility in Response to Thrombin Treatment

Leukocytes stimulate myosin II dependent endothelial cell contraction during diapedesis [10]. Cell contraction disengages cell-cell adhesions and pulls the cells away from each other, enabling the leukocyte to move between endothelial cells $[15,18]$. It is believed that tumor cells adopt some of the behaviors of inflammatory leukocytes during metastasis [9]. If tumor cells behave as leukocytes and induce endothelial cell contraction to ease their passage during transmigration, then the contractility of the endothelial cells could affect this process. To test the contractility of endothelial cells, we measured the baseline isometric tension of SVEC cultures with and without myosin II isoforms, as well as their response to thrombin, which stimulates cell contractility. Figure 4 shows representative force tracings of these experiments. Samples were measured in duplicate for each experiment, and experiments were repeated an additional two times. Parental cells (black line) had a high baseline isometric tension of 100 dynes. Upon treatment with thrombin, the tension increased by almost $75 \%$, indicating a robust contractile response. IIA KD cells (red line), had a baseline tension of just over 60 dynes, $40 \%$ less than parental cells. When these cells were treated with thrombin, they exhibited no increase in tension. This complete absence of a contractile response, along with the decrease in permeability (Fig. 3) could drastically impact how these cells act as a barrier during cancer cell transmigration. The IIB KD cells (green line), on the other hand, exhibited behaviors more similar to the parental cells, though slightly muted. Their baseline tension is just 
above 90 dynes, and upon thrombin treatment, shows a 67\% increase in tension. These data indicate that both myosin II isoforms are needed for tension maintenance and contractile response to thrombin treatment.

\section{Discussion}

Here we show that loss of either the myosin IIA or myosin IIB isoform in SVEC cells has an effect on monolayer barrier function and cell contractility. Loss of IIA had an especially pronounced effect on both of these cell functions, resulting in a lower barrier function and reduced contractility. Changes in the barrier permeability of endothelial cells could have a significant effect on how cancer cells migrate across the endothelial barrier during metastasis. The differences between the roles of the two isoforms could be due the differences in isoform enzyme kinetics. The IIB isoform has a lower ADP release rate than the IIA isoform, and therefore spends a higher proportion of time bound to actin $[39,40]$. Because of this, the actin may be acting as a myosin IIB sponge, making this isoform less able to quickly respond to changes in the environment or signaling that require an increase in cell contractility. Therefore, IIA KD cells, which only have the IIB isoform, are unable to quickly generate cell contraction in response to thrombin treatment in the isometric tension experiments.

The role of endothelial cell mechanics during cancer cell transmigration is potentially very complicated, and could depend on what type of vasculature is involved, which organ it occurs in, and the origin of the cancer cells. It has previously been shown that cancer cells cause a decrease in the stiffness of endothelial cells under co-culture conditions [8]. However, if some cancer cells follow the model of leukocyte diapedesis, then endothelial cell contractility is needed to disengage cell-cell adhesions and create 
gaps in the endothelial barrier [10]. Additionally, previous studies of in vitro cancer cell transmigration have shown that a number of the cancer cells undergo transcellular transmigration, a phenomenon that is also seen in leukocytes. Transcellular transmigration involves cancer cells, or leukocytes, migrating through the endothelial cells themselves, rather than between endothelial cells, which is known as paracellular transmigration. This process is dependent on myosin II if the endothelial cells are to survive the radial pressure the larger cancer cell exerts as it moves through the endothelial cell [41]. Less stiff endothelial cells may make it easier for cancer cells to squeeze between adjacent endothelial cells. However, increased contractility in endothelial cells would also create gaps in the endothelial monolayer that would enable cancer cells to more easily pass between endothelial cells. Determining how these two observed effects work together, or against each other, to enhance or prohibit tumor cell transmigration across an endothelial cell monolayer may yield valuable insight into cancer metastasis and future treatment strategies.

The experiments in this study show that loss of individual myosin II isoforms has differential effects on endothelial cell contractility and barrier function. While loss of either isoform results in a decrease in contractility, loss of the IIA isoform completely blocked the thrombin induced contractile response. IIA KD cells also had a low barrier function. From these results, we speculate that the IIA isoform of nonmuscle myosin II plays a vital role in the barrier function of endothelial cells, perhaps through myosin's function in cellcell adhesions. Tumor cells may induce myosin IIA activation to stimulate endothelial cell contraction and decrease barrier function during transmigration. It would be interesting to test transmigration of tumor cells across endothelial isoforms lacking myosin II isoforms. 
Understanding if tumor cells stimulate endothelial cell contraction, and if this activation is isoform specific, will provide insight into possible signaling mechanisms. These mechanisms could be exploited in targeting metastasis with chemotherapeutic agents. Since the majority of cancer related deaths are the result of metastasis to vital organs, especially in cancers that originate in non-vital organs such as the breast [42], any treatment options that block metastasis, at any stage of metastasis, could be of great benefit to society. 


\section{References}

1. Sumpio BE, Riley JT, Dardik A. Cells in focus: endothelial cell. Int J Biochem Cell Biol. 34. England2002. p. 1508-12.

2. Hahn C, Schwartz MA. Mechanotransduction in vascular physiology and atherogenesis. Nat Rev Mol Cell Biol. 2009;10(1):53-62. Epub 2009/02/07. doi: 10.1038/nrm2596. PubMed PMID: 19197332; PubMed Central PMCID: PMCPmc2719300.

3. Chung AS, Lee J, Ferrara N. Targeting the tumour vasculature: insights from physiological angiogenesis. Nat Rev Cancer. 10. England2010. p. 505-14.

4. Ho KS, Poon PC, Owen SC, Shoichet MS. Blood vessel hyperpermeability and pathophysiology in human tumour xenograft models of breast cancer: a comparison of ectopic and orthotopic tumours. BMC Cancer. 12. England2012. p. 579.

5. Mierke CT. Role of the endothelium during tumor cell metastasis: is the endothelium a barrier or a promoter for cell invasion and metastasis? J Biophys. 2008;2008:183516. PubMed PMID: 20107573.

6. Mierke CT, Zitterbart DP, Kollmannsberger P, Raupach C, Schlotzer-Schrehardt $\mathrm{U}$, Goecke TW, et al. Breakdown of the endothelial barrier function in tumor cell transmigration. Biophys J. 2008;94(7):2832-46. PubMed PMID: 18096634.

7. Hurst VI, Goldberg PL, Minnear FL, Heimark RL, Vincent PA. Rearrangement of adherens junctions by transforming growth factor-beta1: role of contraction. Am J Physiol. 1999;276(4 Pt 1):L582-95. Epub 1999/04/13. PubMed PMID: 10198356.

8. Mierke CT. Cancer cells regulate biomechanical properties of human microvascular endothelial cells. J Biol Chem. 2011;286(46):40025-37. PubMed PMID: 21940631. 
9. Coussens LM, Werb Z. Inflammation and cancer. Nature. 2002;420(6917):860-7. PubMed PMID: 12490959.

10. Muller WA. Leukocyte-endothelial-cell interactions in leukocyte transmigration and the inflammatory response. Trends Immunol. 2003;24(6):327-34. PubMed PMID: 12810109.

11. Betapudi V. Life without double-headed non-muscle myosin II motor proteins. Front Chem. 2014;2:45. Epub 2014/07/30. doi: 10.3389/fchem.2014.00045. PubMed PMID: 25072053; PubMed Central PMCID: PMCPMC4083560.

12. Billington N, Wang A, Mao J, Adelstein RS, Sellers JR. Characterization of three full-length human nonmuscle myosin II paralogs. J Biol Chem. 2013;288(46):33398-410. PubMed PMID: 24072716.

13. Goeckeler ZM, Wysolmerski RB. Myosin light chain kinase-regulated endothelial cell contraction: the relationship between isometric tension, actin polymerization, and myosin phosphorylation. J Cell Biol. 1995;130(3):613-27. PubMed PMID: 7622562.

14. Goeckeler ZM, Bridgman PC, Wysolmerski RB. Nonmuscle myosin II is responsible for maintaining endothelial cell basal tone and stress fiber integrity. Am J Physiol Cell Physiol. 2008;295(4):C994-1006. PubMed PMID: 18701651.

15. Vandenbroucke E, Mehta D, Minshall R, Malik AB. Regulation of endothelial junctional permeability. Ann N Y Acad Sci. 1123. United States2008. p. 134-45.

16. Ramachandran C, Srinivas SP. Formation and disassembly of adherens and tight junctions in the corneal endothelium: regulation by actomyosin contraction. Invest Ophthalmol Vis Sci. 2010;51(4):2139-48. Epub 2009/12/19. doi: 10.1167/iovs.09-4421. PubMed PMID: 20019371; PubMed Central PMCID: PMCPmc2868408. 
17. Lin Z, Natesan V, Shi H, Dong F, Kawanami D, Mahabeleshwar GH, et al. Kruppel-like factor 2 regulates endothelial barrier function. Arterioscler Thromb Vasc Biol. 30. United States2010. p. 1952-9.

18. Garcia JG, Verin AD, Schaphorst KL. Regulation of thrombin-mediated endothelial cell contraction and permeability. Semin Thromb Hemost. 1996;22(4):309-15. Epub 1996/01/01. doi: 10.1055/s-2007-999025. PubMed PMID: 8944415.

19. Sellers JR. Myosins: a diverse superfamily. Biochim Biophys Acta. 2000;1496(1):3-22. PubMed PMID: 10722873.

20. Maciver SK. Myosin II function in non-muscle cells. Bioessays. 1996;18(3):17982. PubMed PMID: 8867731.

21. Aguilar-Cuenca R, Juanes-Garcia A, Vicente-Manzanares M. Myosin II in mechanotransduction: master and commander of cell migration, morphogenesis, and cancer. Cell Mol Life Sci. 2014;71(3):479-92. PubMed PMID: 23934154.

22. Bao J, Ma X, Liu C, Adelstein RS. Replacement of nonmuscle myosin II-B with IIA rescues brain but not cardiac defects in mice. J Biol Chem. 282. United States2007. p. 22102-11.

23. Kolega J. Cytoplasmic dynamics of myosin IIA and IIB: spatial 'sorting' of isoforms in locomoting cells. J Cell Sci. 1998;111 ( Pt 15):2085-95. PubMed PMID: 9664030.

24. Wang A, Ma X, Conti MA, Adelstein RS. Distinct and redundant roles of the nonmuscle myosin II isoforms and functional domains. Biochem Soc Trans. 39. England2011. p. 1131-5.

25. Hindman B, Goeckeler Z, Sierros K, Wysolmerski R. Non-Muscle Myosin II Isoforms Have Different Functions in Matrix Rearrangement by MDA-MB-231 Cells. PLoS One. 2015;10(7):e0131920. Epub 2015/07/03. doi: 10.1371/journal.pone.0131920. PubMed PMID: 26136073. 
26. Clark K, Langeslag M, Figdor CG, van Leeuwen FN. Myosin II and mechanotransduction: a balancing act. Trends Cell Biol. 2007;17(4):178-86. PubMed PMID: 17320396.

27. Pasapera AM, Schneider IC, Rericha E, Schlaepfer DD, Waterman CM. Myosin II activity regulates vinculin recruitment to focal adhesions through FAK-mediated paxillin phosphorylation. J Cell Biol. 188. United States2010. p. 877-90.

28. Schiller HB, Hermann MR, Polleux J, Vignaud T, Zanivan S, Friedel CC, et al. beta1- and alphav-class integrins cooperate to regulate myosin II during rigidity sensing of fibronectin-based microenvironments. Nat Cell Biol. 2013;15(6):62536. PubMed PMID: 23708002.

29. Vicente-Manzanares M, Ma X, Adelstein RS, Horwitz AR. Non-muscle myosin II takes centre stage in cell adhesion and migration. Nat Rev Mol Cell Biol. 2009;10(11):778-90. PubMed PMID: 19851336.

30. Tiscornia G, Singer O, Verma IM. Production and purification of lentiviral vectors. Nat Protoc. 2006;1(1):241-5. Epub 2007/04/05. doi: 10.1038/nprot.2006.37. PubMed PMID: 17406239.

31. Marquez JP, Genin GM, Zahalak GI, Elson EL. The relationship between cell and tissue strain in three-dimensional bio-artificial tissues. Biophys J. 88. United States2005. p. 778-89.

32. Marquez JP, Elson EL, Genin GM. Whole cell mechanics of contractile fibroblasts: relations between effective cellular and extracellular matrix moduli. Philos Trans A Math Phys Eng Sci. 368. England2010. p. 635-54.

33. Wakatsuki T, Kolodney MS, Zahalak GI, Elson EL. Cell mechanics studied by a reconstituted model tissue. Biophys J. 79. United States2000. p. 2353-68.

34. Korn ED, Hammer JA, 3rd. Myosins of nonmuscle cells. Annu Rev Biophys Biophys Chem. 1988;17:23-45. PubMed PMID: 3293586. 
35. Rao Y, Hao R, Wang B, Yao TP. A Mec17-Myosin II Effector Axis Coordinates Microtubule Acetylation and Actin Dynamics to Control Primary Cilium Biogenesis. PLoS One. 92014. p. e114087.

36. Reymond N, d'Agua BB, Ridley AJ. Crossing the endothelial barrier during metastasis. Nat Rev Cancer. 13. England2013. p. 858-70.

37. Conti MA, Even-Ram S, Liu C, Yamada KM, Adelstein RS. Defects in cell adhesion and the visceral endoderm following ablation of nonmuscle myosin heavy chain II-A in mice. J Biol Chem. 279. United States2004. p. 41263-6.

38. Szulcek R, Bogaard HJ, van Nieuw Amerongen GP. Electric cell-substrate impedance sensing for the quantification of endothelial proliferation, barrier function, and motility. J Vis Exp. 2014;(85). Epub 2014/04/22. doi: 10.3791/51300. PubMed PMID: 24747269; PubMed Central PMCID: PMCPmc4159052.

39. Kovacs M, Wang F, Hu A, Zhang Y, Sellers JR. Functional divergence of human cytoplasmic myosin II: kinetic characterization of the non-muscle IIA isoform. J Biol Chem. 2003;278(40):38132-40. PubMed PMID: 12847096.

40. Wang F, Kovacs M, Hu A, Limouze J, Harvey EV, Sellers JR. Kinetic mechanism of non-muscle myosin IIB: functional adaptations for tension generation and maintenance. J Biol Chem. 2003;278(30):27439-48. PubMed PMID: 12704189.

41. Arvanitis C, Khuon S, Spann R, Ridge KM, Chew TL. Structure and biomechanics of the endothelial transcellular circumferential invasion array in tumor invasion. PLoS One. 9. United States2014. p. e89758.

42. Society AC. Breast Cancer Facts \& Figures 2013-2014. Atlanta: American Cancer Society, 2013. 


\section{Figure Legends}

Figure 1. Knockdown of myosin II isoforms (A) Greater than $85 \%$ knockdown of myosin protein content was achieved in stable cell lines expressing shRNA to myosin IIA or IIB. $\beta$-actin was used as a loading control. Myosin isoform levels were assessed for every experiment to verify the level of myosin IIA and IIB knockdown. (B) The appearance of parental, IIA and IIB KD SVEC monolayers was determined using phase contrast microscopy. Parental monolayers had a uniform, cobblestone appearance. IIA KD monolayers consisted of larger cells, of less uniform shape, with a number of spindle-like cells. IIB KD monolayers had a uniform, cobblestone appearance much like the parentals, however the individual cells were larger.

Figure 2. Knockdown of myosin II isoforms induces cytoskeletal changes in SVEC cells in 2D Parental (top two rows), IIA KD (middle two rows) and IIB KD (bottom two rows) cells were fixed, permeabilized, and immunostained with affinity purified polyclonal myosin IIA and IIB primary antibodies and Phalloidin-TRITC to visualize actin filaments and myosin localization. In parental cells, myosin IIA had a cytosolic localization, with some myosin localizee to stress fibers and the leading edge of cells, while myosin IIB had cytosolic, stress fiber, and perinuclear localization. Myosin IIA KD cells had altered actin cytoskeletal structure and significant aberrations in cell shape, while the residual IIA in these cells localized to stress fibers and myosin IIB localization was largely unaffected. Myosin IIB KD cells exhibited a more regular shape, and the residual IIB in these cells exhibited a perinuclear localization. Myosin IIA localization was unaffected.

Figure 3. Myosin II isoforms are needed for efficient barrier permeability. Barrier function of SVEC parental and myosin II KD monolayers were measured using ECIS. 
Cells were seeded at a density of $4 \times 10^{6}$ cells/well and the total electrical resistance measured as the monolayers formed until a stable baseline was reached (approximately 60 hours for parental and IIB KD monolayers, $>96$ hours for IIA KD). Shown are average resistance readings from a representative experiment $(n=4)$. Parental (orange line) monolayers reached a stable baseline of 1700 ohms after 65 hours of incubation. IIA KD monolayers (yellow line) did not reach a stable baseline, even after 96 hours, and only reached a maximum resistance of 1400 ohms. IIB KD monolayers (green line), had an initial resistance higher than that of the parentals (likely due to their increased cell size) and reached a baseline of 1650 ohms after 60 hours of incubation.

Figure 4. Myosin II isoforms are needed for isometric force generation. Parental and myosin II KD SVEC cells were suspended in type I rat tail collagen and poured into Teflon casting molds. After 4 days of incubation, the cells have compressed the collagen into a tight ring that can be removed and hung from force transducers connected to a stepper motor. The baseline tension generated by the constructs is measured before contractility was stimulated using thrombin treatment. Parental cells (black line) had a baseline tension of 100 dynes and showed a $75 \%$ increase in tension after thrombin treatment. IIA KD cells had baseline tension of 60 dynes, and exhibited no change in tension after stimulation. IIB KD cells had a baseline tension of 90 dynes, and increased in tension by $67 \%$ upon thrombin treatment. 
Figure 1

A
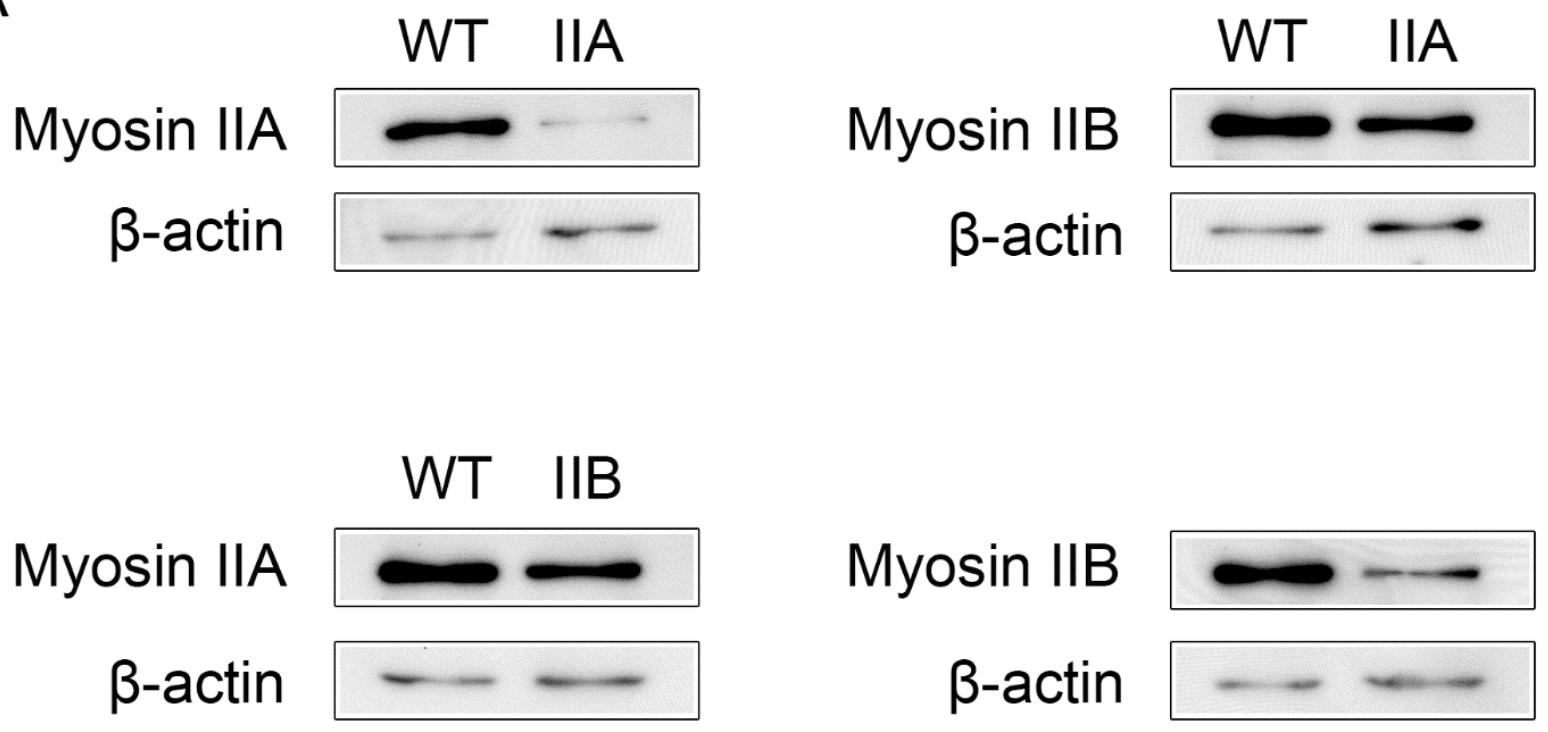

B
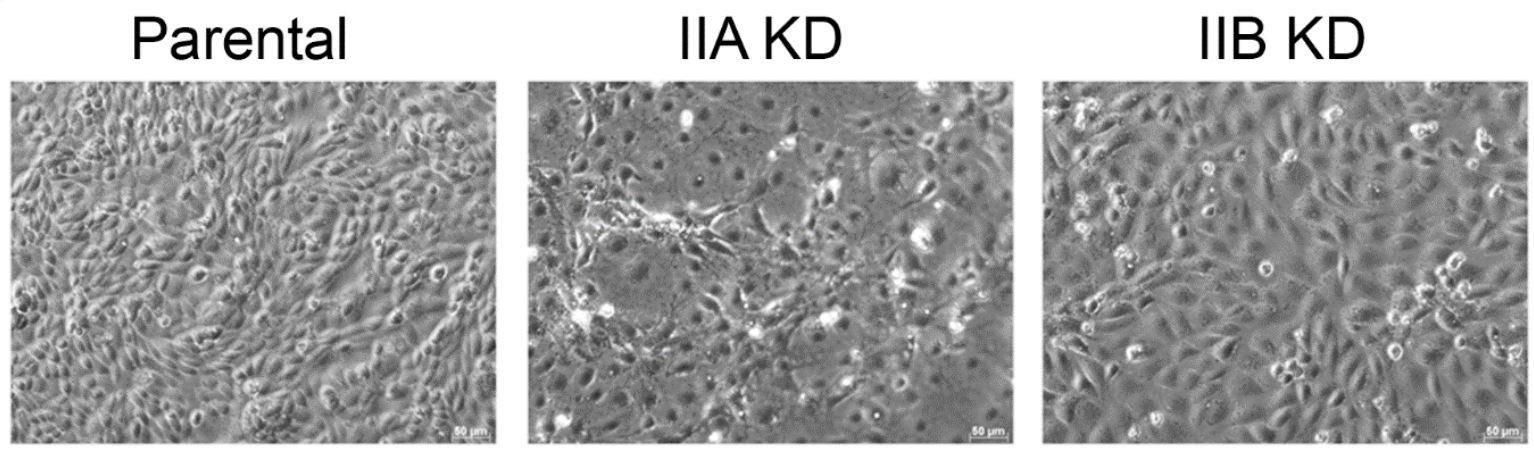
Figure 2
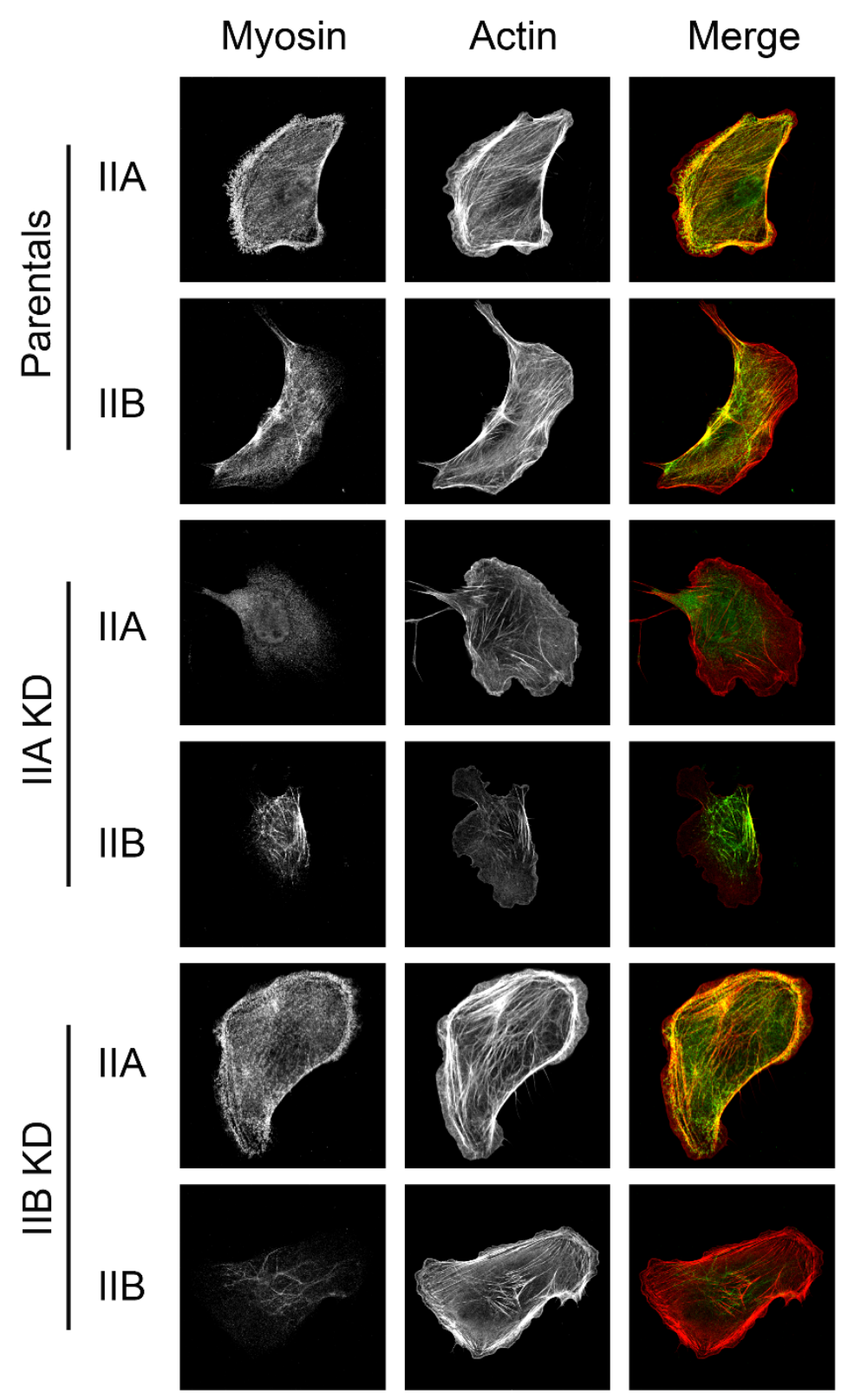
Figure 3

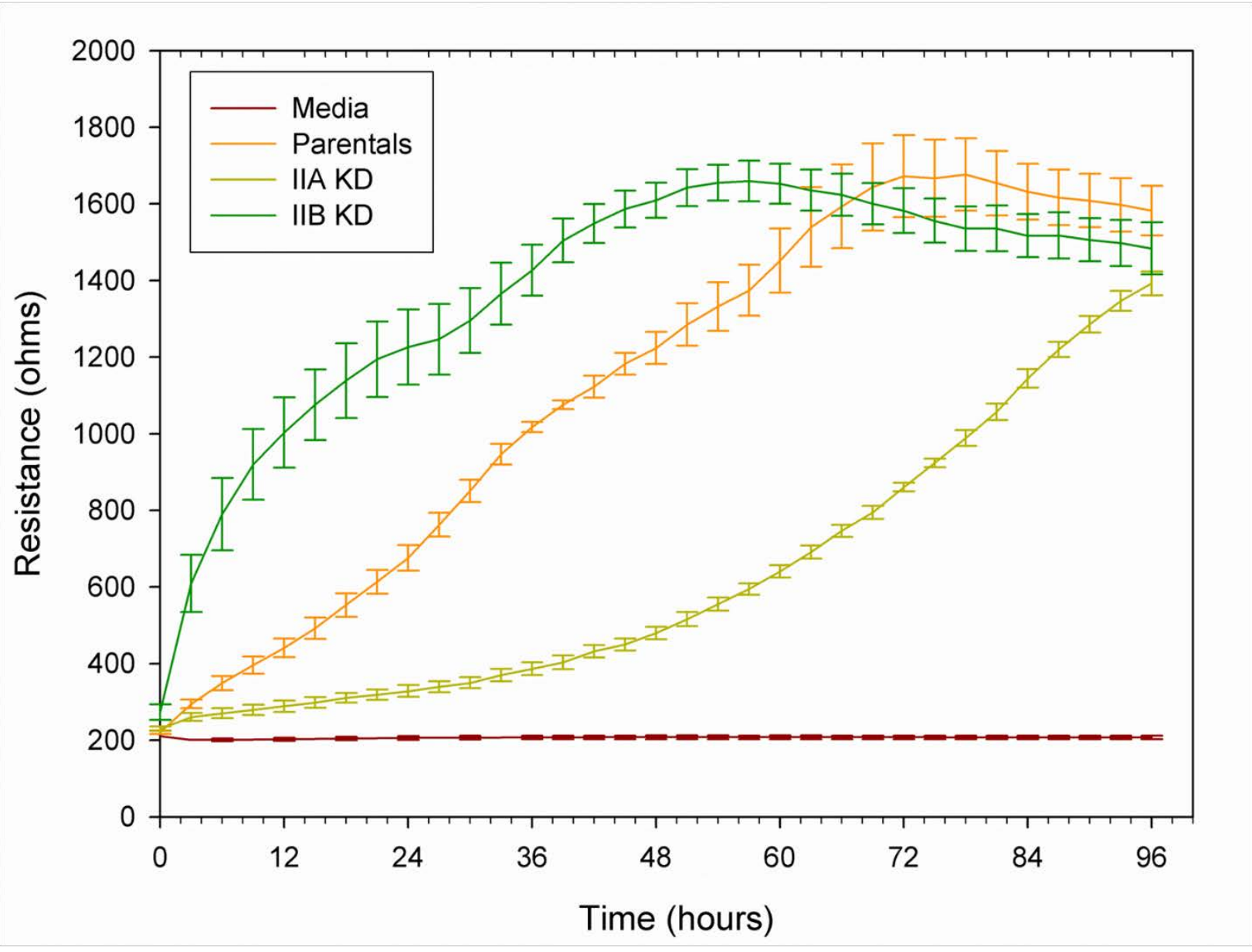


Figure 4

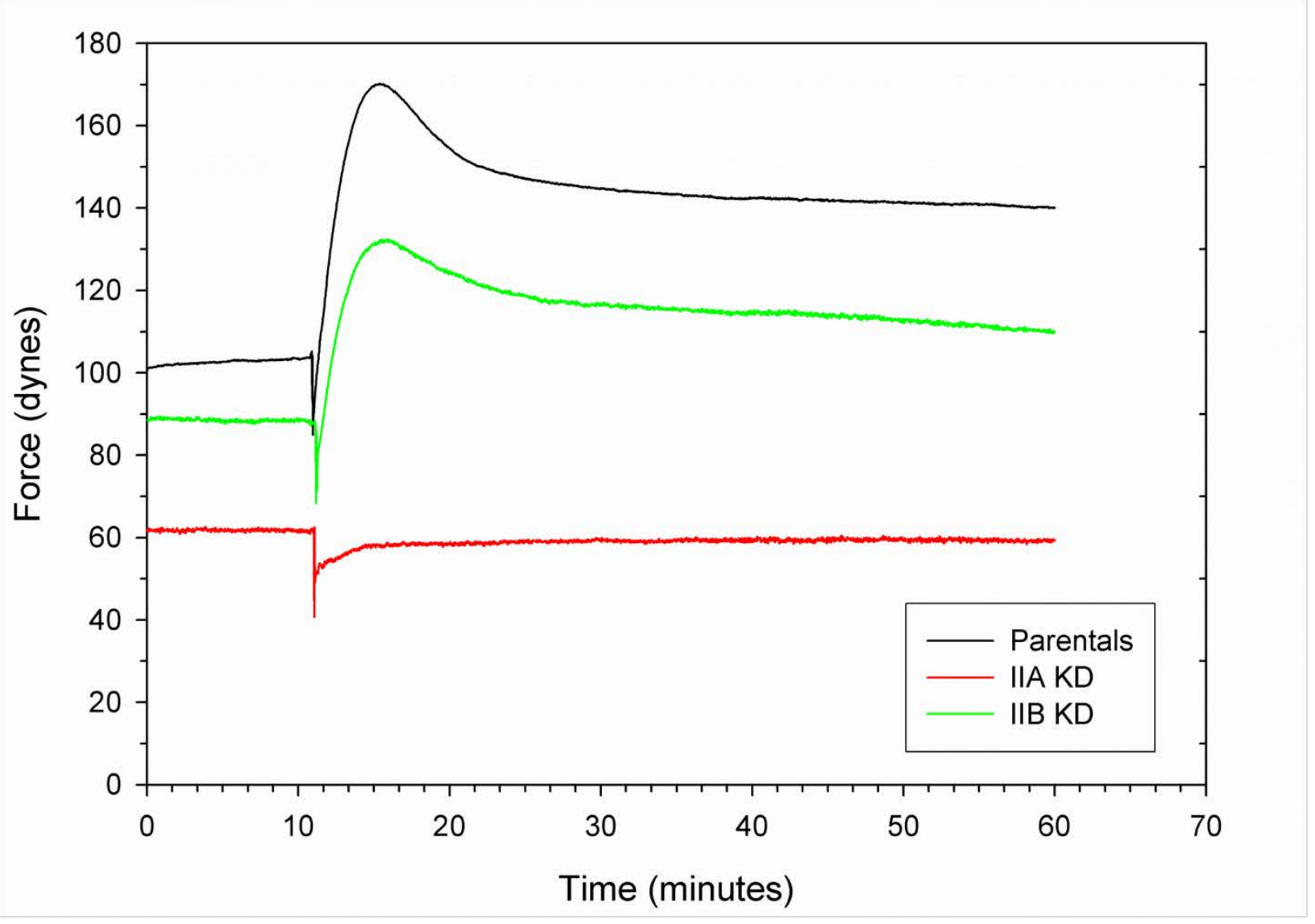




\section{General Discussion}

This dissertation presents studies that describe the role of nonmuscle myosin II isoforms in breast cancer cell interactions with the matrix, breast cancer cell migration, and endothelial cell function (summarized in Figure 1). Each of these processes is involved in cancer progression. During the initial stages of tumorigenesis, the matrix influences the proliferation and invasive potential of tumor cells [1-7]. Increases in matrix stiffness stimulate cell proliferation through integrin mediated adhesions in a myosin II contractility dependent manner $[8,9]$. Additionally, changes in the matrix architecture and organization promote cell migration by providing a physical scaffold for the cells [10-12]. Both of these effects are dependent on the cancer cell's ability to sense and respond to changes in the surrounding ECM, as well as to physically modify the surrounding matrix to support cell migration, abilities which are dependent on cell contractility [2, 13-19]. The data presented here indicate that two isoforms of nonmuscle myosin II, A and B, are both needed for efficient matrix modification by breast cancer cells (Study 1 ). In the first stages of the metastatic process, tumor cells break away from the primary tumor mass and migrate through the interstitial space until they reach a blood or lymphatic vessel [20-25]. In MDA-MB-231 breast cancer cells, loss of either the myosin IIA or IIB isoform results in a significant alteration in migration ability in a 3D collagen matrix (Study 1). Finally, after cancer cells reach a lymph or blood vessel, they must cross the vessel wall. The endothelial cells that line these vessels are a major regulator of vessel permeability, and as such, changes in endothelial cell integrity can promote or inhibit cancer cell transmigration [26-31]. In murine SVEC monolayers, loss of the IIA isoform of nonmuscle myosin II significantly inhibits their ability to form a monolayer with a high barrier function 
(Study 2). Together, these results indicate that nonmuscle myosin II isoforms play critical roles in cellular processes important for cancer progression and the dissemination of cancer cells during metastasis. Understanding how these isoforms are differentially involved in cancer progression will help elucidate the complex signaling pathways involved in mechanosensing, cell migration, and endothelial barrier function, perhaps providing new potential drug targets for the treatment of cancer.

Targeting general myosin II activity in a human patient would likely result in detrimental side effects, at least without specific tumor targeting, due to myosin II's essential role in normal cell processes such as cell division, synaptic plasticity, and blood vessel barrier function [32-35]. Targeting of specific myosin II isoforms is possible and may result in less severe side effects since the isoforms play redundant roles in a number of cell processes [36]. Targeting the ATPase activity of a specific isoform would be extremely difficult as the ATPase domains of these isoforms are highly homologous [3638]. However, the three isoforms differ significantly at the c-terminal tail, allowing for specific interactions with regulatory proteins and enzymes [36, 38-41]. Interactions at this tail region typically regulate myosin II filament assembly. In fact, S100A4 (Mts1) controls myosin II filament assembly through interactions at the tail region, and it is specific for the IIA isoform [41-43]. The design of small molecules specifically targeting myosin II isoforms to prevent filament assembly is possible. Beyond direct targeting of myosin II, understanding the different roles of the isoforms will provide a starting point for future studies into isoform specific regulation by other proteins. For instance, it has been shown that the collagen receptor DDR1, a tyrosine kinase receptor, specifically associates with myosin IIA and regulates filament assembly. Proteins like DDR1 that directly interact with 
the IIA isoform might be therapeutic targets that can be inhibited to block myosin II activation. Targeting proteins that regulate myosin II isoform activity in cancer associated cell processes, especially in signaling cascades that are dysregulated in cancer, could be an ideal way to block myosin II dependent cell processes with reduced detrimental side effects.

The microenvironment is known to significantly influence cancer disease progression, however the specifics have not been entirely defined. Several components of the microenvironment regulate cancer cell survival, proliferation, and invasion. Stromal cells such as fibroblasts can promote disease progression. Tumor associated macrophage infiltration into solid tumors is associated with pathological features such as immunosuppression and neovascularization that are indicative of poor patient prognosis [44]. In the case of cancer associated fibroblasts (CAFs), these altered stromal cells proliferate at a faster rate than normal fibroblasts, secrete more matrix modulating factors, display enhanced collagen production, and can interact directly with the tumor cells to facilitate tumor invasion [45]. Of particular interest to the work presented here is the effect of CAFs on the ECM. The propensity of CAFs to produce more matrix components and matrix modulating enzymes such as LOX changes the biophysical properties of the matrix, generally leading to an increase in matrix stiffness that can stimulate cancer progression independent of the other effects of CAFs on the tumor [45-49]. The increased stiffness of the matrix surrounding the tumor alters the stiffness of the tumor cells, a change which stimulates the tumor cells themselves to further alter the matrix $[1,2,8,47$, 50-53]. This phenomenon is partially documented in the work presented here, i.e. that softer cells may have a reduced capacity to stiffen the surrounding matrix. Cell poking 
measurements show that parental and IIB KD MDA-MB-231 cells have a similar cell stiffness. These cells are able to compress the collagen gel to a similar degree, and the elastic modulus of collagen constructs containing these cells are not significantly different. In contrast, IIA KD cells are softer than either the parental or IIB KD cells, as measured by cell poking, and also produce constructs with a much lower elastic modulus than the other cell types (Study 1). It would be interesting to measure the stiffness of parental, IIA, and IIB KD MDA-MB-231 cells seeded in matrices of varying compliance. These experiments would provide insight into the first step of mechanoreciprocity, the effect of matrix stiffness on cell stiffness. We speculate that the trends seen here would hold true. Parental and IIB KD cells would have an increased cell stiffness in response to increased matrix stiffness, while IIA KD cells would not respond as robustly to changes in matrix compliance. If so, then specifically targeting myosin IIA may partially block the influence of the matrix on the tumor cells, and attenuate the effect of cells on the matrix, becoming an attractive possibility for slowing disease progression.

Changes in the matrix stiffness are transmitted to the cell through cell adhesions to the matrix, most likely through focal adhesions containing integrins $[1,15,50,54-60]$. Myosin II activity and force production is needed for adhesion maturation [61, 62]. Cells also exert forces on the matrix during remodeling, a process which is important during cell invasion and migration [56, 63-65]. The involvement of myosin II in mechanosensing and matrix remodeling by cancer cells has not been fully elucidated. Myosin II isoforms are necessary for matrix directed stem cell differentiation [66, 67], as well as matrix influence on cancer cell invasive potential $[53,61,62]$. However, these studies have looked at general myosin II activity, and not the individual isoforms. The isoforms of 
nonmuscle myosin II have been shown to have differential roles in MDA-MB-231 cell spreading and migration, as well as in other cell processes [32, 68-71]. Therefore, in Study 1 , we investigated the role of the two main isoforms of myosin II, IIA and IIB, in MDA-MB-231 cell mediated matrix organization.

In order to investigate potential changes in MDA-MB-231 cell interactions with a collagen matrix, a force conditioning model to measure the stiffness of cell altered collagen matrices was used. In addition, using cytoskeletal disrupting agents and detergents, we were able to measure the elastic modulus of the overall collagen constructs, the matrix modulus, and the cell modulus. Cells lacking either of the two main myosin II isoforms, IIA or IIB, generated matrices with altered biophysical characteristics as compared to parental cells. IIA KD cells were unable to significantly alter collagen, as measured by gel compression assays and isometric force modeling. The cells themselves were also significantly softer than their parental counterparts. IIB KD cells, on the other hand, generated collagen constructs with an overall elastic modulus similar to the parental cells. However, the cell modulus was lower than parental cells, and the matrix modulus was slightly higher. These results indicate that both nonmuscle myosin II isoforms present in MDA-MB-231 cells are needed for efficient cell interactions with a collagen matrix. There are several possibilities for myosin II involvement in matrix stiffening. Myosin II contractility is necessary for integrin mediated adhesion maturation, and myosin IIA is specifically associated with the collagen receptor DDR1 [18, 54, 61, 62, 72]. Loss of this isoform may therefore prevent the formation of strong cell adhesions to the collagen matrix. This inability to form mature adhesions may explain why loss of the IIA isoform has a greater effect on the cells, since adhesions are necessary for mechanosensing by 
cells and for physical rearrangement of the collagen fibers [17-19, 50]. Loss of the IIB isoform had a less profound effect on cell mediated collagen organization. However, the cells are unable to organize the matrix as effectively as parental cells, as indicated by the decreased elastic modulus of IIB KD collagen constructs. The IIB isoform may be necessary later in the process of collagen organization, perhaps for maintenance of the initial tension produced during adhesion maturation. This speculation is supported by the fact that myosin IIB has a higher duty ration than IIA, i.e., it spends more time bound to actin, making it ideal for maintaining cell tension through the actin cytoskeleton $[73,74]$. In this model of cell mediated collagen organization, myosin IIA contractility is needed for integrin mediated adhesion maturation and collagen binding through the DDR1 receptor, which produces an initial cell tension. Myosin IIB is then needed to maintain cell tension. Staining the cells within the collagen matrix may begin to elucidate if this model is applicable. Parental cells would show fully matured matrix adhesions and IIA association with DDR1. Myosin IIA KD cells would not have mature adhesions, and possible alterations in DDR1 receptor localization. Myosin IIB KD cells would have mature adhesions, since the IIA isoform is present in these cells. Combining these studies with further biochemical and mechanics testing would effectively test this model of cell adhesion and tension.

The ability of cancer cells to interact with and modify the ECM affects the migration of cells. Prior to migration, cells rearrange the collagen fibers in the matrix until they are oriented perpendicular to the edge of the cell mass in 3D migration models $[11,12]$. Using magnetic beads to arrange the collagen fibers prior to cell migration significantly increased migration [11]. The data in Study 1 shows that myosin IIA is needed for cell 
organization of the collagen matrix. We postulated that this would correspond with a significant defect in the migration ability of these cells. Migration is an important step in the metastatic process, and actomyosin contractility plays a vital role in cell migration [18, 20, 51, 68, 69, 72, 75]. Myosin involvement in migration extends beyond matrix interaction. Cells exert contractile forces to pull themselves through their surroundings, and myosin contractility is needed in 2D migration, where interaction with and rearrangement of the matrix is not a factor $[63,65]$. The data presented in Study 1 show that the IIA and IIB isoforms of myosin II are both needed for cancer cell-mediated matrix rearrangements. Since matrix interactions are also involved in cell migration, we sought to investigate the roles of the different isoforms in cell migration.

To study the migration ability of MDA-MB-231 cells lacking myosin II isoforms, we developed a model of 3D migration we refer to as the "mini-tumor" or "plug" model. Cells are suspended at a high density in silicone molds and allowed to rearrange the matrix until they have formed a compressed, cell-dense, collagen plug. This plug is then embedded into a 3D collagen matrix and the migration of individual cells migrating away from the plug is tracked using time lapse microscopy. The model was used because it better recapitulates the pathological situation of individual cancer cells leaving the celldense tumor and migrating through the relatively cell free ECM. Using this model of cell migration, we tested the ability of cells lacking either myosin IIA or IIB to migrate through a collagen matrix. Myosin IIA KD cells were unable to efficiently migrate in this $3 D$ environment. These cells moved at a speed between the parental and IIB KD cells, and in fact traveled a greater total distance than either of the other cell types, though with a lower displacement. A closer look at the track patterns of the IIA KD cells shows that they 
continuously move in a circle at the edge of the cellularized plug and occasionally extend a process into the surrounding collagen. Essentially, these cells move relatively quickly in a small area. Myosin IIB KD cells migrate at a slower speed than the parental cells, however, their displacement is closer to that of the parental cells than the IIA KD cells. Considering the migration statistics and the migration track patterns presented here, it is evident that the three cell types, parental, IIA KD and IIB KD have unique and distinct migration patterns. These results indicate that both isoforms are necessary for efficient cell migration in a 3D collagen environment and that they play distinct and non-redundant roles in this process. The IIA KD cells send protrusions into the surrounding collagen, but the cell body never follows as happens with the parental and IIB KD cells. This could be due to two reasons. One, the cells do not form mature adhesions to the collagen, as discussed above. Or, two, the cells are unable to generate the contractile forces necessary to pull the cell body through the collagen matrix. Myosin IIA is necessary for one or both of these steps of cell migration. This speculation is supported by previous studies showing that myosin IIA localizes to forward protrusions of migrating cells while the IIB isoform is needed for contraction of the cell rear [76, 77]. The need for myosin IIB contractility for retraction of the cell rear may explain why the IIB KD cells migrate at a slower speed than parental cells.

During the metastatic process, after cells have migrated through the ECM in the interstitial space until they reach a blood or lymphatic vessel, they must undergo a process known as intravasation, or crossing the vessel wall from outside the vessel, to enter the bloodstream and travel to a distant organ. Once a secondary organ has been reached, the cells can extravasate, or exit, from the vessel [20]. During the intravasation 
or extravasation process, the tumor cells must transmigrate the vessel wall. Endothelial cells are a key component of blood vessel walls. These cells are responsible for regulating the flow of signaling molecule and cells such as lymphocytes out of the bloodstream [31, $78,79]$. As such, the endothelial cell layer imposes a significant physical barrier to cancer metastasis, and the cancer cells circumvent normal endothelial cell function to enable their transmigration. There are a few possibilities as to how cancer cells are able to cross the blood vessel wall. Angiogenesis induced by tumor signaling often results in abnormal or leaky blood vessels within the tumor, making it easier for cancer cells to enter the bloodstream. [26, 27, 31]. In some circumstances, extravasating cancer cells use similar machinery to that used by leukocytes during the inflammation response [23]. Cancer cells can also alter the biomechanical properties of the endothelial cells, which may result in the endothelial layer posing less of a physical barrier to the transmigration of the tumor cells $[28,30]$. There are also two different mechanisms for how tumor cells actually cross the endothelial barrier: paracellular, where cancer cells pass through the junctions between endothelial cells: or transcellular, where cancer cells pass through the endothelial cells. Paracellular is the more common form of transmigration in in vitro models, though a small percentage of cells take the transcellular path [80, 81]. Endothelial cell actomyosin contractility is involved in both of these transmigration pathways. In paracellular transmigration, the role of contractility remains unclear. Cancer cells decrease endothelial cell stiffness in an integrin dependent manner and the endothelial cells actually stimulate cancer cell transmigration [29, 30]. A more compliant endothelial cell monolayer is easier for the tumor cells to push through. However, increased actin contractility in endothelial cells disrupts cell-cell adhesions, providing gaps for the tumor 
cells to exploit [82-85]. Tumor cells may use either of these, a more pliant endothelium or stimulating endothelial contractility to cause gaps, during paracellular transmigration In transcellular transmigration, the endothelial cells exert force in order to counteract the radial pressure caused by the larger cancer cells pushing through the endothelial cells [80]. Understanding how myosin contractility is involved in cancer cell transmigration across an endothelial barrier will yield important insights into cancer metastasis, and may lead to future treatment options targeting this process.

To test the role of myosin II isoforms in endothelial cell barrier function, we knocked down expression of the IIA or IIB isoform in murine endothelial cells (Study 2). Myosin IIA KD cells had significant changes in monolayer appearance. Parental cell monolayers had a uniform, cobblestone monolayer appearance. IIA KD cell monolayers were disrupted, with spindle shaped cells, less well defined cell borders, and larger cells overall. IIB KD cell monolayers had a similar appearance to parental cells, though the individual cells were larger. Loss of either myosin II isoform had an effect on monolayer barrier function, as measured by ECIS. Cells lacking myosin IIA were significantly delayed in reaching a baseline resistance, which remained lower than that reached by parental or IIB KD cells. IIB KD cells, on the other hand, had an initial resistance higher than that of parental cells, though the final steady resistance reached was not significantly different. The initial increase in resistance could be due to the larger size of the IIB KD cells. During the first 24 hours, the cells have not reached confluency and measurements taken during this time period reflect cell spreading more than true monolayer barrier efficiency. Larger cells cover a surface more quickly, explaining the initial increased resistance. This is supported by previous data showing that electrical resistance increases as cells adhere and spread 
after seeding [86]. In addition to ECIS, we measured the ability of these endothelial cell embedded in collagen to generate isometric tension and respond to the contractility stimulating agent thrombin. Parental and IIB KD cell constructs generated substantial basal tension and had a robust response to thrombin treatment, though IIB KD cell constructs did exhibit a decreased basal tension. IIA KD cell constructs not only had an extremely low basal tension, they also had no response to thrombin treatment. These results indicate that while myosin IIA plays the major role in endothelial cell tension generation and barrier function, the IIB isoform is also needed for tension generation and are consistent with previous studies using blebbistatin to inhibit total myosin II activity [87].

The studies presented here investigate three separate cell functions involved in cancer progression: cancer cell mediate matrix rearrangement, cancer cell migration, and endothelial cell barrier function. In each of these processes, we presented data that indicate the two main isoforms of nonmuscle myosin II in MDA-MB-231 and murine endothelial cells play distinct and non-redundant roles. Additionally, in each of these studies, loss of the IIA isoform of nonmuscle myosin II had a more pronounced and drastic effect on cell function, though there were defects in IIB KD cells as well. The differences in isoform function are not unexpected. Ablation of either isoform in mice has different detrimental effects leading to embryonic death [32, 36, 38]. The two isoforms have also been shown to play separate roles in cell spreading, migration, and invasion $[68,70]$. In fact, breast cancer subtypes have different myosin II isoform expression profiles, with the less aggressive luminal subtypes expressing IIC, but not IIB, where the more aggressive basal subtypes tend to express IIB but not IIC [70]. The differences in IIA and IIB function 
in the experiments presented here may be due to the different kinetics of the two isoforms. Myosin IIB has a higher duty ratio than IIA, meaning it spends more time bound to actin. This characteristic of the IIB isoforms makes it better suited for maintaining cell tension, rather than quickly responding to changes in the microenvironment or signaling cascades $[73,74]$. Myosin IIA KD breast cancer cells, which contain the IIB isoform, are unable to respond to the physical strain placed on them during the stretching protocol used to measure changes in matrix stiffness (Study 1). Additionally, these cells are significantly softer than either the parental or IIB KD cells and lack the ability to migrate in 3D collagen. The cell poking protocol used to measure cell stiffness uses an apparatus that directly indents the cell membrane and measures the elastic response of the cell as it rebounds to its original shape [88]. Since the IIA isoform spends a smaller proportion of its time bound to actin than does the IIB isoform, it is possibly responsible for responding to rapid changes in the environment, such as those presented by cell poking $[73,74,88,89]$. Cells lacking this isoform, while they may be able to maintain some basal tension due to the presence of the IIB isoform, are not able to generate the force necessary to quickly respond to the indentation of cell poking, and are therefore softer than parental cells. There is a further explanation for the drastic changes seen in IIA KD cell matrix interactions and migration; in mesenchymal stem cells, myosin IIA assembles in oriented stress fibers in response to a stiff matrix before IIB polarizes to the rear of the cell to allow for migration [90]. The polarization of IIB in migrating cells is necessary for the contractility of the cell rear that allows cells to pull the cell body through the matrix after initially extending processes in the direction of migration $[65,68]$. If the mechanism seen in mesenchymal stem cells holds true in breast cells, it explains the inability of IIA KD cells 
to migrate in 3D collagen. Without the IIA isoform, the stress fibers may never orient within the cell, and the remaining IIB isoform is not stimulated to polarize to the rear of the cell. This would prevent cells lacking the IIA isoform cells from migrating in a persistent direction. These cells may instead move randomly in place, as seen in Study 1.

Myosin II is needed for adhesion maturation. The contractile force myosin generates recruits and activates focal adhesion proteins. Contractility also assists in regulating the axial distribution of the focal adhesion proteins, a characteristic that is tightly controlled during adhesion formation and maturation $[8,61,62,91]$. While general myosin II contractility is important for cell adhesions, it is unknown if this process is dependent on a single isoform or is a redundant function since studies investigating this phenomenon rely on the general myosin II inhibitor blebbistatin [61, 62]. While there is some redundancy in myosin II isoform function, there are some processes in which one isoform cannot replace another [35, 36]. Based on the relative duty ratios of the IIA and IIB isoforms, and the changes in cell-matrix interactions presented in Study 1, we speculate that the IIA isoform is primarily involved in adhesion maturation. Myosin IIA is better suited for quickly responding to changes in the cell environment, such as integrin signaling. In the studies presented here, cells lacking the IIA isoform are unable to organize a surrounding collagen matrix. Myosin IIA KD cells are also unable to from strong cell-cell adhesions in endothelial cells. Myosin IIB KD cells, on the other hand, retain a partial ability to modify a collagen matrix. Further investigation into how the different isoforms of nonmuscle myosin $\|$ are involved in adhesion maturation and integrin signaling is needed to fully understand the mechanisms involved. 
The involvement of myosin II isoforms in adhesions is also a prime suspect in the changes in endothelial cell barrier function presented in Study 2. However, the mechanisms of the effects seen in these cells may differ from breast cancer cells. Endothelial cells and cells of epithelial origin have very different physiological functions, and the regulation of myosins in these two disparate cell types may be very different $[32$, $35,71,79,92]$. However, the changes in cell function in endothelial cells follow a pattern similar to the breast cancer cell lines; loss of IIA had a drastic effect on cell function, while loss of the IIB isoform had a more muted effect. While the data presented here represent a characterization of cells lacking either isoform, the effect of this loss on cancer cell transmigration has yet to be determined. Endothelial cells lacking myosin IIA seem unable to form the strong cell-cell adhesions needed to maintain a high monolayer barrier function. The "leaky" monolayer, and softer cells, may provide a less significant obstacle to tumor cell transmigration, similar to previous studies showing that cancer cells alter the biophysical properties of endothelial cells to make them more compliant [30]. Tumor cells are able to overcome the physical barrier the endothelial cells impose through a variety of means, including inducing apoptosis in the endothelial cells, choosing crossing points where the junctions between endothelial cells are weakest, and changing the properties of the endothelial cells $[26-30,84]$. Because of this, it is difficult to predict how changes in endothelial contractility will affect transmigration until further studies have been performed.

Overall, the data presented in this dissertation support the conclusion that two of the isoforms of non-muscle myosin II, IIA and IIB, have distinct and non-redundant functions in a number of cell processes that are involved in cancer disease progression. 
Both of these isoforms are needed for breast cancer cells to modify a collagen matrix into a stiff environment, as well as for cancer cell migration and endothelial cell barrier function. We postulate that at least part of these effects are due to the IIA isoform's involvement in adhesion maturation. Without sufficient interaction with the matrix, cells are unable to sense their surroundings, physically modify the matrix, or migrate in 3D collagen. Nor are endothelial cells able to form the strong cell-cell attachments needed to form a monolayer with a high barrier function. While globally targeting myosin II activity in a patient would likely have serious detrimental side effects, a better understanding of how the different isoforms are involved in cancer associated cell processes, and how this is regulated, may lead to better treatment options in the future. 


\section{References}

1. Levental KR, Yu H, Kass L, Lakins JN, Egeblad M, Erler JT, et al. Matrix crosslinking forces tumor progression by enhancing integrin signaling. Cell. 2009;139(5):891-906. PubMed PMID: 19931152.

2. Huang S, Ingber DE. Cell tension, matrix mechanics, and cancer development. Cancer Cell. 8. United States2005. p. 175-6.

3. $\mathrm{Yu} \mathrm{H}$, Mouw JK, Weaver VM. Forcing form and function: biomechanical regulation of tumor evolution. Trends Cell Biol. 2010;21(1):47-56. PubMed PMID: 20870407.

4. Butcher DT, Alliston T, Weaver VM. A tense situation: forcing tumour progression. Nat Rev Cancer. 2009;9(2):108-22. PubMed PMID: 19165226.

5. Kumar S, Weaver VM. Mechanics, malignancy, and metastasis: the force journey of a tumor cell. Cancer Metastasis Rev. 2009;28(1-2):113-27. PubMed PMID: 19153673.

6. Paszek MJ, Zahir N, Johnson KR, Lakins JN, Rozenberg GI, Gefen A, et al. Tensional homeostasis and the malignant phenotype. Cancer Cell. 8. United States2005. p. 24154.

7. Lopez JI, Kang I, You WK, McDonald DM, Weaver VM. In situ force mapping of mammary gland transformation. Integr Biol (Camb). 2011;3(9):910-21. PubMed PMID: 21842067.

8. Provenzano PP, Keely PJ. Mechanical signaling through the cytoskeleton regulates cell proliferation by coordinated focal adhesion and Rho GTPase signaling. J Cell Sci. 124. England2011. p. 1195-205.

9. Provenzano PP, Inman DR, Eliceiri KW, Knittel JG, Yan L, Rueden CT, et al. Collagen density promotes mammary tumor initiation and progression. BMC Med. 6. England2008. p. 11.

10. Conklin MW, Eickhoff JC, Riching KM, Pehlke CA, Eliceiri KW, Provenzano PP, et al. Aligned collagen is a prognostic signature for survival in human breast carcinoma. Am J Pathol. 178. United States: 2011 American Society for Investigative Pathology. Published by Elsevier Inc; 2011. p. 1221-32. 
11. Provenzano PP, Eliceiri KW, Campbell JM, Inman DR, White JG, Keely PJ. Collagen reorganization at the tumor-stromal interface facilitates local invasion. BMC Med. 2006;4(1):38. PubMed PMID: 17190588.

12. Provenzano PP, Inman DR, Eliceiri KW, Trier SM, Keely PJ. Contact guidance mediated three-dimensional cell migration is regulated by Rho/ROCK-dependent matrix reorganization. Biophys J. 2008;95(11):5374-84. PubMed PMID: 18775961.

13. Parekh A, Weaver AM. Regulation of cancer invasiveness by the physical extracellular matrix environment. Cell Adh Migr. 2009;3(3):288-92. PubMed PMID: 19458499.

14. DuFort CC, Paszek MJ, Weaver VM. Balancing forces: architectural control of mechanotransduction. Nat Rev Mol Cell Biol. 12. England2011. p. 308-19.

15. Ingber DE. Cellular mechanotransduction: putting all the pieces together again. FASEB J. 20. United States2006. p. 811-27.

16. Wozniak MA, Chen CS. Mechanotransduction in development: a growing role for contractility. Nat Rev Mol Cell Biol. 10. England2009. p. 34-43.

17. Clark K, Langeslag M, Figdor CG, van Leeuwen FN. Myosin II and mechanotransduction: a balancing act. Trends Cell Biol. 2007;17(4):178-86. PubMed PMID: 17320396.

18. Aguilar-Cuenca R, Juanes-Garcia A, Vicente-Manzanares M. Myosin II in mechanotransduction: master and commander of cell migration, morphogenesis, and cancer. Cell Mol Life Sci. 2014;71(3):479-92. PubMed PMID: 23934154.

19. Burridge $\mathrm{K}$, Wittchen ES. The tension mounts: stress fibers as force-generating mechanotransducers. J Cell Biol. 200. United States2013. p. 9-19.

20. Sahai E. Illuminating the metastatic process. Nat Rev Cancer. 2007;7(10):737-49. PubMed PMID: 17891189.

21. Alexander S, Weigelin B, Winkler F, Friedl P. Preclinical intravital microscopy of the tumour-stroma interface: invasion, metastasis, and therapy response. Curr Opin Cell Biol. 2013;25(5):659-71. Epub 2013/07/31. doi: 10.1016/j.ceb.2013.07.001. PubMed PMID: 23896198. 
22. Chambers AF, Groom AC, MacDonald IC. Dissemination and growth of cancer cells in metastatic sites. Nat Rev Cancer. 2. England2002. p. 563-72.

23. Coussens LM, Werb Z. Inflammation and cancer. Nature. 2002;420(6917):860-7. PubMed PMID: 12490959.

24. Friedl P, Wolf K. Proteolytic interstitial cell migration: a five-step process. Cancer Metastasis Rev. 2009;28(1-2):129-35. Epub 2009/01/21. doi: 10.1007/s10555-008-91743. PubMed PMID: 19153672.

25. Woodhouse EC, Chuaqui RF, Liotta LA. General mechanisms of metastasis. Cancer. 80. United States1997. p. 1529-37.

26. Hida K, Ohga N, Akiyama K, Maishi N, Hida Y. Heterogeneity of tumor endothelial cells. Cancer Sci. 2013;104(11):1391-5. Epub 2013/08/13. doi: 10.1111/cas.12251. PubMed PMID: 23930621.

27. Ho KS, Poon PC, Owen SC, Shoichet MS. Blood vessel hyperpermeability and pathophysiology in human tumour xenograft models of breast cancer: a comparison of ectopic and orthotopic tumours. BMC Cancer. 12. England2012. p. 579.

28. Mierke CT, Zitterbart DP, Kollmannsberger P, Raupach C, Schlotzer-Schrehardt U, Goecke TW, et al. Breakdown of the endothelial barrier function in tumor cell transmigration. Biophys J. 2008;94(7):2832-46. PubMed PMID: 18096634.

29. Mierke CT. Role of the endothelium during tumor cell metastasis: is the endothelium a barrier or a promoter for cell invasion and metastasis? J Biophys. 2008;2008:183516. PubMed PMID: 20107573.

30. Mierke CT. Cancer cells regulate biomechanical properties of human microvascular endothelial cells. J Biol Chem. 2011;286(46):40025-37. PubMed PMID: 21940631.

31. Reymond N, d'Agua BB, Ridley AJ. Crossing the endothelial barrier during metastasis. Nat Rev Cancer. 13. England2013. p. 858-70.

32. Betapudi V. Life without double-headed non-muscle myosin II motor proteins. Front Chem. 2014;2:45. Epub 2014/07/30. doi: 10.3389/fchem.2014.00045. PubMed PMID: 25072053; PubMed Central PMCID: PMCPMC4083560. 
33. Rex CS, Gavin CF, Rubio MD, Kramar EA, Chen LY, Jia Y, et al. Myosin Ilb regulates actin dynamics during synaptic plasticity and memory formation. Neuron.

2010;67(4):603-17. PubMed PMID: 20797537.

34. Conti MA, Even-Ram S, Liu C, Yamada KM, Adelstein RS. Defects in cell adhesion and the visceral endoderm following ablation of nonmuscle myosin heavy chain II-A in mice. J Biol Chem. 279. United States2004. p. 41263-6.

35. Bao J, Ma X, Liu C, Adelstein RS. Replacement of nonmuscle myosin II-B with II-A rescues brain but not cardiac defects in mice. J Biol Chem. 282. United States2007. p. 22102-11.

36. Wang A, Ma X, Conti MA, Adelstein RS. Distinct and redundant roles of the non-muscle myosin II isoforms and functional domains. Biochem Soc Trans. 39. England2011. p. 1131-5.

37. Maciver SK. Myosin II function in non-muscle cells. Bioessays. 1996;18(3):179-82. PubMed PMID: 8867731.

38. Sellers JR. Myosins: a diverse superfamily. Biochim Biophys Acta. 2000;1496(1):3-22. PubMed PMID: 10722873.

39. Beach JR, Licate LS, Crish JF, Egelhoff TT. Analysis of the role of Ser1/Ser2/Thr9 phosphorylation on myosin II assembly and function in live cells. BMC Cell Biol. 2011;12:52. Epub 2011/12/06. doi: 10.1186/1471-2121-12-52. PubMed PMID: 22136066; PubMed Central PMCID: PMCPmc3257205.

40. Clayton JE, Pollard LW, Murray GG, Lord M. Myosin motor isoforms direct specification of actomyosin function by tropomyosins. Cytoskeleton (Hoboken). 2015. Epub 2015/02/26. doi: 10.1002/cm.21213. PubMed PMID: 25712463.

41. Dulyaninova NG, Malashkevich VN, Almo SC, Bresnick AR. Regulation of myosin-IIA assembly and Mts1 binding by heavy chain phosphorylation. Biochemistry. 2005;44(18):6867-76. PubMed PMID: 15865432. 
42. Ford HL, Silver DL, Kachar B, Sellers JR, Zain SB. Effect of Mts1 on the structure and activity of nonmuscle myosin II. Biochemistry. 1997;36(51):16321-7. PubMed PMID: 9405067.

43. Li ZH, Spektor A, Varlamova O, Bresnick AR. Mts1 regulates the assembly of nonmuscle myosin-IIA. Biochemistry. 2003;42(48):14258-66. Epub 2003/12/04. doi: 10.1021/bi0354379. PubMed PMID: 14640694.

44. Ostuni R, Kratochvill F, Murray PJ, Natoli G. Macrophages and cancer: from mechanisms to therapeutic implications. Trends Immunol. 2015;36(4):229-39. Epub 2015/03/17. doi: 10.1016/j.it.2015.02.004. PubMed PMID: 25770924.

45. Madar S, Goldstein I, Rotter V. 'Cancer associated fibroblasts'--more than meets the eye. Trends Mol Med. 2013;19(8):447-53. Epub 2013/06/19. doi: 10.1016/j.molmed.2013.05.004. PubMed PMID: 23769623.

46. Allen M, Louise Jones J. Jekyll and Hyde: the role of the microenvironment on the progression of cancer. J Pathol. 2011;223(2):162-76. Epub 2010/12/03. doi:

10.1002/path.2803. PubMed PMID: 21125673.

47. Discher DE, Janmey P, Wang YL. Tissue cells feel and respond to the stiffness of their substrate. Science. 310. United States2005. p. 1139-43.

48. Marquez JP, Elson EL, Genin GM. Whole cell mechanics of contractile fibroblasts: relations between effective cellular and extracellular matrix moduli. Philos Trans A Math Phys Eng Sci. 368. England2010. p. 635-54.

49. Polyak K, Kalluri R. The role of the microenvironment in mammary gland development and cancer. Cold Spring Harb Perspect Biol. 2. United States2010. p. a003244.

50. Baker EL, Bonnecaze RT, Zaman MH. Extracellular matrix stiffness and architecture govern intracellular rheology in cancer. Biophys J. 97. United States2009. p. 1013-21.

51. Baker EL, Srivastava J, Yu D, Bonnecaze RT, Zaman MH. Cancer cell migration: integrated roles of matrix mechanics and transforming potential. PLoS One. 2011;6(5):e20355. PubMed PMID: 21647371. 
52. Ng MR, Brugge JS. A stiff blow from the stroma: collagen crosslinking drives tumor progression. Cancer Cell. 16. United States2009. p. 455-7.

53. Swaminathan V, Mythreye K, O'Brien ET, Berchuck A, Blobe GC, Superfine R. Mechanical stiffness grades metastatic potential in patient tumor cells and in cancer cell lines. Cancer Res. 2010;71(15):5075-80. PubMed PMID: 21642375.

54. Berrier AL, Yamada KM. Cell-matrix adhesion. J Cell Physiol. 2007;213(3):565-73. Epub 2007/08/08. doi: 10.1002/jcp.21237. PubMed PMID: 17680633.

55. Geiger B, Spatz JP, Bershadsky AD. Environmental sensing through focal adhesions. Nat Rev Mol Cell Biol. 10. England2009. p. 21-33.

56. Mierke CT, Frey B, Fellner M, Herrmann M, Fabry B. Integrin alpha5beta1 facilitates cancer cell invasion through enhanced contractile forces. J Cell Sci. 2011;124(Pt 3):36983. PubMed PMID: 21224397.

57. Schiller HB, Hermann MR, Polleux J, Vignaud T, Zanivan S, Friedel CC, et al. beta1and alphav-class integrins cooperate to regulate myosin II during rigidity sensing of fibronectin-based microenvironments. Nat Cell Biol. 2013;15(6):625-36. PubMed PMID: 23708002.

58. Schwartz MA. Integrins and extracellular matrix in mechanotransduction. Cold Spring Harb Perspect Biol. 2. United States2010. p. a005066.

59. Seguin L, Desgrosellier JS, Weis SM, Cheresh DA. Integrins and cancer: regulators of cancer stemness, metastasis, and drug resistance. Trends Cell Biol. 2015;25(4):234-40. Epub 2015/01/13. doi: 10.1016/j.tcb.2014.12.006. PubMed PMID: 25572304; PubMed Central PMCID: PMCPMC4380531.

60. Wang N, Tytell JD, Ingber DE. Mechanotransduction at a distance: mechanically coupling the extracellular matrix with the nucleus. Nat Rev Mol Cell Biol. 10. England2009. p. 75-82.

61. Pasapera AM, Schneider IC, Rericha E, Schlaepfer DD, Waterman CM. Myosin II activity regulates vinculin recruitment to focal adhesions through FAK-mediated paxillin phosphorylation. J Cell Biol. 188. United States2010. p. 877-90. 
62. Rubashkin MG, Cassereau L, Bainer R, DuFort CC, Yui Y, Ou G, et al. Force engages vinculin and promotes tumor progression by enhancing $\mathrm{PI} 3 \mathrm{~K}$ activation of phosphatidylinositol (3,4,5)-triphosphate. Cancer Res. 74. United States: 2014 American Association for Cancer Research.; 2014. p. 4597-611.

63. Kraning-Rush CM, Carey SP, Califano JP, Smith BN, Reinhart-King CA. The role of the cytoskeleton in cellular force generation in 2D and 3D environments. Phys Biol. 2011;8(1):015009. PubMed PMID: 21301071.

64. Mierke CT, Kollmannsberger P, Zitterbart DP, Diez G, Koch TM, Marg S, et al. Vinculin facilitates cell invasion into three-dimensional collagen matrices. J Biol Chem. 2010;285(17):13121-30. PubMed PMID: 20181946.

65. Poincloux R, Collin O, Lizarraga F, Romao M, Debray M, Piel M, et al. Contractility of the cell rear drives invasion of breast tumor cells in 3D Matrigel. Proc Natl Acad Sci U S A. 2011;108(5):1943-8. PubMed PMID: 21245302.

66. Engler AJ, Sen S, Sweeney HL, Discher DE. Matrix elasticity directs stem cell lineage specification. Cell. 126. United States2006. p. 677-89.

67. Walker A, Su H, Conti MA, Harb N, Adelstein RS, Sato N. Non-muscle myosin II regulates survival threshold of pluripotent stem cells. Nat Commun. 1. England2010. p. 71.

68. Betapudi V, Licate LS, Egelhoff TT. Distinct roles of nonmuscle myosin II isoforms in the regulation of MDA-MB-231 breast cancer cell spreading and migration. Cancer Res. 2006;66(9):4725-33. PubMed PMID: 16651425.

69. Betapudi V, Gokulrangan G, Chance MR, Egelhoff TT. A proteomic study of myosin II motor proteins during tumor cell migration. J Mol Biol. 407. England: 2011 Elsevier Ltd; 2011. p. 673-86.

70. Beach JR, Hussey GS, Miller TE, Chaudhury A, Patel P, Monslow J, et al. Myosin II isoform switching mediates invasiveness after TGF-beta-induced epithelialmesenchymal transition. Proc Natl Acad Sci U S A. 2011;108(44):17991-6. PubMed PMID: 22025714. 
71. Billington N, Wang A, Mao J, Adelstein RS, Sellers JR. Characterization of three fulllength human nonmuscle myosin II paralogs. J Biol Chem. 2013;288(46):33398-410. PubMed PMID: 24072716.

72. Huang $\mathrm{Y}$, Arora $\mathrm{P}, \mathrm{McCulloch} \mathrm{CA}$, Vogel WF. The collagen receptor DDR1 regulates cell spreading and motility by associating with myosin IIA. J Cell Sci. 122. England2009. p. 1637-46.

73. Kovacs M, Wang F, Hu A, Zhang Y, Sellers JR. Functional divergence of human cytoplasmic myosin II: kinetic characterization of the non-muscle IIA isoform. J Biol Chem. 2003;278(40):38132-40. PubMed PMID: 12847096.

74. Wang F, Kovacs M, Hu A, Limouze J, Harvey EV, Sellers JR. Kinetic mechanism of nonmuscle myosin IIB: functional adaptations for tension generation and maintenance. J Biol Chem. 2003;278(30):27439-48. PubMed PMID: 12704189.

75. Conti MA, Adelstein RS. Nonmuscle myosin II moves in new directions. J Cell Sci. 121. England2008. p. 11-8.

76. Kolega J. Asymmetric distribution of myosin IIB in migrating endothelial cells is regulated by a rho-dependent kinase and contributes to tail retraction. Mol Biol Cell.

2003;14(12):4745-57. Epub 2003/09/10. doi: 10.1091/mbc.E03-04-0205. PubMed PMID: 12960430; PubMed Central PMCID: PMCPmc284780.

77. Kolega J. Cytoplasmic dynamics of myosin IIA and IIB: spatial 'sorting' of isoforms in locomoting cells. J Cell Sci. 1998;111 ( Pt 15):2085-95. PubMed PMID: 9664030.

78. Muller WA. Leukocyte-endothelial-cell interactions in leukocyte transmigration and the inflammatory response. Trends Immunol. 2003;24(6):327-34. PubMed PMID: 12810109.

79. Sumpio BE, Riley JT, Dardik A. Cells in focus: endothelial cell. Int J Biochem Cell Biol. 34. England2002. p. 1508-12.

80. Arvanitis C, Khuon S, Spann R, Ridge KM, Chew TL. Structure and biomechanics of the endothelial transcellular circumferential invasion array in tumor invasion. PLoS One. 9. United States2014. p. e89758. 
81. Muller WA, Luscinskas FW. Assays of transendothelial migration in vitro. Methods Enzymol. 2008;443:155-76. PubMed PMID: 18772016.

82. Garcia JG, Verin AD, Schaphorst KL. Regulation of thrombin-mediated endothelial cell contraction and permeability. Semin Thromb Hemost. 1996;22(4):309-15. Epub 1996/01/01. doi: 10.1055/s-2007-999025. PubMed PMID: 8944415.

83. Goeckeler ZM, Wysolmerski RB. Myosin light chain kinase-regulated endothelial cell contraction: the relationship between isometric tension, actin polymerization, and myosin phosphorylation. J Cell Biol. 1995;130(3):613-27. PubMed PMID: 7622562.

84. Hurst VI, Goldberg PL, Minnear FL, Heimark RL, Vincent PA. Rearrangement of adherens junctions by transforming growth factor-beta1: role of contraction. Am J Physiol. 1999;276(4 Pt 1):L582-95. Epub 1999/04/13. PubMed PMID: 10198356.

85. van Nieuw Amerongen GP, Musters RJ, Eringa EC, Sipkema P, van Hinsbergh WW. Thrombin-induced endothelial barrier disruption in intact microvessels: role of RhoA/Rho kinase-myosin phosphatase axis. Am J Physiol Cell Physiol. 294. United States2008. p. C1234-41.

86. Wegener J, Keese CR, Giaever I. Electric cell-substrate impedance sensing (ECIS) as a noninvasive means to monitor the kinetics of cell spreading to artificial surfaces. Exp Cell Res. 2000;259(1):158-66. Epub 2000/08/16. doi: 10.1006/excr.2000.4919. PubMed PMID: 10942588.

87. Goeckeler ZM, Bridgman PC, Wysolmerski RB. Nonmuscle myosin II is responsible for maintaining endothelial cell basal tone and stress fiber integrity. Am J Physiol Cell Physiol. 2008;295(4):C994-1006. PubMed PMID: 18701651.

88. Zahalak GI, McConnaughey WB, Elson EL. Determination of cellular mechanical properties by cell poking, with an application to leukocytes. J Biomech Eng. 1990;112(3):283-94. PubMed PMID: 2214710.

89. Kovacs M, Thirumurugan K, Knight PJ, Sellers JR. Load-dependent mechanism of nonmuscle myosin 2. Proc Natl Acad Sci U S A. 2007;104(24):9994-9. PubMed PMID: 17548820. 
90. Raab M, Swift J, Dingal PC, Shah P, Shin JW, Discher DE. Crawling from soft to stiff matrix polarizes the cytoskeleton and phosphoregulates myosin-II heavy chain. J Cell Biol. 2012;199(4):669-83. Epub 2012/11/07. doi: 10.1083/jcb.201205056. PubMed PMID: 23128239; PubMed Central PMCID: PMCPmc3494847.

91. Delorme-Walker VD, Peterson JR, Chernoff J, Waterman CM, Danuser G, DerMardirossian C, et al. Pak1 regulates focal adhesion strength, myosin IIA distribution, and actin dynamics to optimize cell migration. J Cell Biol. 2011;193(7):1289-303. PubMed PMID: 21708980.

92. Golomb E, Ma X, Jana SS, Preston YA, Kawamoto S, Shoham NG, et al. Identification and characterization of nonmuscle myosin II-C, a new member of the myosin II family. $\mathrm{J}$ Biol Chem. 279. United States2004. p. 2800-8. 


\section{Figure Legends}

Figure 1. Summary of major results. The studies undertaken here are summarized in graphic form. Experiments performed on cancer cells are presented in shades of blue while experiments performed on endothelial cells are presented in shades of orange. Experiments and major results are presented in flow chart form. From left to right, cell type (cancer cells or endothelial), cell process investigated, myosin IIA or IIB KD, summarization of effect of loss of indicated isoform on the cell process being investigated. 


\section{Figure 1}

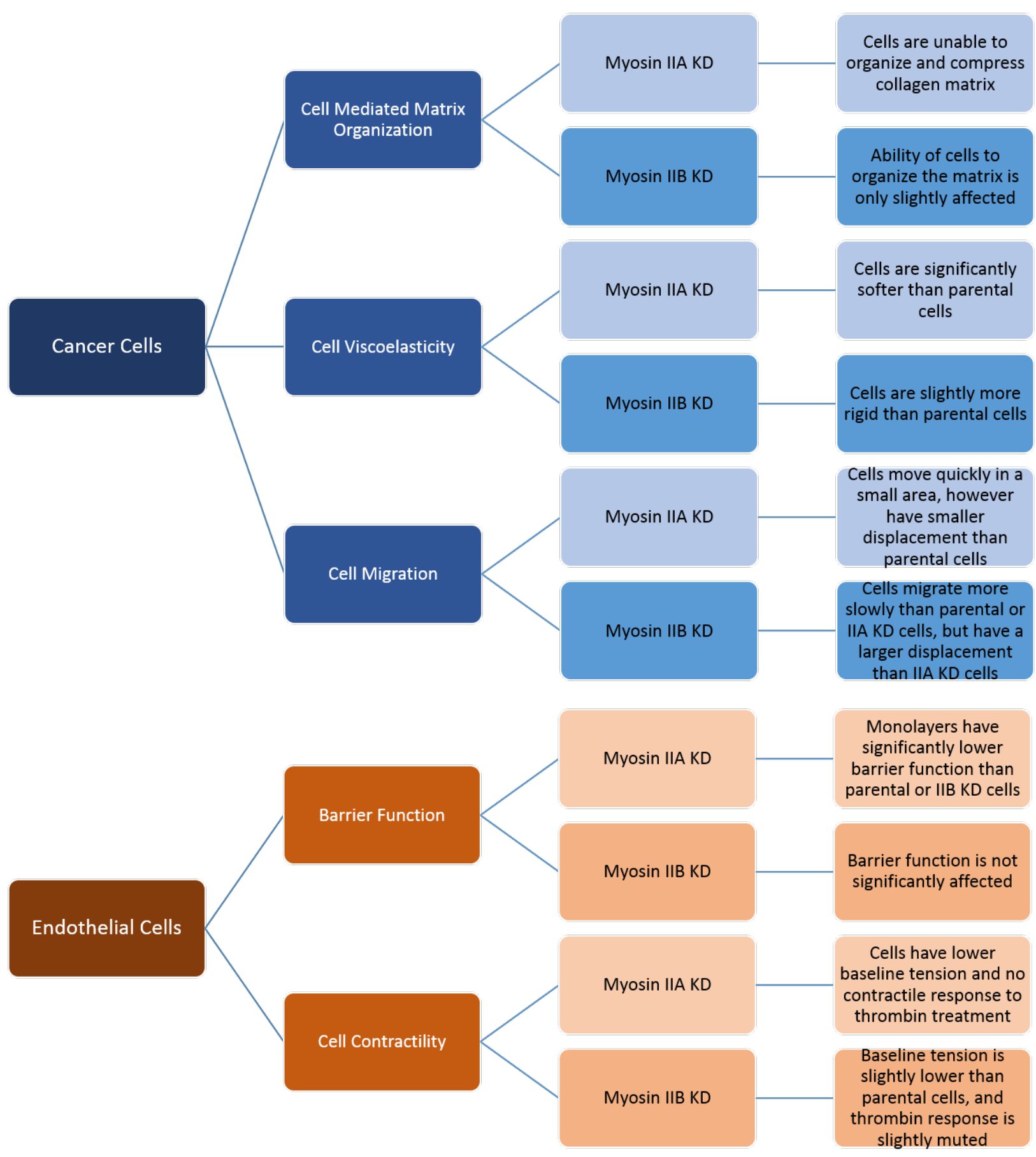




\section{Bridget Hindman}

971 Valley View Ave, Apt 109, Morgantown, WV 26505

(903) 821-2626

bhindman@hsc.wvu.edu

\section{EDUCATION}

PhD. Biomedical Sciences, Program in Cancer Cell Biology, West Virginia University, Morgantown, WV. Degree expected: Fall, 2015

BS, Molecular Biology and Criminology, University of Texas at Dallas, Richardson, TX. Degree conferral: May, 2009

\section{PROFESSIONAL WORK HISTORY}

August, 2010-Present

PhD Candidate, West Virginia University, Mary Babb Randolph Cancer Center, in the Lab of Robert Wysolmerski, PhD, Morgantown, WV

Research involves the role of nonmuscle myosin II isoforms in breast cancer cell migration and cell mediated matrix alterations. Developed migration assays and a model to measure the elastic modulus of collagen samples.

June 2005-August 2005 Clark Summer Research Scholar, NanoTech Institute, University of Texas at Dallas, Richardson, TX. Undergraduate summer research working with graduate students investigating the physical properties of carbon-based nanofibers

\section{PROFESSIONAL DEVELOPMENT}

\section{Fellowships}

- NanoSAFE Graduate Fellow August 2014 present
o Stipend, supplies, and travel

- NHLBI T32 Grant, Cardiovascular and Pulmonary Diseases

June 2011 June 2013

o Stipend, supplies, and travel

Awards

- WVU Health Magazine Scientific Images Contest, Third Place

October 2012

- NanoBridge Award Recipient May 2010 


\section{Conferences}

- $\quad$ The American Society for Cell Biology Annual Meeting, December 6-10, 2014

o Poster Presentation: Role of Myosin II Isoforms in MDA-MB-231 Cell Mediated Matrix Rearrangement

- Appalachia Regional Cell Conference, Student-run meeting sponsored by ASCB, October 26, 2013

o Poster Presentation: Role of Myosin II in Endothelial Cell Barrier Function and Cell Migration

- $\quad$ The American Society for Cell Biology Annual Meeting, December 15-19, 2012

o Poster Presentation: Involvement of Myosin II in MDA-MB-213 Cell Migration

- Appalachian Regional Cell Conference, Student-run meeting sponsored by ASCB, October 12, 2012

o Poster Presentation: Involvement of Myosin II in MDA-MB-231 Cell Migration

\section{RELEVANT TECHNICAL ABILITIES}

- Small animal models: General mouse handling, intraperitoneal injections, IVIS imaging, ultrasound imaging, necropsy

- Cellular adhesion and migration assays: ECIS, 3D migration models, microfluidic device based migration models

- Cell matrix interaction assays: gel compression models, strain conditioning models to measure elastic modulus of biological samples

- DNA subcloning for mammalian expression

- Protein analysis: Western blotting, ELISA, SDS-PAGE

- Tissue/Cell Culture techniques: Maintaining cell lines, cellular transfection, lentivirus preparation and subsequent cellular infection, 3D cultures, Type I Collagen isolation from rat tails for cell culture

- Cell and tissue preparation for immunofluorescence/immunohistochemistry

- Imaging systems: Zeiss LSM 510 laser scanning confocal, Zeiss Axiovert 200M, Nikon Swept Field, institution built two-photon microscope, Vevo 2100 High-Frequency Ultrasound, IVIS Lumina Imaging system

- Software: Adobe Photoshop, Adobe Illustrator, ImageJ, Zeiss LSM and Zen, Nikon NISElements, IMARIS, Sigmaplot, Microsoft PowerPoint and Excel, Vevo and VevoCQ, IVIS Lumina

\section{LEADERSHIP/TEACHING/OUTREACH EXPERIENCE}


- Laboratory management: Responsible for ordering, obtaining quotes and interacting with sales representatives.

- Trained undergraduate honors students in how to perform various laboratory techniques, and collect and interpret data, both as a graduate student at WVU and as an undergraduate TA in the introductory biology lab course at UTD

- Contributed during the reorganization of the Cell Methods course at WVU, an introductory course for first year graduated students designed to familiarize them with various laboratory techniques

- Graduate student representative to Cancer Cell Biology Faculty Meetings, January 2012 to present. Attended monthly faculty meetings and brought student concerns to their attention, as well as giving input on curriculum and other matters important to students

- Organized the 2013 Appalachian Regional Cell Conference, along with students from Marhsall University, University of Kentucky, and Ohio University. Conference was supported in part by ASCB.

- Led journal clubs with first year graduate students as part of their first year curriculum at request of faculty

- Worked with other NanoSAFE fellows to develop and teach a workshop for local high school advanced science students focused on the impact of chemical spills on the environment. Workshop included chemical experiments using ultraviolet-visible spectroscopy and biological experiments using mouse endothelial cells and brine shrimp, as well as a discussion on the ethics of environmental regulations on chemical companies.

- Participated in community outreach efforts including Nano Days at the Children's Discovery Museum of West Virginia and the Expanding Your Horizons conference for young women interested in science at Potomac State College.

\section{SCHOLARLY ACTIVITIES}

- Cell Biology Training Program: A student led program to provide a forum for discussion of various concepts and techniques useful in the study of cellular biology. Students and faculty interacted in an informal environment, with students being primarily responsible for choosing subjects of interest to discuss, techniques to study, and seminar speakers to invite.

- Journal Club: Weekly discussion of papers important in cancer biology.

- Van Liere Research Day: West Virginia University's yearly celebration of the biomedical research being conducted at its Health Sciences Center campus. Poster presented in 2011 and 2012

- Student Seminar Presentations: Formal seminars given annually that are designed to allow students to present their research and to equip them with the fundamentals of scientific speaking in front of faculty and peers. 
- Seminar in Nanoscience: Weekly meetings of all NanoSAFE and IGERT fellows to discuss important aspects of nanomaterial based research. Fellows in both programs represent interdisciplinary research endeavors in the fields of Chemical Engineering, Physics, and Biomedical Sciences. Various activities included student presentation of research, discussion of papers, and invitation of speakers.

\section{PROFESSIONAL MEMBERSHIPS}

- The American Society for Cell Biology

- The Association for Women in Science

\section{PUBLICATIONS}

Hindman B, Goeckeler Z, Sierros K, Wysolmerski R (2015) Non-Muscle Myosin II Isoforms Have Different Functions in Matrix Rearrangement by MDA-MB-231 Cells. PLoS ONE 10(7): e0131920. doi:10.1371/journal.pone.0131920 